INSTITUTO DE QUIMICA

Unlversldade de São Paulo

UNIVERSIDADE DE SÃO PAULO

INSTITUTO DE QUÍMICA

DESENVOL VIMENTO DE PROCESSO DE TTTULACAO POR PROCURA BINÁRIA, EM FLUXO CONIÍNUO, COM DETECCAOO ESPECTROFOTOMÉTRICA

MAURO KORN

Doutorado - Química Analítica

Profa. Dra. ELISABETH DE OLIVEIRA

Orientadora

São Paulo

Qedulo 2367602

1996

Assunto: 4.06.03.00-5

$4.06 .03 .10-9$ 


\section{"DESENVOLVIMENTO DE PROCESSO DE TITULAÇÃO POR PROCURA BINÁRIA, EM FLUXO CONTÍNUO, COM DETECÇÃO ESPECTROFOTOMÉTRICA".}

\section{MAURO KORN}

Tese de Doutorado submetida ao Instituto de Química da Universidade de São Paulo como parte dos requisitos necessários à obtenção do grau de Doutor em Ciências - Área: Química Analítica.

Aprovada por:

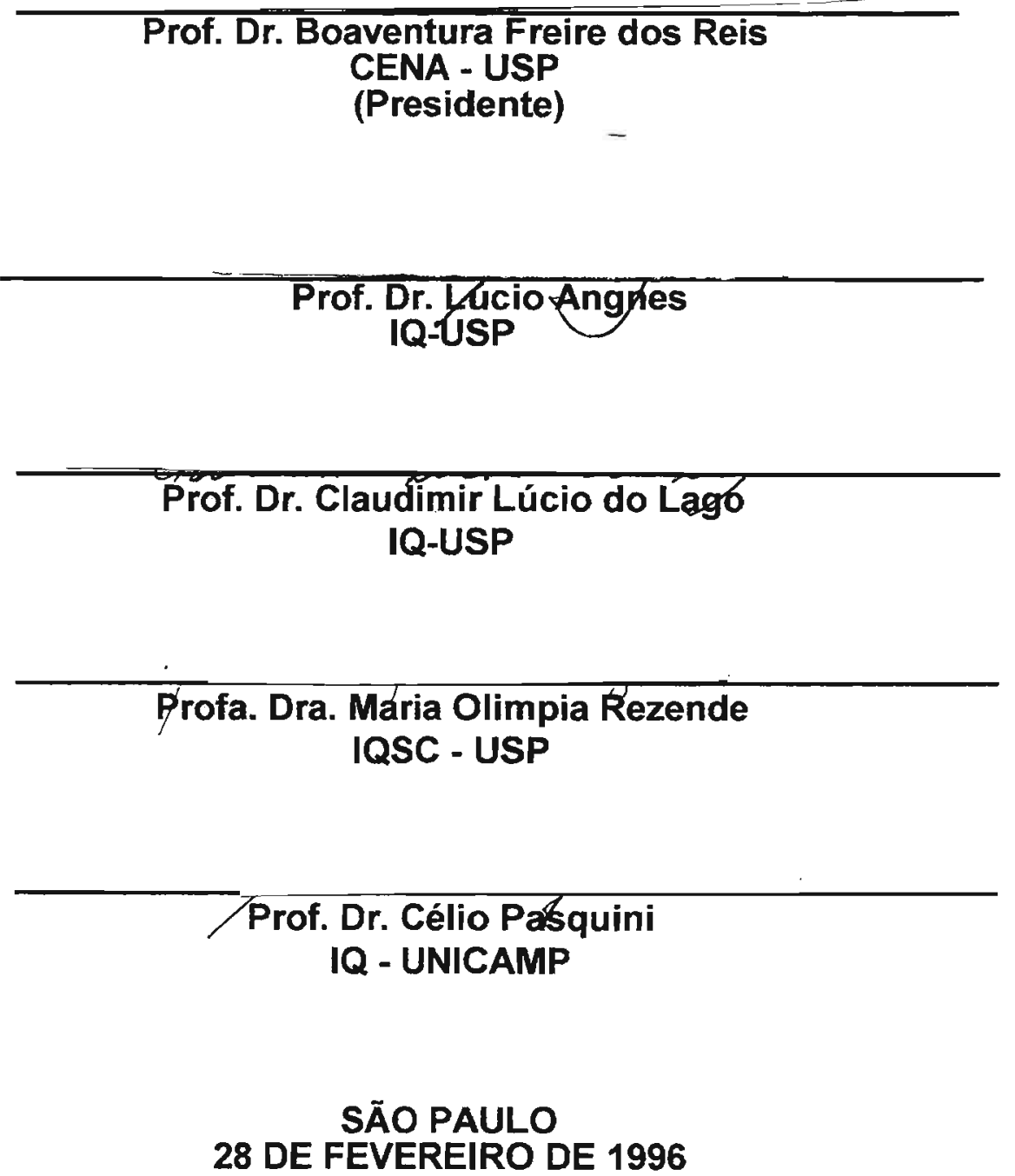


Ao querido amigo e professor, Boaventura Freire dos Reis 


\section{AGRADECIMENTOS}

Ao Prof. Dr. Boaventura Freire dos Reis pelas muitas horas agradáveis de discussões e pelas tantas doses de café ou cerveja.

À Profa. Dra. Elisabeth de Oliveira pelo estímulo e amizade.

A todos do CENA - USP, especialmente aos alunos, técnicos e professores da Química Analítica, pela inesgotável paciência.

Especial agradecimento pelos vôos e pousos ao Prof. Dr. Elias Zagatto.

Aos amigos do laboratório do CENA: Paula, Eloisa, Patrícia e Jonas.

A todos os professores do Departamento de Química Funadamental do IQUSP que contribuiram para a minha formação.

Especial agradecimento, pelo estímulo, à parceira Profa. Dra. Lilian Carvalho (IQUSP).

Ao Prof. Dr. Sérgio Massaro (IQ-USP), pela amizade e divertida troca de figurinhas.

Ao Prof. Dr. Jivaldo Matos, pelo ombro e significativas doses de café, apesar do seu evidente mau gosto clubístico.

Aos amigos do laboratório do IQ-USP: Maria Josefa, Roseli, Joel e Darilena.

Ao sócio Luis Gouveia da Universidade de Lisboa.

Aos Professores Celso Spínola, Jailson Andrade e Merílio Veiga pelo encorajamento e confiança.

Aos colegas do Departamento de Química do CETEBA - UNEB.

À CAPES pelo apoio financeiro.

Aos heróis Gal, Allan e Julie, por suportarem a convivência comigo. 


\section{RESUMO}

O processo de análise química denominado de titulação por procura binária foi desenvolvido e aplicado em sistema de injeção em fluxo. Este procedimento de análise, baseado no método das variações contínuas, procura o menor intervalo em fração volumétrica do titulante, ou da solução da amostra, que contenha o ponto final de uma titulação. Ao ser introduzida alíquota da solução da amostra no percurso analítico, o sinal gerado pelo detector deve ser significativamente diferente daquele gerado com a inserção de uma alíquota da solução do titulante. Neste processo descontínuo, a procura do ponto final segue a lógica binária, reduzindo os incrementos de fração volumétrica, da solução de amostra ou do titulante, em $50 \%$, a cada nova tentativa de procura. Os sinais gerados por um detector espectrofotométrico, acoplado ao sistema de fluxo, eram convertidos em sinais digitais e comparados com os sinais fornecidos pelo detector nas duas tentativas iniciais da procura. Um programa foi desenvolvido para gerenciar este procedimento de titulação, determinando o volume das alíquotas das soluções, para cada tentativa, bem como estabelecendo a rota de procura.

O procedimento foi aplicado à uma série de titulações envolvendo reações de neutralização e complexação. Uma titulação, aplicando este procedimento, pode ser executada em 3 minutos, consumindo aproximadamente $2 \mathrm{~cm}^{3}$ das soluções reagentes. As limitações para a aplicação deste procedimento de análise são discutidas, bem como a inviabilidade de sua aplicação sem o emprego de recursos de automatização. 


\section{SUMMARY}

A flow injection analytical procedure named as binary search titrimetric process was studied. It was based on volumetric fraction variation methodology. Under its directive, the microcomputer can control the titrand and titrant solutions delevering into the analytical path, by varying both volumetric fractions, following an algorithm based on successive aproximation method. Analytical signals assessed from the analog output of the spectrophotometer for each tentatives were converted to digital making use of an interface card, attached in the microcomputer main board. After each solutions handling cycles, the data collected were processed in order to decide about the next tentative to be carried out, obeying the settled binary search algorithm. The feasibility was ascertained by titrating solutions employing neutralization and complexation reactions. The time interval to perform this titration process employing binary search concept was about 3 minutes, consuming ca 2 $\mathrm{cm}^{3}$ of reagents solutions. No significant difference at $5 \%$ probability level was observed by comparing of the results obtained applying this procedure with those produced by manual procedures. 
$\begin{array}{llll}\text { CAPÍTULO: } & 1 & \text { Introdução } & 1\end{array}$

1.1. Titulações Volumétricas em Sistemas 5 FIA

1.2. Automação de Processos de 10 Titulação em Sistemas FIA

$\begin{array}{lllll}\text { CAPÍTULO: } 2 \text { Fundamentos da Titulação por } & 2 \text { }\end{array}$ Procura Binária

2.1. O Processo de Procura Binária 24

2.2. Consumo de Reagentes na Procura 40 Binária

CAPÍTULO: 3 Condições Experimentais 42

3.1. Instrumentação e Diagrama de Fluxo 42

3.2. Sistema FIA e Variáveis 46 Experimentais

3.3. Métodos de Preparo de Soluções 
3.4. Programa para a Execução das

Titulações por Procura Binária

CAPÍTULO: $4 \quad$ Resultados e Discussão

4.1. Fatores que Afetam o Processo de

Titulação por Procura Binária

4.1.1 Número de Passos de Busca do Ponto Final

4.1.2 Formação de uma Sequência

4.1.3 Relevância da Sincronização da 78 Pulsação da Bomba Peristáltica

4.1.4 O Fator de Comparação

4.2. Critérios para a Viabilização da Titulação por Procura Binária

4.2.1 Modos de Interpretação dos Sinais Gerados pelo Detector

4.2.2 Titulação Fotométrica e Titulação com Detecção Fotométrica do Ponto Final 
4.3. Seleção de Indicadores para o

Processo de Titulação por Procura

Binária

4.4. Adicionando Indicadores na

Titulação por Busca Binária

4.5. Aplicando o Conceito de Titulação por Busca Binária

4.6. O Programa Desenvolvido para

Procura Binária

4.7. Outras Aplicações do Processo de

Titulação por Busca Binária

CAPÍTULO: 5 Conclusão

5.1. Trabalhos Futuros

CAPÍTULO: 6 Referências Bibliográficas 


\section{LISTA DE TABELAS}

Tabela 1. Acessórios empregados em diferentes processos de 9 titulação em sistema de fluxo.

Tabela 2. Valores selecionados para as variáveis operacionais na titulação de solução de ácido clorídrico com hidróxido de sódio pelo processo de procura binária.

Tabela 3. Comportamento de uma titulação de $\mathrm{HCl}$ com $\mathrm{NaOH}$ 59 pelo método da busca binária.

Tabela 4. Andamento presumível do processo de procura binária 70 na titulação de $\mathrm{HCl} 0,01 \mathrm{M}$ com $\mathrm{NaOH} 0,01 \mathrm{M}$, usando solução de fenolftaleína como indicador.

Tabela 5. Variação do intervalo do conjunto verdade com o 91 avanço do método de busca, para a titulação de solução $0,01 \mathrm{M}$ de $\mathrm{HCl}$ com solução $0,01 \mathrm{M}$ em $\mathrm{NaOH}$, empregando fenolftaleína como indicador. 
Tabela 6. Valores selecionados para as variáveis operacionais nas titulações de solução de ácido acético com hidróxido de sódio pelo processo de procura binária, empregando diferentes indicadores.

Tabela 7. Concentrações determinadas de ácido acético aplicando 96 o processo de titulação por procura binária com solução padronizada de $\mathrm{NaOH} \quad 0,09338 \mathrm{M}$, empregando diferentes indicadores.

Tabela 8. Características dos indicadores ácido - base 96 selecionados.

Tabela 9. Número de soluções a serem preparadas para a 102 realização de uma titulação por busca binária caso o sistema não fosse automatizado. 


\section{LISTA DE FIGURAS}

Figura 1. Volume de titulante adicionado com o aumento do

número de alíquotas, para duas rotinas distintas de titulação.

Figura 2. Diagrama de fluxo do primeiro sistema proposto por Ruzicka e colaboradores.

Figura 3. Um diagrama de fluxo comum para sistemas de titulação volumétrica em fluxo contínuo.

Figura 4. Proposta de diagrama de blocos para um sistema 12 especialista de titulação volumétrica baseado no método de Sagara.

Figura 5. Variação das frações volumétricas das espécies A e B 18 com o volume da solução de B utilizado para o preparo das soluções com volume final igual a $10 \mathrm{~cm}^{3}$.

Figura 6. Processo de aproximações sucessivas aplicado no 25 método de titulação por busca binária. 
Figura 7. Método esquemático de dois possíveis cursos para o processo de busca binária.

Figura 8. Variação do pH com a fração volumétrica da solução do titulante para titulações de soluções equimolares de ácido forte $(\mathrm{HX})$ com base forte $(\mathrm{YOH})$, seguindo o processo das variações contínuas.

Figura 9. Curvas teóricas de titulação baseadas no processo das variações contínuas. Ácido forte $0,01 \mathrm{M}$ com base forte a) $0,01 \mathrm{M}$, b) $0,02 \mathrm{M} \mathrm{e} \mathrm{c)} 0,05 \mathrm{M}$.

Figura 10. Representação de curva teórica da variação de pH com 40 volume adicionado de titulante, para um sistema de titulação de um ácido fraco monoprótico com base forte.

Figura 11. Diagrama de fluxo empregado para o processo de titulação por procura binária.

Figura 12. Diagrama de blocos correspondente ao processo de 49 leitura dos sinais transientes e estabelecimento do máximo.

Figura 13. Esquema do processo de geração de uma sequência 
baseado no conceito de amostragem por multicomutação.

Figura 14. Diagrama de blocos global do processo de titulação por busca binária.

Figura 15. Curva típica de titulação por busca binária de uma 60 solução de ácido clorídrico $0,02 \mathrm{M}$ com solução padronizada 0,0100 M de hidróxido de sódio, e fenolftaleína como corante indicador.

Figura 16. Variação do desvio padrão da média do sinal máximo obtido com a fração volumétrica do titulante em cada tentativa da procura, para a titulação de $\mathrm{HCl} 0,02 \mathrm{M}$ com $\mathrm{NaOH} 0,0100 \mathrm{M}$, utilizando fenolftaleína como indicador.

Figura 17. Variação do incremento na fração volumétrica em função dos passos de busca.

Figura 18. Apresentação esquemática da variação do intervalo de tempo de acionamento de um conjunto de válvulas (V1V2 ou V1-V3) solenóides com a tentativa de procura.

Figura 19. Representação gráfica da variação do sinal gerado pelo 
detector em função da fração volumétrica da solução $0,01002 \mathrm{M}$ de $\mathrm{NaOH}$, para titulações por procura binária de soluções de $\mathrm{HCl}$ (a) 0,15 M, (b) 0,01 M e (c) $0,001 \mathrm{M}$.

Figura 20. Variação do intervalo de fração volumétrica de $\mathrm{NaOH}$, que contém a proporção estequiométrica, em função do número de passos de busca.

Figura 21. Esquematização do processo de dispersão mútua no percurso analítico quando é empregado o conceito de amostragem binária.

Figura 22. Variação do erro analítico em função do número de 75 pulsos.

Figura 23. Variação do sinal de absorvância gerado pelo 76 espectrofotômetro com o comprimento do percurso analítico.

Figura 24. Variação da vazão produzida por uma bomba 79 peristáltica em função do tempo.

Figura 25. Variação do volume amostrado em função da posição do rolete, expresso em tempo, no início da amostragem. 
Figura 26. Variação do pH com a fração volumétrica para titulação de neutralização.

Figura 27. Resposta a presença de coloração em função da fração volumétrica do titulante para o processo de titulação de solução de $0,01 \mathrm{M} \mathrm{em} \mathrm{HCl}$ por procura binária.

Figura 28. Trânsito de informações entre as partes componentes do 86 sistema de titulação por procura binária.

Figura 29. Função limiar aplicada comumente em circuitos digitais.

Figura 30. Processo de busca implementado para a titulação por 90 procura binária, conforme tabela 4 , de solução $0,01 \mathrm{M}$ de $\mathrm{HCl}$ com solução $0,01 \mathrm{M}$ em $\mathrm{NaOH}$, empregando fenolftaleína como indicador.

Figura 31. Variação da absorvância na titulação por procura binária de solução amoniacal $0,1 \mathrm{M}$ de $\mathrm{Cu}$ (II) com a fração volumétrica da solução $0,050 \mathrm{M}$ de EDTA.

Figura 32. Diagrama de fluxo opcional para o sistema de titulação 100 por procura binária. 
Figura 33. Diagrama de fluxo alternativo para titulações de uma série de soluções de amostras aplicando o conceito de procura binária.

Figura 34. Diagrama de blocos simplificado para o processo 106 alternativo de busca binária. 


\section{CAPÍTULO 1. INTRODUÇÃO}

O desenvolvimento de sistemas para a automação de processos volumétricos de análise química, tem gerado interesse em pesquisadores desde o início do século. Inicialmente foram desenvolvidos processos de automatização nas etapas de introdução do titulante ${ }^{1-6}$ e no sistema de detecção do ponto final das titulações.

O sistema desenvolvido por $Z_{i e g e l}{ }^{1}$ é reconhecido como a primeira tentativa de automação das análises volumétricas. Neste sistema, reportado na segunda década deste século, é executada a titulação de uma solução de dicromato usando uma solução padronizada de íons $\mathrm{Fe}(\mathrm{II})$, sendo automatizado o controle de adição do titulante. Assim, o controle manual de uma bureta foi substituído por um sistema eletromagnético para gerir o escoamento do titulante.

Ainda na primeira metade deste século foram propostos uma série de artifícios para automação de titulações com detecção potenciométrica do ponto estequiométrico ${ }^{2-5}$. Entre as diversas propostas de automação, a apresentada por Lingane ${ }^{5}$ deve ser destacada, uma vez que é ainda hoje, a mais empregada nos laboratórios de análise química. Este titulador desenvolvido era baseado em uma bureta de pistão, diminuindo sensivelmente o volume mínimo da solução do titulante que poderia ser adicionado à solução da amostra. A bureta de pistão foi construída a partir de uma seringa hipodérmica de $50 \mathrm{~mL}$, cujo êmbolo era movimentado, a velocidade constante, através de um parafuso conectado a um motor. 
A possibilidade de amostrar alíquotas de volumes menores do titulante com maior precisão pode ser evidenciada com a grande evolução do sistema, proposto por Lingane, para titulações. Baseado neste conceito e somando o desenvolvimento tecnológico nas áreas da eletrônica e da mecânica, os motores de passo produzidos atualmente permitem a adição de alíquotas de volumes ainda menores, possibilitando adições reprodutíveis da ordem de $1 \mathrm{~mm}^{3}$.

Durante a década de 60 foram propostos diversos tituladores verdadeiramente automáticos baseados em processamento contínuo ou descontínuo das amostras. Estes tituladores, por excelência, não necessitavam de nenhuma operação manual e, apresentavam como principal campo de aplicação o controle de processos industriais na própria área de produção das empresas ${ }^{6}$.

Até esta época o conceito das operações envolvidas no processo titulação não havia sido modificado. Este processo de análise era executado seguindo a mesma rotina: selecionado o sistema de detecção do ponto final, era tomada uma alíquota de volume conhecido da solução da amostra e, sob constante agitação, adicionadas alíquotas da solução titulante até que fosse atingido o ponto final da titulação. Os avanços tecnológicos incorporados a esta técnica analítica buscavam diminuir o volume das alíquotas da solução titulante adicionadas ao sistema em determinação, para consequentemente, diminuir a incerteza do processo de análise. Na Figura 1 é esquematizado o aumento na exatidão do processo de titulação em função da potencialidade do sistema em amostrar alíquotas de menores volumes. A Figura 1 exemplifica duas rotinas de titulação, nas quais são adicionadas alíquotas de volume constante de $2 \mathrm{~cm}^{3}$ e $1 \mathrm{~cm}^{3}$ da solução do titulante à solução da amostra. 
Assumindo que o volume total da solução do titulante que deve ser adicionado para atingir o ponto estequiométrico é de $11,7 \mathrm{~cm}^{3}$. Para as duas situações exemplificadas, o ponto estequiométrico é localizado após a adição de $12 \mathrm{~cm}^{3}$ da solução do titulante. Como para o primeiro caso o volume de cada alíquota é de $2 \mathrm{~cm}^{3}$, o volume correspondente ao ponto estequiométrico seria de $11 \pm 1 \mathrm{~cm}^{3}$. Para o segundo caso, o volume estabelecido de titulante seria de $11,5 \pm 0,5 \mathrm{~cm}^{3}$. Assim, reduzindo os incrementos em $50 \%$, o valor da incerteza no volume é reduzido na mesma ordem. Com base neste fato, muito esforço foi canalizado para fornecer condições de serem adicionados volumes cada vez menores da solução titulante.

A precisão no volume de titulante adicionado em cada alíquota é irrelevante nos procedimentos convencionais de titulação, uma vez que através da escala das buretas, após prévia calibração, pode ser determinado o volume total da solução do titulante adicionado.

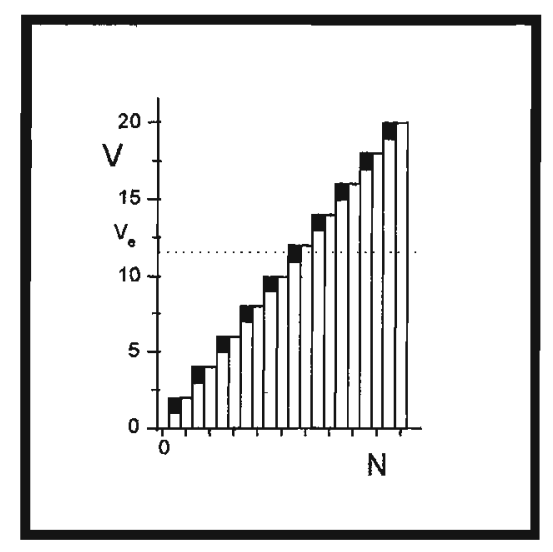

Figura 1. Volume de titulante adicionado com o número de alíquotas para duas rotinas distintas de titulação. Barras brancas = alíquotas de 1 $\mathrm{cm}^{3}$. Barras pretas $=$ alíquotas de $2 \mathrm{~cm}^{3} . \mathrm{V}=$ volume do titulante. $\mathrm{N}=$ número de alíquotas. $\mathrm{V}_{\mathrm{e}}=$ volume no ponto estequiométrico $\left(11,7 \mathrm{~cm}^{3}\right)$. 
Uma nova fase no processo de automação de titulações volumétricas pôde ser verificada com a proposição de Blaedel e Laessig $^{7}$ de executar esta metodologia em sistema de fluxo contínuo. Neste procedimento de análise química as soluções da amostra e do titulante fluiam para uma câmara de mistura onde a reação química se processava. O conceito desta metodologia de análise volumétrica foi baseado na variação das proporções molares da amostra e do titulante na câmara de mistura. A variação de proporção era obtida alterando a vazão da solução do titulante e mantendo constante a vazão da solução da amostra. $O$ produto da interação entre as soluções era, então, continuamente encaminhado no percurso analítico para um detector espectrofotométrico. Este, por sua vez, ao gerar os sinais fornecia as condições necessárias para a determinação da concentração da espécie em análise.

O sistema de titulação volumétrica proposto por Blaedel e Laessig foi uma das metodologias precursoras da análise em fluxo contínuo (CFA), que por sua vez foi um dos alicerces para o desenvolvimento do processo de análise por injeção em fluxo (FIA $)^{8}$.

As inúmeras possibilidades de aplicação de análise em fluxo, e sua difundida maleabilidade foram anteriormente constatadas por Blaedel e Hicks ${ }^{9}$, quando um sistema de análise em fluxo contínuo, similar ao empregado para as titulações, pôde ser utilizado para determinar a velocidade de reações químicas.

O processo de titulação de Blaedel e Laessig $^{7}$ revolucionou o procedimento clássico de titulação ao extender o conceito de quantidade do titulante adicionado de volume para vazâo. Contudo, o elevado consumo de amostra é uma limitação desta técnica, visto que a corrente 
de amostra mantinha, continuamente, a célula de detecção preenchida com solução.

\subsection{Titulações Volumétricas em Sistemas FIA}

Um novo impulso foi dado aos métodos de análise química em fluxo com o advento da técnica FIA, na qual uma alíquota de volume conhecido da amostra é inserida no percurso analítico e se dispersa no fluido carregador.

$O$ conceito de geração de gradiente de concentração para a execução de titulações volumétricas, sugerido por Fleet $\mathrm{e} \mathrm{Ho}^{10}$, foi a base conceitual para a implementação do primeiro processo de titulação volumétrica empregando análise por injeção em fluxo. Este procedimento, relatado por Ruzicka e colaboradores ${ }^{11}$, proporcionou uma mudança nos processos das análises volumétricas. Este procedimento foi desenvolvido baseado na característica, comum aos sistemas de análise por injeção em fluxo, de gerar um gradiente de concentração reprodutível, a partir da dispersão parcial de uma alíquota de amostra introduzida em uma corrente fluxo não segmentada.

O diagrama de fluxo apresentado na Figura 2, representa o primeiro sistema proposto de titulação volumétrica em sistema FIA ${ }^{11}$. Para este sistema, a determinação da concentração da espécie em análise é conduzida através da interpolação do valor referente a largura do sinal transiente, em uma curva de calibração construída à partir de soluções de referência. De modo mais preciso, a razão estequiométrica entre titulante e analíto é definida por uma relação matemática entre a variação da 
largura do sinal transiente com o logarítmo da concentração da espécie de interesse.

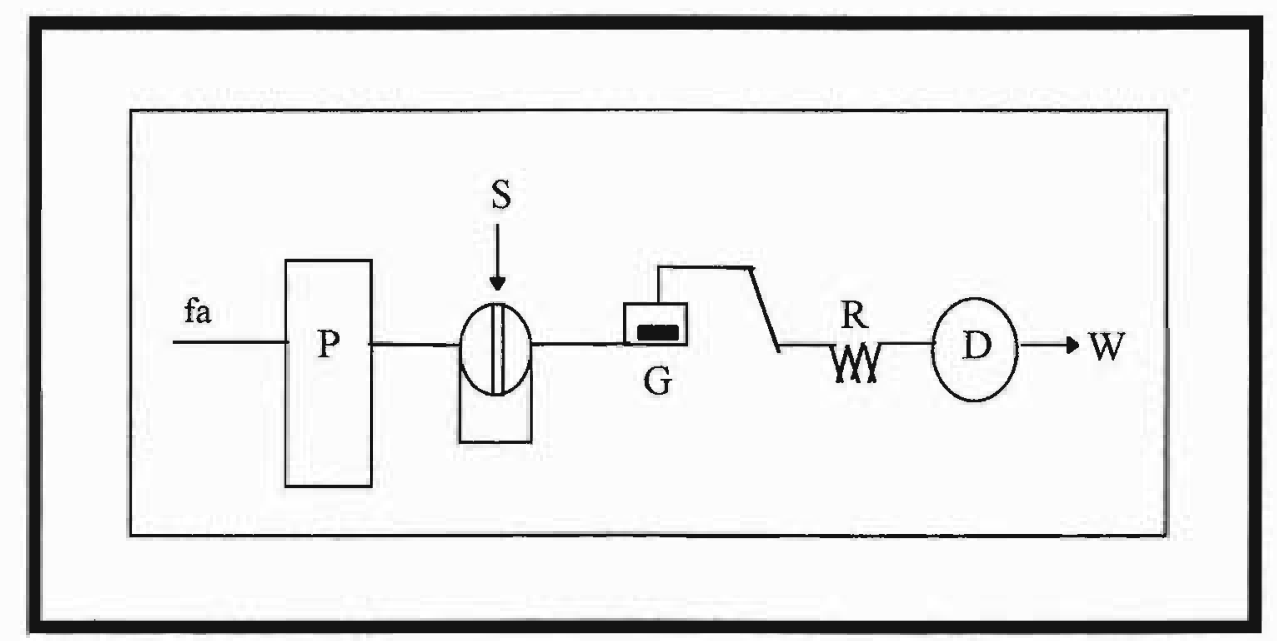

Figura 2. Diagrama de fluxo do primeiro sistema proposto por Ruzicka e colaboradores ${ }^{11} . \mathrm{P}=$ bomba peristáltica; $\mathrm{R}=$ reator; $\mathrm{D}=$ detector; $\mathrm{W}=$ descarte; $\mathrm{G}=$ câmara de dispersão de volume conhecido; $\mathrm{S}=$ ponto de introdução de volume conhecido da alíquota da amostra; e $\mathrm{f}_{\mathrm{A}}=$ vazões de bombeamento do titulante.

O mesmo conceito de titulação foi ainda empregado para a elaboração de outros processos ${ }^{12,13}$. Esta metodologia de análise química provocou uma grande polêmica entre diversos autores, sobre a viabilidade do emprego do termo titulação a uma técnica onde as concentrações do analito e do titulante é que são equivalentes ${ }^{12-15}$. Afetada, ou não, por esta polêmica poucas aplicações deste procedimento de análise volumétrica foram posteriormente reportadas, apesar de abrir um campo amplo de pesquisas na área de análise em injeção em fluxo.

O conceito de titulação volumétrica em fluxo contínuo, implementado por Blaedel e Laessig ${ }^{7,16}$, foi revisitado por Martinez- 
Calatayud et $a l^{17}$. Estes autores apresentaram uma metodologia para a titulação de ácidos ou bases pouco dissociadas em fluxo contínuo, empregando curvas de titulação linearizadas. Nesta metodologia, a mistura dos fluxos das soluções do titulante e do analito foi feita através de uma confluência e, o sistema foi concebido de tal forma que permitisse a variação manual da vazão de bombeamento da solução titulante, mantendo constante a vazão de bombeamento da solução do analito. Desta forma, para um dado intervalo de tempo qualquer, a quantidade de reagente misturado ao analito variava proporcionalmente com a vazão estabelecida para o titulante.

Este procedimento de titulação volumétrica em fluxo contínuo foi automatizado $^{18-21}$, através do controle da variação da vazão da solução do titulante em função do tempo. $O$ controle da vazão foi realizado conectando uma ou duas bombas peristálticas a uma interface de potência.

Ambos os conceitos podem ser associados a um conjunto de pressupostos comuns a quaisquer métodos de titulação volumétrica em sistemas de fluxo contínuo e que são apresentados no diagrama de fluxo da Figura 3 e na Tabela 1. Para os sistemas de titulação em fluxo contínuo existem, normalmente, duas linhas de fluxo distintas por onde são escoadas, por exemplo, as soluções da amostra e do titulante. Estas linhas de fluxo devem se encontrar em $\mathbf{z}$, afim de produzir algum nível de interação química entre as soluções geradoras da corrente de fluxo resultante. A interação entre as soluções pode ser favorecida pelo emprego de algum dispositivo que facilite a dispersão, ou mistura, das soluções originais. A solução resultante da mistura é conduzida, através de fluxo contínuo, para um detector $\mathbf{D}$ que tenha capacidade de gerar 
sinais, possibilitando a indicação direta ou indireta da concentração do analito na amostra em estudo.

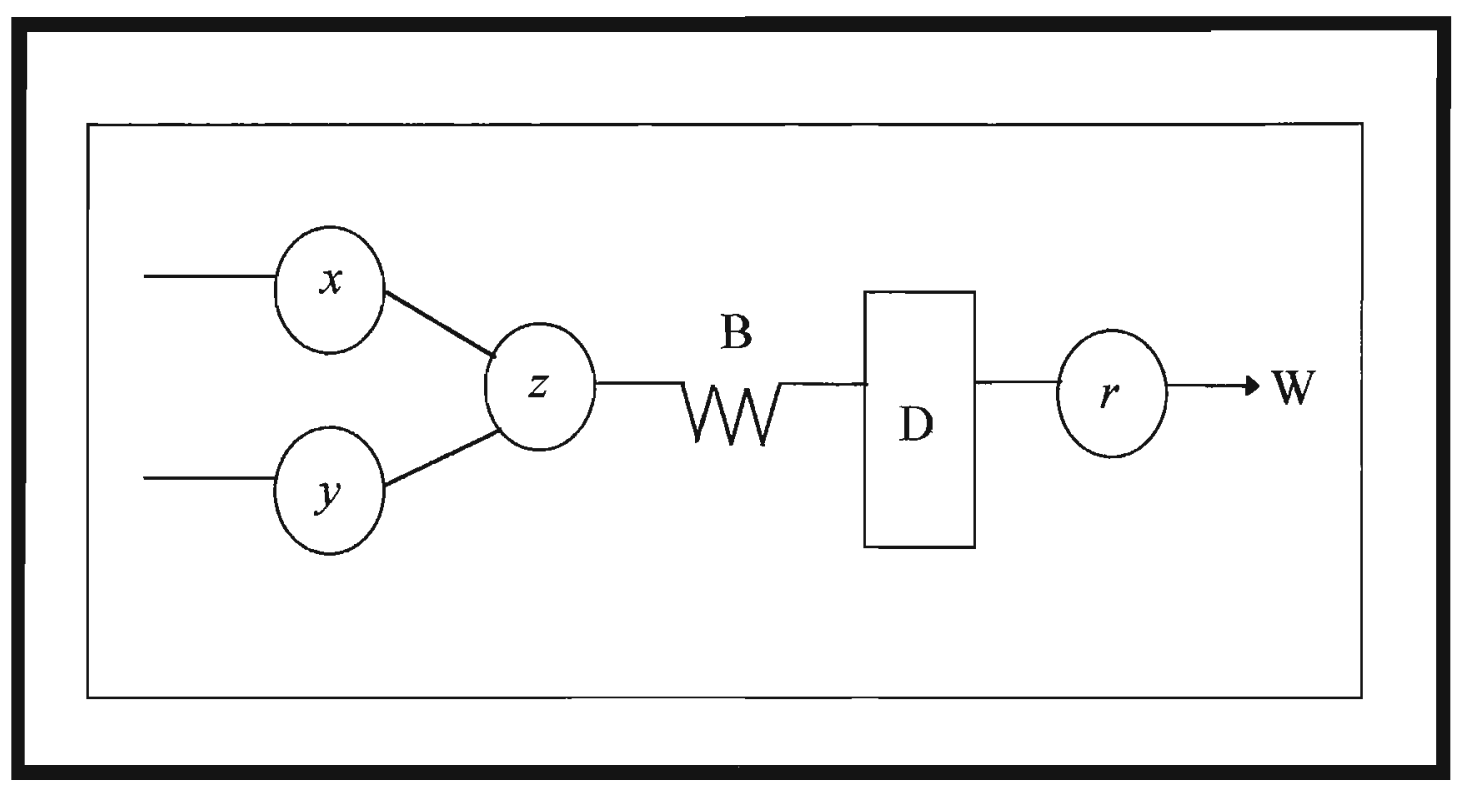

Figura 3. Diagrama de fluxo comum para sistemas de titulação volumétrica em fluxo contínuo. $\mathbf{B}=$ bobina de reação; $\mathbf{D}=$ detector; $\mathbf{W}=$ descarte; $\mathbf{x}, \mathbf{y}, \mathbf{z}$ e $\mathbf{r}=$ aparatos variados como especificado na Tabela 1. 
Tabela 1. Aparatos empregados em diferentes processos de titulação em sistemas de fluxo. $x, y, z$ e $r$, conforme a Figura 3 .

\begin{tabular}{|c|c|c|c|c|c|}
\hline Autores & Referência & $x$ & $y$ & $z$ & $r$ \\
\hline $\begin{array}{l}\text { Blaedel e } \\
\text { Laessig }\end{array}$ & 7 & ne & ne & $\begin{array}{l}\text { câmara de } \\
\text { mistura }\end{array}$ & ne \\
\hline $\begin{array}{l}\text { Ruzicka, } \\
\text { Hansen e } \\
\text { Mosbaek }\end{array}$ & 11 & $\begin{array}{c}\text { bomba } \\
\text { peristáltica }\end{array}$ & seringa & $\begin{array}{l}\text { câmara de } \\
\text { dispersão }+ \\
\text { confluência }\end{array}$ & ne \\
\hline $\begin{array}{l}\text { Ramsing, } \\
\text { Ruzicka e } \\
\text { Hansen }\end{array}$ & 12 & $\begin{array}{c}\text { bomba } \\
\text { peristáltica }\end{array}$ & $\begin{array}{c}\text { válvula } \\
\text { rotária }+ \\
\text { câmara de } \\
\text { dispersão }\end{array}$ & confluência & ne \\
\hline $\begin{array}{l}\text { Marcos, Ríos } \\
\text { e Valcárcel }\end{array}$ & 18,19 & $\begin{array}{c}\text { bomba } \\
\text { peristáltica } \\
\text { (vazão } \\
\text { constante) }\end{array}$ & $\begin{array}{c}\text { bomba } \\
\text { peristáltica } \\
\text { (vazão } \\
\text { variável) }\end{array}$ & confluência & ne \\
\hline $\begin{array}{l}\text { Yarnitzky, } \\
\text { Klein e Cohen }\end{array}$ & 20,21 & $\begin{array}{c}\text { bomba } \\
\text { peristáltica } \\
\text { (vazão } \\
\text { variável) } \\
\end{array}$ & $\begin{array}{l}\text { bomba } \\
\text { peristáltica } \\
\text { (vazão } \\
\text { variável) } \\
\end{array}$ & confluência & ne \\
\hline $\begin{array}{l}\text { Bartrolí e } \\
\text { Alerm }\end{array}$ & 22 & $\begin{array}{c}\text { bomba } \\
\text { peristáltica }\end{array}$ & $\begin{array}{c}\text { bureta } \\
\text { automática }\end{array}$ & confluência & ne \\
\hline $\begin{array}{l}\text { Bartrolí, } \\
\text { Alerrm, } \\
\text { Garcia- } \\
\text { Raurich e } \\
\text { Masip } \\
\end{array}$ & 23 & $\begin{array}{c}\text { bomba } \\
\text { peristáltica }\end{array}$ & $\begin{array}{c}\text { bureta } \\
\text { automática }\end{array}$ & confluência & ne \\
\hline $\begin{array}{l}\text { Agudo, } \\
\text { Marcos, Ríos } \\
\text { e Valcárcel }\end{array}$ & 24 & $\begin{array}{c}\text { bomba } \\
\text { peristáltica } \\
\text { (vazão } \\
\text { variável) }\end{array}$ & $\begin{array}{c}\text { bomba } \\
\text { peristáltica } \\
\text { (vazão } \\
\text { variável) }\end{array}$ & confluência & ne \\
\hline $\begin{array}{l}\text { Sagara, } \\
\text { Kobayashi, } \\
\text { Tajima, Ijyuin, } \\
\text { Yoshida, Ishii } \\
\text { e Ueno }\end{array}$ & 25 & ne & $\begin{array}{l}\text { bureta de } \\
\text { precisão }\end{array}$ & $\begin{array}{l}\text { câmara de } \\
\text { mistura }\end{array}$ & $\begin{array}{c}\text { alça de } \\
\text { circulação }\end{array}$ \\
\hline $\begin{array}{l}\text { Korn, } \\
\text { Gouveia, de } \\
\text { Oliveira e Reis }\end{array}$ & 26 & $\begin{array}{c}\text { válvula } \\
\text { solenóide }\end{array}$ & $\begin{array}{l}\text { válvula } \\
\text { solenóide }\end{array}$ & confluência & $\begin{array}{c}\text { bomba } \\
\text { peristáltica }\end{array}$ \\
\hline $\begin{array}{l}\text { Fuhrmann e } \\
\text { Spohn }\end{array}$ & 27,28 & mini bomba & $\begin{array}{c}\operatorname{mini} \\
\text { bomba }\end{array}$ & confluência & ne \\
\hline
\end{tabular}

ne = não empregado 
Os conceitos que nortearam o estabelecimento dos procedimentos de titulação volumétrica em sistemas FIA, podem ser agrupados em 3 conjuntos distintos:

i) geração de gradiente de concentração ${ }^{10-13,22,23,29}$;

ii) variação da vazão da solução da amostra e/ou do titulante para gerar gradiente de concentração ${ }^{17-20,24,27,28,30}$;

iii) introdução de volume discreto de titulante em zona de fluxo circulante $^{25}$.

\subsection{Automação de Processos de Titulação em Sistemas FIA}

Todos os sistemas de análise em fluxo contínuo apresentam algum grau de automatização. Isto se deve ao fato da etapa de medição do sinal analítico ser realizada em linha, sem que ocorra qualquer intervenção do operador entre as etapas de amostragem e de medição ${ }^{31}$. Tomando como exemplo o método de titulação espectrofotométrica em fluxo circulante ${ }^{25}$ de uma solução de íons zinco com EDTA, pode ser evidenciado o alto grau de automação que este processo atingiria. A titulação volumétrica em questão foi baseada na adição de microvolumes de titulante à alíquota de amostra, sendo a homogeneização, das soluções de amostra e titulante, efetuada através da circulação de todo o volume por um tubo capilar cuja superficie interna havia sido recoberta de sílica.

A automatização deste procedimento de análise química por titulação pode ser efetivada empregando o mesmo conceito aplicado por Olim e Wikmark ${ }^{32}$ no desenvolvimento de um sistema para a determinação de solubilidade. Neste projeto o controle de uma bureta de pistão, para a adição de volumes do solvente em uma cubeta contendo o 
soluto, era realizado através do sinal gerado por um eletrodo íon seletivo imerso na mesma. O sistema de análise, ao receber a informação de que havia sido atingida a estabilidade do sinal analítico, respondia com o acionamento da bureta. Permitindo a introdução de uma nova alíquota, com volume previamente estabelecido, do reagente ao meio de análise. Traduzindo, Olim e Wikmark ${ }^{32}$, desenvolveram um sistema especialista $^{33}$.

A elaboração de um sistema especialista para o processo de titulação volumétrica desenvolvido por Sagara et $a l^{25}$, poderia seguir o diagrama de blocos apresentado na Figura 4. Para a execução deste processo de titulação é necessário que tanto o detector como a bureta estejam conectados a um computador.

O trânsito de informações entre os instrumentos de análise química, os dispositivos mecânicos e o computador é garantido pelas interfaces ${ }^{34}$. As interfaces têm por função condicionar sinais elétricos. Assim, uma interface possibilita aumentar a diferença de potencial para o acionamento de uma válvula solenóide, filtrar sinais provenientes de um detector, diminuir a corrente, etc. Os conceitos envolvidos no interfaceamento são dois: i) os sinais usados para comunicação e ii) a transformação destes sinais em funções mecânicas ou outras.

Para efeito de comunicação existem soluções padronizadas, como - American Standard Code for Information Interchange (ASCII), o Extended Binary Coded Decimal Interchange Code $(\text { EBCDIC })^{35}$ e o recente UNICODE. Contudo para a transformação dos sinais em funções mecânicas, o grau de generalização é bastante reduzido, uma vez que a automação da adição de um titulante em um processo de titulação volumétrica é bastante diferente das condições necessárias para a 
automação do controle de injeção de amostra e de temperaturas requeridos para uma análise cromatográfica ${ }^{36}$.

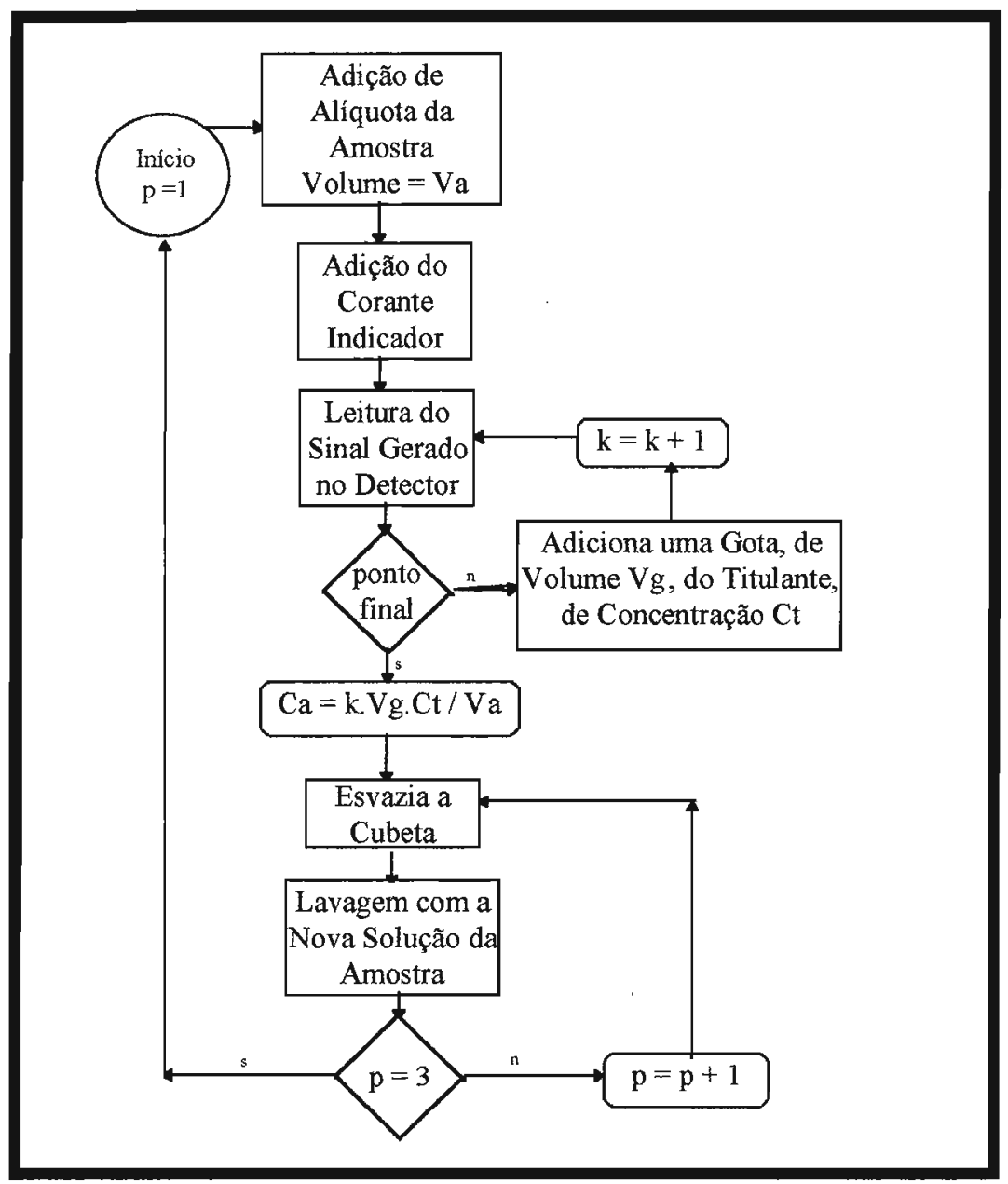

Figura 4. Proposta de diagrama de blocos para um sistema especialista de titulação volumétrica baseado no método de Sagara ${ }^{25}$.

Propostas de automação de processos de titulação em sistema FIA tem sido reportadas. Algumas dessas propostas utilizam sistemas que aplicam o conceito de variação da proporção entre as quantidades de amostra e do titulante a partir da variação da razão entre as vazões de bombeamento de suas soluções. Sistemas baseados nesse conceito têm sido implementados independentemente pelo grupo espanhol da 
Universidade de Córdoba ${ }^{18,19,24}$ e pelo grupo da Universidade de Haifa, em Israel ${ }^{20,21}$.

Uma dificuldade na implementação da automação destes processos está relacionada com a forma como é executada a variação das vazões de bombeamento das soluções da amostra e do titulante. Variações lineares e contínuas das vazões de bombeamento das soluções podem desfavorecer a determinação da proporção correspondente ao ponto estequiométrico. Do momento em que as soluções se encontram na confluência até a solução resultante da mistura alcançar a célula de detecção existe um intervalo de tempo correspondente ao trânsito da solução pelo percurso analítico. Portanto deve ser efetuada uma subtração deste intervalo de tempo de forma que o sistema - computador possa determinar as vazões de bombeamento das soluções no momento em que estas se encontraram na confluência.

A proposta do grupo de Haifa $^{20}$, variando exponencialmente as vazões de bombeamento das soluções, tende a atenuar este obstáculo. Nas proximidades do ponto estequiométrico a variação das vazões em função do tempo é pequena criando facilidades para o operador em determinar a proporção estequiométrica entre as soluções da amostra e do titulante.

Por sua vez, a metodologia de análise volumétrica desenvolvida nesta tese, denominada de titulação por procura $^{26}$ binária, pode ser classificada como um processo de titulação descontínuo em sistema FIA. $O$ processo de localização da proporção estequiométrica entre as soluções da amostra e do titulante neste procedimento é executado em passos, aqui denominados de tentativas. A variação das proporções volumétricas em cada tentativa é realizada alterando os intervalos de 
tempo que um conjunto de válvulas solenóides permanece acionada, mantendo constante a vazão. O método é estabelecido sobre uma série numérica que define os intervalos de tempo de acionamento das válvulas solenóides. A titulação por procura binária pode ser executada em 3 minutos, com consumo das soluções reagentes de cerca de $2 \mathrm{~cm}^{3}$. As vantagens e limitações do método foram averigüadas e são apresentadas ao longo da tese. 


\section{CAPÍTULO 2. FUNDAMENTOS DA TITULAÇÃO POR PROCURA BINÁRIA}

O procedimento de titulação por procura binária é baseado operacionalmente no método das variações contínuas, aplicado para a determinação da estequiometria de compostos de coordenação. Este método é atribuído a $\mathrm{Job}^{37}$, sendo posteriormente modificado por Vorburgh e Copper ${ }^{38}$.

Para a determinação da estequiometria de compostos de coordenação é requerido o preparo de uma série de soluções com o mesmo volume final. Estas soluções são preparadas de forma que a soma dos volumes das alíquotas das soluções contendo o íon central e o ligante seja sempre a mesma, variando as razões volumétricas entre as soluções contendo o íon central e o ligante. Assim, cada uma das soluções preparadas apresentará diferente valor de fração volumétrica da solução contendo a espécie química eleita como espécie de controle, íon metálico ou ligante.

As soluções, assim preparadas, são levadas a um detector espectrofotométrico, sendo posteriormente construída uma curva que relaciona a variação do sinal gerado pelo detector com a fração volumétrica do ligante, em um dado valor de comprimento de onda.

Caso, no comprimento de onda selecionado, apenas a espécie complexa absorver, o detector produzirá sinal igual a zero, quando forem medidas as absorvâncias das soluções com fração volumétrica da solução 
do ligante igual a 0 ou 1. Partindo da mesma lógica, quanto maior a concentração do complexo formado, tanto maior será o sinal de absorvância gerado pelo detector. A curva que relaciona a variação da absorvância com a fração volumétrica de uma das espécies reagentes, ín central ou ligante, selecionada como espécie controle, apresentará um aumento do sinal com o aumento da fração volumétrica até que seja atingido o máximo de absorvância. Aumentando ainda mais a fração volumétrica da espécie controle, o sinal gerado pelo espectrofotômetro será reduzido, uma vez que a concentração do composto de coordenação nas soluções preparadas irá diminuindo até o caso extremo, no qual a fração volumétrica da solução controle assumir o valor 1 .

Extrapolando as duas semi retas uma passando pelo ponto $[\mathrm{A}=0 \mathrm{e}$ $\mathrm{F}=0]$ e outra passando pelo ponto $[\mathrm{A}=0 \mathrm{e} \mathrm{F}=1]$, haverá um ponto de encontro entre as duas retas. A localização deste ponto será tão mais exata quanto maior a estabilidade do composto de coordenação formado. O mesmo ocorrendo quando é aplicado, ao invés do método das variações contínuas, o método da razão das tangentes ${ }^{39,40}$. $O$ valor da fração volumétrica correspondente ao ponto de interseção das duas semi retas é empregado para o cálculo da proporção estequiométrica entre o íon metálico e o ligante no complexo em avaliação.

O método das variações contínuas pode ser mais facilmente comprendido através de um exemplo, no qual o objetivo é determinar a estequiometria do composto de coordenação $\mathbf{A B}_{\mathrm{n}}$, formado pela reação:

$$
\mathbf{A}+n \mathbf{B} \rightarrow \mathbf{A B}_{n}
$$


onde $\mathbf{A}$ é o íon central, $\mathbf{B}$ o ligante e $n$ o número de ligantes que se associam ao íon central para a formação do complexo. Caso a solução contendo o ligante B seja definida como solução de controle, a solução que corresponderia a fração volumétrica da espécie-controle igual a zero seria a solução de $\mathbf{A}$. Em oposição, sendo a fração volumétrica da solução de controle igual a 1 , a solução apresentará a mesma concentração que em $\mathbf{B}$. A fração volumétrica da espécie controle, $\mathbf{B}$, é calculada como mostra a equação 1 ,

$$
\mathrm{F}_{\mathrm{B}}=\frac{\mathrm{V}_{\mathrm{B}}}{\mathrm{V}_{\mathrm{A}}+\mathrm{V}_{\mathrm{B}}}
$$

onde $V_{A}$ e $V_{B}$ são os volumes das alíquotas das soluções de $\mathbf{A}$ e $\mathbf{B}$, respectivamente, usados para preparar quaisquer das misturas. A soma das frações volumétricas das soluções de A e B sendo sempre igual a 1 e mantendo inalterado o volume final das soluções após a mistura, a variação das frações volumétricas das soluções em função do volume das alíquotas das espécies químicas usado no preparo das soluções finais é apresentado na Figura 5. 


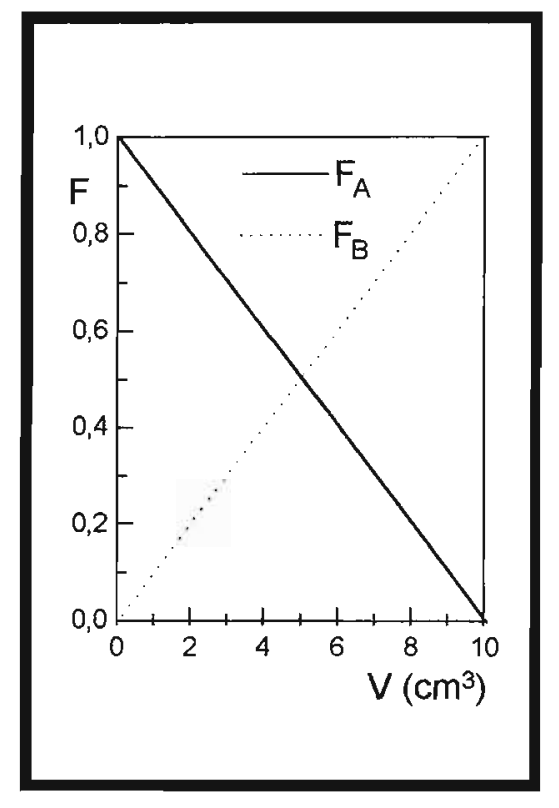

Figura 5. Variação das frações volumétricas das espécies A e B com o volume da solução de $\mathbf{B}$ utilizado para o preparo das soluções com volume final igual a $10 \mathrm{~mL} . \mathrm{F}=$ fração volumétrica. $\mathrm{V}=$ volume da espécie $\mathbf{B} \mathrm{em} \mathrm{cm}^{3}$.

A concentração do complexo formado em qualquer das soluções pode ser expressa, de forma simplificada, pela equação 2 , se $\mathrm{F}_{\mathbf{A}} \cdot \mathrm{C}_{\mathbf{A}}$ for maior que $\mathrm{F}_{\mathbf{B}} \cdot \mathrm{C}_{\mathbf{B}} / n$, ou pela equação 3 , caso $\mathrm{F}_{\mathbf{A}} \cdot \mathrm{C}_{\mathbf{A}}$ seja menor que $\mathrm{F}_{\mathbf{B}} \cdot \mathrm{C}_{\mathrm{B}} / n$,

$$
\begin{array}{ll}
{\left[\mathrm{AB}_{n}\right]=\mathrm{F}_{\mathrm{B}} \cdot \mathrm{C}_{\mathrm{B}} \cdot \frac{1}{n}} & \text { (Eq. 2), } \\
{\left[\mathrm{AB}_{n}\right]=\mathrm{F}_{\mathrm{A}} \cdot \mathrm{C}_{\mathrm{A}}} & \text { (Eq. 3), }
\end{array}
$$

onde $C_{A}$ e $C_{B}$ são as concentrações das soluções originais do íon central e do ligante; $\left[\mathrm{AB}_{n}\right]$ é a concentração no equilíbrio do complexo em estudo; $F_{\mathbf{A}}$ e $F_{\mathbf{B}}$ são as frações volumétricas das soluções de $\mathbf{A}$ e $\mathbf{B}$. As equações 
2 e 3 são simplificadas, uma vez que não levam em conta a instabilidade do complexo formado nas condições do meio. Como, para o exemplo, a um dado comprimento de onda apenas o complexo absorve radiação, a relação entre o valor de absorvância gerado pelo detector (A) e a concentração do complexo pode ser expressa como na equação 4 ,
$\mathbf{A}=\varepsilon \cdot b \cdot\left[\mathrm{AB}_{n}\right]$
(Eq. 4),

onde $\varepsilon$ é a absortividade molar do complexo; e $\mathrm{b}$ designa o caminho ótico. Pelas equações 2, 3 e 4 pode ser previsto que a curva que representa a variação da absorvância em função da fração volumétrica da solução contendo a espécie de controle $(\mathbf{B})$ é ascendente enquanto $\mathrm{F}_{\mathbf{A}} \mathrm{e}$ maior que $\mathrm{F}_{\mathbf{B}} / n$, e se mostra descendente para valores de $\mathrm{F}_{\mathbf{B}}$ maiores que $\mathrm{F}_{\mathbf{A}} \cdot n$, caso sejam iguais as concentrações de $\mathrm{C}_{\mathbf{A}}$ e $\mathrm{C}_{\mathbf{B}}$. A fração volumétrica correspondente ao ponto de interseção das duas semi retas, uma passando pelo ponto $F=0$ e a outra por $F=1$, é designada por $\mathbf{F}_{\mathbf{m}}$. Este ponto, onde $\mathrm{dA} / \mathrm{dF}=0$, pode ser relacionado com o número de ligantes $(n)$, como mostra a equação 5 , permitindo a determinação da estequiometria do complexo.

$$
\mathrm{F}_{\mathrm{m}}=\frac{n}{n+1}
$$

A relação entre a fração volumétrica correspondente ao ponto de máxima absorvância $\mathbf{m}$ e o número de ligantes $n$ é determinada para as condições em que as equações 2 e 3 se igualam. Como para qualquer situação a soma das frações volumétricas é igual a unidade $\left(\mathrm{F}_{\mathrm{A}}+\mathrm{F}_{\mathrm{B}}=\right.$ 1) e sendo $C_{A}=C_{B}$, no ponto $\mathbf{m}$ igualando as equações 2 e 3 temos que 
$\mathrm{F}_{\mathrm{B}, \mathbf{m}}=n \cdot \mathrm{F}_{\mathrm{A}, \mathbf{m}}$. Assim, as frações volumétricas de ambas espécies em $\mathbf{m}$ são expressas por $\mathrm{F}_{\mathrm{A}, \mathrm{m}}=1 /(n+1)$ e $\mathrm{F}_{\mathrm{B}, \mathrm{m}}=n /(n+1)$.

Com base nas considerações feitas anteriormente, relacionadas com o volume final das soluções preparadas e com a soma das frações volumétricas, pode ser afírmado que a concentração analítica da espécie A em qualquer uma das $j$ soluções preparadas, $\mathbf{C}_{\mathbf{A} j}$, é expressa pela equação 6,

$\mathbf{C}_{\mathrm{A}, j}=\mathbf{C}_{\mathrm{A}} \cdot \mathbf{V} \cdot \mathbf{F}_{\mathrm{A}, j}$

(Eq. 6),

BIBLIOTECA

MSTHUTO OE CUMACA

onde $C_{A}$ é a concentração original do reagente $\mathbf{A}, \mathbf{V}$ é o volume final das soluções e $\mathbf{F}_{\mathbf{A}_{j}}$ é a fração volumétrica da espécie $\mathbf{A}$ na solução $j$. A fração volumétrica da espécie $\mathbf{B}$ na mesma solução, pode ser relacionada com a mesma variável $\mathbf{F}_{\mathrm{A}, j}\left(\mathbf{F}_{\mathrm{B}, j}=1-\mathbf{F}_{\mathrm{A}, j}\right)$. Desta forma a concentração $\mathbf{C}_{\mathbf{B}, j}$ pode, também, ser expressa em função de $\mathbf{F}_{\mathbf{A}, j}$, como na equação 7 ,

$\mathbf{C}_{\mathbf{B}, j}=\mathbf{C}_{\mathbf{B}} \cdot \mathbf{V} \cdot\left(1-\mathbf{F}_{\mathrm{A}, j}\right) \quad$ (Eq. 7).

O número de ligantes associados ao íon central no complexo $\mathbf{A B}_{n}$ pode ser determinado pela razão entre as concentrações de $\mathbf{A}$ e $\mathbf{B}$ no ponto onde se interceptam as duas retas. Quando as concentrações de A e $\mathbf{B}$ nas soluções originais são iguais, e com base na equação $5, n$ pode ser obtido a partir das razões entre as frações volumétricas, como expressa a equação 8 ,

$n=\left(1-\mathbf{F}_{\mathrm{A}, m}\right) / \mathbf{F}_{\mathbf{A}, m}$

(Eq. 8). 
Como citado anteriormente, a operacionalização da titulação por procura binária apresenta similaridades com a metodologia das variações contínuas, empregada para a determinação da estequiometria de compostos de coordenação. Similarmente, (i) devem ser preparadas uma série de soluções com diferentes proporções volumétricas das soluções da amostra e do titulante; (ii) as soluções preparadas devem apresentar o mesmo volume final; e, (iii) as soluções de partida, utilizadas para o preparo das misturas, devem ser as mesmas, não sendo sujeitas a diluições prévias.

De outro modo, os parâmetros necessários para sua aplicação são os mesmos empregados em qualquer processo de titulação, ou seja, é imprescindível que seja previamente conhecida a estequiometria da reação e deve ser garantido que no ponto estequiométrico ocorrerá uma transição abrupta de alguma grandeza física possível de ser monitorada por algum instrumento de medição. Uma das grandezas físicas em condições de ser monitorada é a absorvância. Assim ocorrendo, detectado o ponto de transição, $\mathbf{F}_{e}$, é possível determinar a concentração absoluta ou relativa da espécie em análise.

Conhecida a concentração do titulante $\left(\mathrm{C}_{\mathrm{T}}\right)$, a concentração da amostra $\left(C_{A}\right)$ pode ser calculada pela equação 9 ,

$$
\mathbf{C}_{\mathbf{A}}=\left(\mathbf{C}_{\mathbf{T}} / n\right) \cdot\left(\left(1-\mathbf{F}_{\mathrm{A}, e}\right) / \mathbf{F}_{\mathrm{A}, e}\right) \quad(\text { Eq. 9), }
$$

onde $\mathrm{F}_{\mathrm{A}, e}$ é a fração volumétrica da amostra na proporção em que ocorreu uma alteração abrupta no valor de uma grandeza física em monitoramento; e $n$ a proporção estequiométrica da espécie formada entre a espécie de interesse e o titulante. 
Enquanto que para a determinação da estequiometria de compostos de coordenação o método de Job pode ser operacionalizado sem grandes dificuldades, o mesmo não acontece quando este procedimento é aplicado para titulações volumétricas.

No caso da determinação da estequiometria de compostos de coordenação, o objeto em análise é o cálculo do parâmetro $n$. Se o complexo em estudo não apresenta ligações intermetálicas, a razão entre as frações volumétricas da solução contendo o ligante e da solução do íon central pode assumir apenas alguns poucos valores, visto que $n$ é um número que pertence ao conjunto dos números inteiros $\mathrm{e}$, necessariamente positivo. Assim, se a fração volumétrica relativa ao ponto em que $\mathrm{dA} / \mathrm{dF}=0$ apresenta valor de 0,52 , pode ser assumido que o valor de $n$ é igual a 1 . A imprecisão pode ser resultado do número reduzido de soluções avaliadas, de erros inerentes aos processos de extrapolação e da estabilidade reduzida do complexo formado.

A mesma possibilidade de aproximação de valores não é aceitável para a determinação da concentração de uma espécie química por titulação. No caso das titulações, a única certeza possível de ser assumida é de que o valor da concentração da espécie de interesse na solução da amostra pertence ao conjunto dos números reais e positivos. Assim, em um processo de titulação empregando a lógica das variações contínuas, a fração volumétrica da solução titulante no ponto final sendo igual a 0,52 induz a um valor de concentração da espécie química de interesse na solução da amostra significativamente diferente do obtido caso a fração volumétrica seja 0,51 . No caso da estequiometria da reação de titulação ser 1:1, a diferença entre as razões de concentração para os valores de fração volumétrica 0,52 e 0,51 corresponderia a cerca de $4 \%$. 
Partindo deste pressuposto, o operador deveria preparar, antecipadamente, um número muito grande de soluções com diferentes proporções das soluções originais do titulante e do analito, para garantir o sucesso na aplicação deste método. Isto é fato, visto que seria necessário preparar 101 soluções com variações em fração volumétrica de 0,01 para suprir todas as possíveis misturas de $\mathrm{F}=0$ até $\mathrm{F}=1$, assumindo incerteza da ordem de $4 \%$, na melhor das condições. Esta é a difículdade da aplicação desta metodologia de titulação, caso não sejam aproveitados recursos de automação.

Várias seriam as opções de automação deste processo de titulação, seja empregando sistemas estacionários, ou sistemas de fluxo contínuo, partindo do processamento contínuo ou descontínuo das amostras ${ }^{30,41}$. Para este trabalho optou-se por um processo de titulação volumétrica em fluxo contínuo seguindo a lógica da procura binária ${ }^{26}$.

Como discutido anteriormente, a análise sendo executada passo a passo, o sistema deve gerar um número elevado de misturas de alíquotas com variadas proporções volumétricas das soluções da amostra e do titulante, para garantir uma incerteza mínima na concentração da espécie química em determinação. É óbvio que aumentando o número de soluções a serem preparadas e monitoradas, maior será o período necessário para a execução da análise. A aplicação do conceito de procura binária, como gestor deste processo de titulação volumétrica, reduz significativamente o tempo de análise, sem comprometer a exatidão requerida para esta classe de análise química ${ }^{42}$. 


\subsection{O Processo de Procura Binária}

A concentração de uma espécie em análise por titulação volumétrica convencional ${ }^{43}$ é determinada através de comparações imediatas e sucessivas da solução na qual são adicionadas as alíquotas do titulante $^{44}$. Em outras palavras, quando é empregado um indicador externo, a coloração que a solução adquire após a adição de um volume do titulante é comparada com a coloração da solução antes da introdução deste volume. Caso a coloração da solução antes e após a adição da alíquota da titulante seja a mesma, o operador segue introduzindo a solução do titulante. A comparação e adição de alíquotas são etapas repetidas até que ocorra uma variação abrupta da coloração, indicando que o ponto final da titulação foi atingido, caso esta coloração persista. A lógica deste procedimento é similar àquela apresentada no diagrama de blocos da Figura 4.

Em uma titulação direta, onde são duas as espécies químicas reativas $(i=2)$, titulante e titulando, a espécie $x$ reage com a espécie $y$, produzindo uma mudança em um parâmetro físico-químico, provocando uma variação no sinal $(\boldsymbol{S})$ gerado pelo detector.

A titulação volumétrica por busca binária consiste na procura da menor variação da fração volumétrica das soluções, titulante e titulando, que produza uma transição no sistema químico em análise. Caso o processo de procura seja monitorado através de um espectrofotômetro, o sistema averigüa transição na coloração do meio. Como no método das variações contínuas, o processo de procura binária foi implementado mantendo constante a soma do volume das alíquotas de titulante e 
titulando e variando, para cada passo da busca do ponto de transição, as frações volumétricas das soluções que contém as espécies $x$ e $y$.

A busca binária é um processo de aproximações sucessivas ${ }^{45}$. Na Figura 6 são apresentados todos os possíveis valores de fração volumétrica que podem ser obtidos com esta lógica até o sétimo ciclo de procura do ponto final.

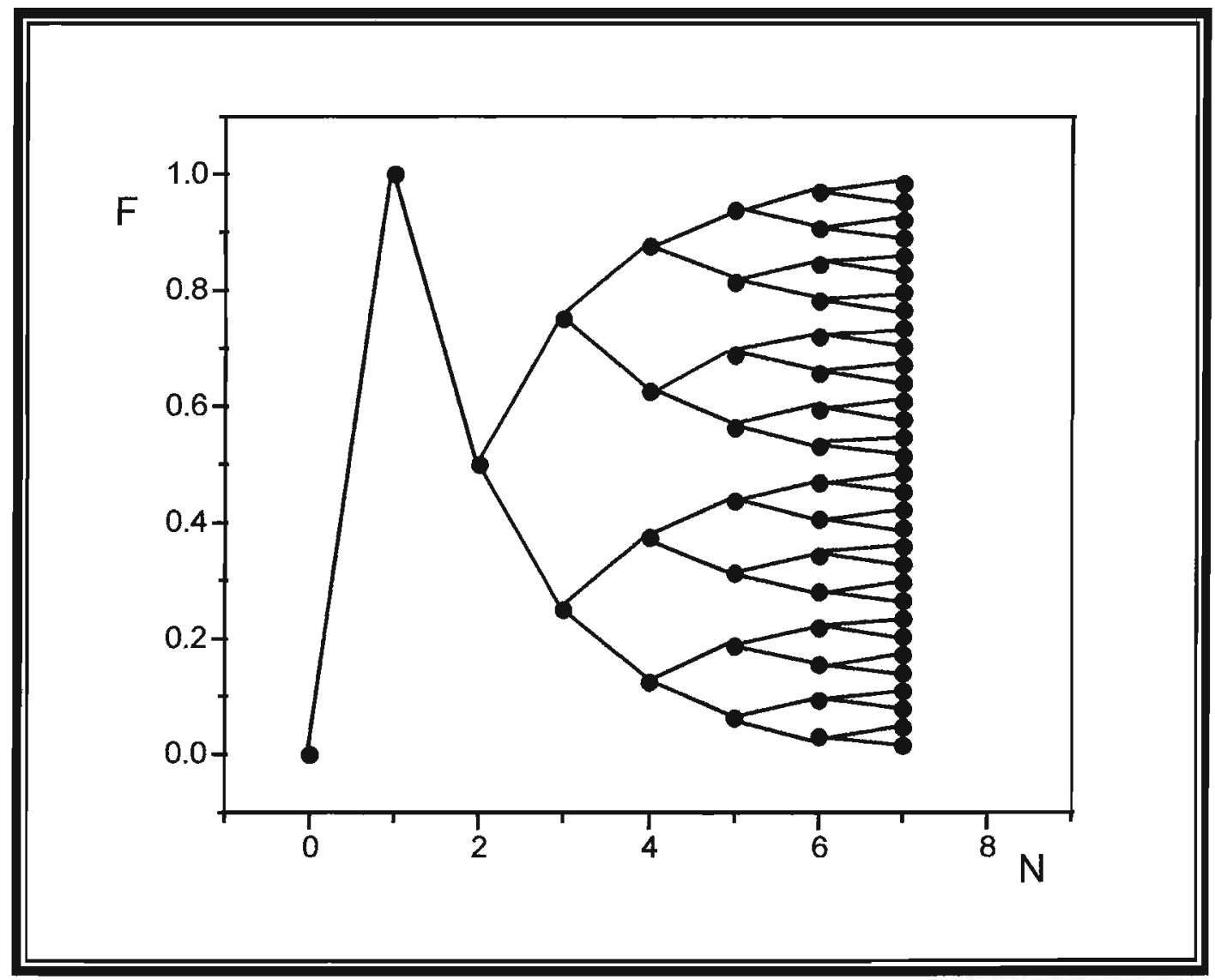

Figura 6. Processo de aproximações sucessivas aplicado no método de titulação por busca binária. $\mathrm{F}=$ fração volumétrica. $\mathrm{N}=$ ciclo de procura. - = Valores possíveis de fração volumétrica até o sétimo ciclo de busca do ponto final; $-=$ rotas de aproximação. 
Sendo $x$ a espécie química controle, normalmente o titulante, para os dois primeiros passos da procura do ponto de transição, as frações volumétricas da espécie $x, \mathbf{F}_{x, 0}$ e $\mathbf{F}_{x, 1}$, têm sempre os valores 0 e 1 , respectivamente. Assim, para o primeiro passo da procura, a solução resultante é constituída exclusivamente da solução que contém a espécie $y$ e, para o segundo passo, $\mathbf{F}_{x, 1}=1$, a solução resultante é uma alíquota, de igual volume, da solução original que contém a espécie química $x$. Os sinais gerados por um detector fotométrico, para estas duas tentativas iniciais, $\mathbf{S}_{0}$ e $\mathbf{S}_{1}$, devem ser nitidamente diferentes. Como, por princípio, a fração volumétrica é uma grandeza adimensional, e para qualquer situação seu valor não pode ultrapassar os limites entre 0 e 1 , também pode ser assumido que os sinais fotométricos $\mathbf{S}_{0}$ e $\mathbf{S}_{1}$, correspondentes aos limites superior e inferior da escala de fração volumétrica, são o maior e o menor sinal possíveis de serem gerados pelo detector.

Definido nos dois passos iniciais da procura o comportamento do sistema para todo o universo de valores de fração volumétrica (de zero até um), o processo de procura binária é realizado reduzindo à metade o conjunto de valores possíveis de fração volumétrica que contenha a transição em cada tentativa $j$ de busca. A lógica do processo a cada passo de procura segue a expressão apresentada na equação 10. Este procedimento é realizado a fim de determinar um intervalo, tão pequeno quanto o estipulado, de fração volumétrica que provoque variação no sinal gerado pelo detector.

$$
\mathbf{F}_{x, j}=\mathbf{F}_{x, j-1} \pm 2^{-j}, \quad \text { para } j \geq 3
$$


O mínimo da função é estabelecido pela interpolação de valores de fração volumétrica ${ }^{45}$, dentro do conjunto de valores definidos nas duas tentativas iniciais da procura binária, $\mathrm{F}_{\mathrm{x}, 0}$ e $\mathrm{F}_{\mathrm{x}, 1}$.

A partir da terceira tentativa, $j$ maior que 2 , a rota de procura do menor intervalo de fração volumétrica que contenha a transição de coloração, é definida pelo processamento do sinal gerado pelo detector. De forma mais específica, a procura é realizada pela comparação do sinal gerado com um valor limiar, $\mathbf{S}_{\mathrm{C}}$, calculado pelos sinais gerados nas duas primeiras tentativas de busca, $\mathbf{S}_{0}$ e $\mathbf{S}_{1}$, como descrito nas equações 11 e 12.

$$
\begin{array}{ll}
\text { Caso } \mathbf{S}_{0}<\mathbf{S}_{1}: & \mathbf{S}_{\mathrm{C}}=\mathbf{S}_{0}+\mathbf{f} .\left(\mathbf{S}_{1}-\mathbf{S}_{0}\right) \\
\text { Caso } \mathbf{S}_{0}>\mathbf{S}_{1}: & \mathbf{S}_{\mathrm{C}}=\mathbf{S}_{1}+\text { f. }\left(\mathbf{S}_{0}-\mathbf{S}_{1}\right)
\end{array}
$$

onde $\mathbf{f}$ é o fator de comparação. O valor deste fator de comparador é selecionado pelo operador baseado nas características do sistema indicador. Assim, sendo $\mathbf{S}_{j-1}$ maior que $\mathbf{S}_{\mathrm{C}}$ e $\mathbf{S}_{0}$ menor que $\mathbf{S}_{1}$, o termo $2^{-j}$, da equação 10 , é subtraído da fração volumétrica de $x$, para executar a próxima tentativa de busca; se $\mathbf{S}_{j-1}$ for menor que $\mathbf{S}_{\mathrm{C}}$, a fração volumétrica na tentativa $j$, será incrementada de $2^{-j}$ em relação a tentativa anterior. Caso $\mathbf{S}_{j-1}$ for igual a $\mathbf{S}_{\mathrm{C}}$, o processo de busca será interrompido, dada a localização do ponto de final. Na Figura 7 são apresentados, esquematicamente, dois possíveis cursos do processo de busca binária, onde é destacado através da variação do comprimento dos segmentos as alterações nos volumes das alíquotas das soluções de amostra e titulante para seis tentativas de procura do ponto final da titulação. 


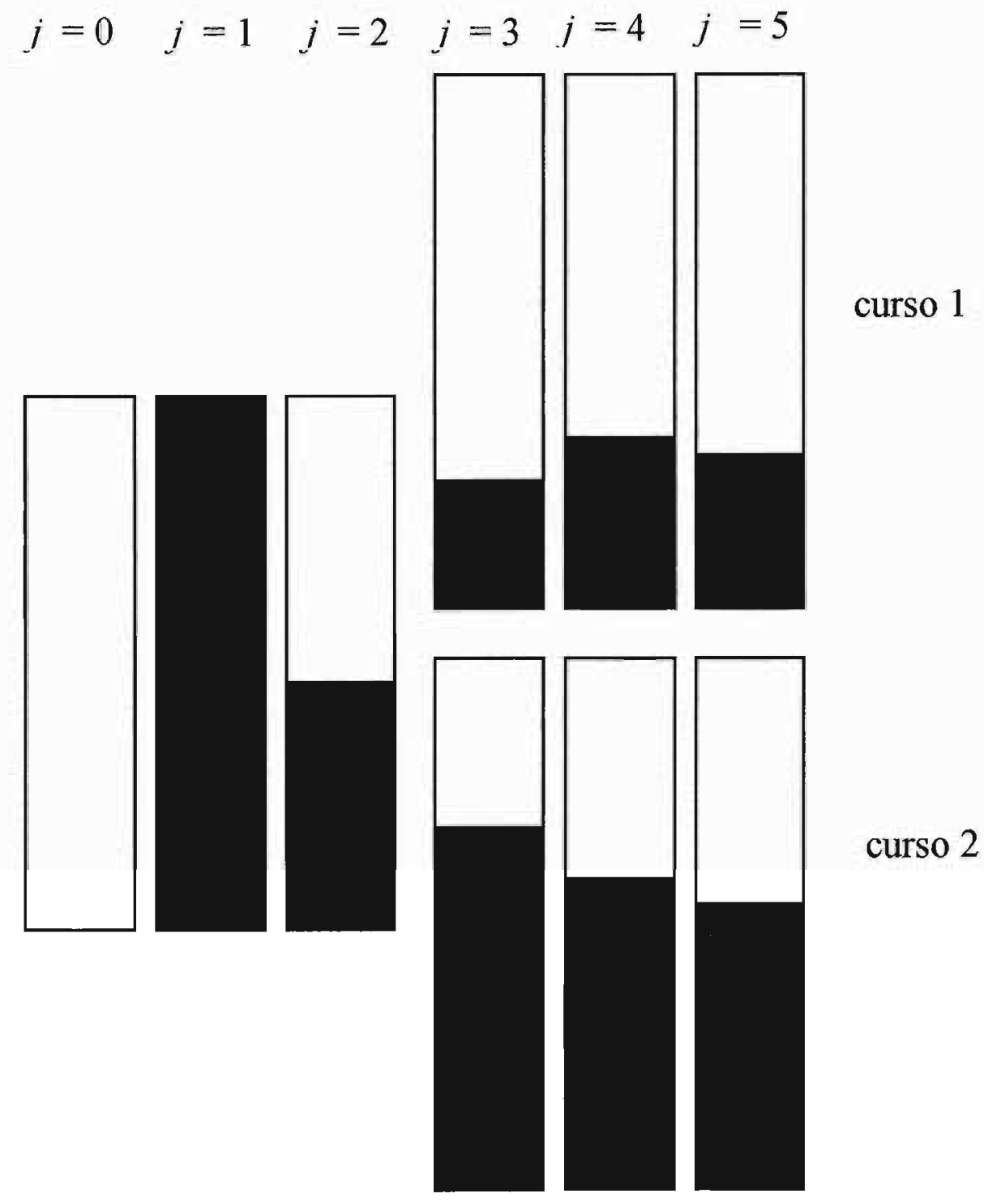

Figura 7. Modelo esquemático de dois possíveis cursos para o processo de busca binária. Os 3 primeiros passos são invariáveis, independentemente da razão de concentracão entre a solucão de amostra e do titulante. 
O termo f presente nas equações 11 e 12 , denominado de fator de comparação, pode assumir qualquer valor entre 0 e 1 . Caso $S_{0}$ seja menor que $S_{1}$ e o operador definindo como zero o fator de comparação, o sistema assumiria que qualquer solução produzida pela mistura das soluções originais que acarrete, a um dado comprimento de onda previamente estabelecido, uma maior absorção da radiação quando comparada àquela gerada pelo detector no passo de procura $\mathbf{F}_{x}, 0$, como tendo esta solução superado o ponto final.

Tendo em conta que o sistema de análise pode apresentar ruídos, a seleção dos valores zero ou um para o fator f não demonstram ser adequados. Os efeitos dos valores impostos ao fator de comparação nas titulações por procura binária são discutidos em capítulo posterior.

Uma equação geral que explicita o processo de aproximações sucessivas nas titulações por procura binária pode ser expresso pela equação 13 , na qual $\mathrm{F}_{\mathrm{j}}$ é a fração volumétrica no passo $j$ de procura do ponto final, para $j$ maior ou igual a 1 ; e $z$ é um parâmetro que pode assumir apenas os valores 0 ou 1 , a depender do sinal obtido no passo de procura $j-1$.

$\mathrm{F}_{j}=\mathrm{F}_{j-1}+(-1)^{z} \cdot 2^{-(j-1)}$, para $j \geq 3$ (Eq. 13)

A fração volumétrica para o passo $j$ será incrementada ou decrementada do valor obtido em $2^{-(j-1)}$, dependendo do valor assumido por $z$ no passo precedente de procura do ponto estequiométrico da titulação. A definição do valor do parâmetro $z$, para qualquer passo de procura $j$, se $j$ for maior que 2 , é estabelecida por similaridade do sinal gerado pelo detector no passo de procura $j-1$ com os dois passos iniciais de 
busca $(j=0$ e $j=1)$ ou, através de comparação do sinal obtido no passo $j$ $I$ com o valor calculado de $\mathrm{S}_{\mathrm{C}}$.

Para $j=0$, necessariamente $F_{\mathrm{j}}$ e $z$ assumem o valor zero, o sinal gerado pelo detector $\left(\mathrm{S}_{0}\right)$ necessariamente deve ser diferente do sinal produzido pelo detector no passo de busca seguinte $(j=1)$. Aplicando a equação 13 , o valor de fração volumétrica no passo de procura $j=1$ é sempre 1, e o parâmetro $z$ assume o valor 1 . Desta forma para $j=2$, a fração volumétrica da solução contendo a espécie controle sofre um decréssimo de $2^{-1}$, assim assumindo o valor para $\mathrm{F}_{2}=0,50$. $\mathrm{O}$ sinal gerado pelo detector $\left(S_{2}\right)$ para a sequência formada por alíquotas de mesmo volume $(F=0,50)$ é comparado com o valor de $S_{C}$, para indicar se $z$ assumirá o valor 0 ou 1 no passo seguinte da procura binária. Portanto, para $S_{1}>S_{0}$, sendo $S_{C}$ calculado como na equação 11 , caso $S_{2}>S_{C}$, o termo $z$ assume o valor 1 para o cálculo da fração volumétrica a ser empregada no preparo da solução no passo seguinte da procura binária. Desta forma, o processo de aproximação é iniciado, uma vez que o conjunto de valores possíveis para fração volumétrica é reduzido em 50 \%. Assim, o valor de fração volumétrica referente ao ponto estequiométrico da titulação, é um número real contido no intervalo de valores entre os limites $F_{0}$ e $F_{2}$. Diferentemente, para em contraponto $S_{2}<$ $\mathrm{S}_{\mathrm{C}}, z$ assumirá o valor 0 , restringindo o valor de fração volumétrica correspondente ao ponto final a qualquer valor contido no intervalo entre $F_{1}$ e $F_{2}$.

O termo $2^{-(j-1)}$, da equação 13 , gera uma sucessão numérica convergente, cujo limite para $n$ tendendo a infinito é zero ${ }^{46}$. Portanto, o valor de $F_{\mathrm{j}}$ tende a um valor entre os limites 0 e 1 , considerado como a 
fração volumétrica correspondente ao ponto final $F_{e}$, com o aumento do número de tentativas de procura.

Uma peculiaridade do processo de titulação por procura binária é relacionada com o fato de ser empregada fração volumétrica da solução padronizada ao invés de volume adicionado do titulante. Por princípio, o volume de titulante adicionado $(\mathrm{Vt})$ a um determinado volume da solução amostra (Va) pode assumir qualquer valor entre 0 e $+\infty$. A fração volumétrica do titulante em um processo convencional de titulação é calculada como na equação 14 . $O$ limite de $F_{t}$ para $V_{t}$ tendendo a infinito é igual a 1 .

$$
\mathrm{F}_{t}=\frac{\mathrm{V}_{t}}{\mathrm{~V}_{t}+\mathrm{V}_{a}}
$$

Para o processo convencional de titulação, o intervalo em fração volumétrica do titulante é estipulado por $0 \leq \mathrm{F}_{\mathrm{t}}<1$, podendo assumir qualquer valor dentro dos limites deste intervalo. Em contraposição, para o processo de titulação por procura binária o intervalo em fração volumétrica do titulante é definido por $0 \leq F_{t} \leq 1$, isto porque são preparadas várias soluções com diferentes proporções volumétricas de solução da amostra e do titulante.

Nas análises titrimétricas uma espécie $A$ (analito), presente na solução da amostra, reage com uma espécie química $B$ (reagente), presente na solução do titulante, formando como produto a espécie $C$. A solução do titulante (espécie $B$ ) é adicionada em alíquotas, passo a passo, à solução 
da amostra. Para a viabilização deste processo é necessário empregar um sensor, que indique o momento no qual a totalidade da espécie de interesse, contida na amostra, tenha reagido com o titulante.

A reação que traduz o processo aplicado à titulação pode ser exemplificada através da seguinte equação,

$$
A+\mathrm{n} B \rightleftarrows C,
$$

na qual 1 mol da espécie $\mathrm{A}$, relacionada com a solução da amostra, reage com $n$ moles da espécie $B$, gerando $1 \mathrm{~mol}$ da espécie química $C$. Operacionalmente, diversos são os parâmetros possíveis de serem monitorados para indicar o momento em que o processo de adição de alíquotas da solução do titulante deva ser interrompida. Os parâmetros de sensoriamento devem estar diretamente relacionados a uma dentre as seguintes alternativas: i) consumo total da espécie química $A$; ii) excesso da espécie $B$; ou iii) limite máximo de produção de $C$ nas condições de análise.

Durante um procedimento convencional de titulação e supondo que a reação entre $A$ e $B$ seja sempre completa, a concentração da espécie de interesse $[\mathrm{A}]$ varia com o volume adicionado do titulante contendo a espécie $B$, como sugere a equação 15 ,

$$
[A]=\frac{C_{A} \cdot V_{A}}{V_{A}+V_{B}}-\frac{1}{n} \cdot \frac{C_{B} \cdot V_{B}}{V_{A}+V_{B}}
$$


onde $[\mathrm{A}]$ é a concentração da espécie $A$ no equilíbrio, $\mathrm{C}_{\mathrm{A}}$ e $\mathrm{C}_{\mathrm{B}}$ as concentrações originais das espécies químicas $A$ e $B, V_{\mathrm{A}}$ o volume da solução de amostra e $V_{B}$ o volume adicionado da solução do titulante.

A equação 15 deve ser entendida exclusivamente como uma representação algébrica do processo, uma vez que pela equação, sem que seja aplicada uma condição de contorno a concentração da espécie A pode assumir qualquer valor entre $C_{A}$ e $-\infty$, o que é fisicamente improcedente. As equações 16 e 17 são também representações algébricas que sugerem respectivamente a indicação do andamento da titulação pelo súbito excesso da espécie $B$ ou pelo valor máximo da concentração de $C$.

$$
\begin{aligned}
& {[B]=\frac{C_{B} \cdot V_{B}}{V_{A}+V_{B}}-n \cdot \frac{C_{A} \cdot V_{A}}{V_{A}+V_{B}}} \\
& {[C]=\frac{C_{B} \cdot V_{B}}{V_{A}+V_{B}} \cdot \frac{1}{n}=\frac{C_{A} \cdot V_{A}}{V_{A}+V_{B}}}
\end{aligned}
$$

Equações que representem corretamente o processo de titulação são formuladas a partir dos equilíbrios químicos envolvidos e dos balanceamentos de carga e massa pertinentes as espécies envolvidas neste processo de análise. Exemplificando, a variação da concentração do íon $\mathrm{H}_{3} \mathrm{O}^{+}$durante a titulação de um ácido fraco monoprótico, $\mathrm{HX}$, com uma base forte, $\mathrm{YOH}$, pode ser calculada pelos equilíbrios químicos, equações 18 e 19; pelos balanços de massa equações 20 e 21; e pelo balanço de carga, descrito pela equação 22 .

$$
K_{1}=\frac{\left[H^{+}\right] \cdot\left[X^{-}\right]}{[H X]}
$$




$$
\begin{aligned}
& K_{W}=\left[H^{+}\right] \cdot\left[O H^{-}\right] \\
& {\left[Y^{+}\right]=\frac{C_{Y O H} \cdot V_{B}}{V_{A}+V_{B}}} \\
& {[H X]+\left[X^{-}\right]=\frac{C_{H X} \cdot V_{A}}{V_{A}+V_{B}}} \\
& {\left[H^{+}\right]+\left[Y^{+}\right]=\left[O H^{-}\right]+\left[X^{-}\right]}
\end{aligned}
$$

Rearranjando a equação 18 em função de [HX] e substituindo na equação 20 , a concentração do íon $\mathrm{X}^{-}$pode ser expressa como na equação 23.

$$
\left[X^{\sim}\right]=C_{H X} \cdot \frac{V_{A}}{V_{A}+V_{B}} \cdot\left(\frac{K 1}{K 1+\left[H^{+}\right]}\right)
$$

Substituindo os termos devidos das equações 19, 21 e 23, na equação 22, temos

$$
\left[H^{+}\right]+C_{Y} \cdot \frac{V_{B}}{V_{A}+V_{B}}=C_{H X} \cdot \frac{V_{A}}{V_{A}+V_{B}} \cdot\left(\frac{K 1}{K 1+\left[H^{+}\right]}\right)+\frac{K_{W}}{\left[H^{+}\right]}
$$

Para facilitar a resolução da equação é conveniente desmembrar os termos da equação em termos de $V_{A}$ e $V_{B}$, obtendo a equação 24 . 


$$
V_{A}=-V_{B} \cdot\left\{\frac{\left[H^{+}\right]^{3}+\left(K 1-C_{Y}\right) \cdot\left[H^{+}\right]^{2}+\left(K 1 \cdot C_{Y}-K_{W}\right) \cdot\left[H^{+}\right]-K_{W} \cdot K 1}{\left[H^{+}\right]^{3}+K 1 \cdot\left[H^{+}\right]^{2}-\left(C_{X}+K_{W}\right) \cdot\left[H^{+}\right]-K_{W} \cdot K 1}\right\} \text { (Eq. 24) }
$$

A equação geral (equação 24) pode ser apresentada em termos de fração volumétrica seguindo os princípios das variações contínuas. Para esta condição, a soma de $V_{A}$ e $V_{B}$ é constante e assume o valor $V$, como mostra a equação 25 .

$$
\mathrm{V}=\mathrm{V}_{\mathrm{A}}+\mathrm{V}_{\mathrm{B}}
$$

Pela equação 24 pode ser constatado que $\mathrm{V}_{\mathrm{A}}=\mathrm{Q}$. $\mathrm{V}_{\mathrm{B}}$, onde $\mathrm{Q}$ é um fator de proporcionalidade. Substituindo o termo $V_{A}$ da equação 25 por $\mathrm{Q} . \mathrm{V}_{\mathrm{B}}$, é obtida a relação $\mathrm{V}=\mathrm{V}_{\mathrm{B}} \cdot(1+\mathrm{Q}) \mathrm{e}$, portanto a fração volumétrica da solução contendo a espécie química $B$ é dada pela equação 26 .

$$
F_{B}=\frac{1}{1+Q}
$$

Expressando a equação $26 \mathrm{em}$ termos das concentrações das espécies químicas presentes no equilíbrio é obtida a equação 27 que traduz a variação da fração volumétrica da espécie química $B$ em função da 
concentração de $\mathrm{H}^{+}$, para a titulação de um ácido fraco monoprótico com uma base forte de fórmula $\mathrm{YOH}$.

$$
F_{B}=\frac{\left[H^{+}\right]^{3}+K 1 \cdot\left[H^{+}\right]^{2}-(C x+K w) \cdot\left[H^{+}\right]-K w \cdot K 1}{C y \cdot\left[H^{+}\right]^{2}-(C x+K 1 \cdot C y) \cdot\left[H^{+}\right]}
$$

De maneira semelhante pode ser deduzida uma equação que evidencie a variação da fração volumétrica com a concentração do íon hidrogênio em uma titulação de ácido forte com base forte baseada no processo das variações contínuas. Na equação 28 é mostrada a relação.

$$
F_{B}=\frac{-\left[H^{+}\right]^{2}+C_{A} \cdot\left[H^{+}\right]+K w}{\left(C_{A}+C_{B}\right) \cdot\left[H^{+}\right]}
$$

Nas Figuras 8 e 9 são apresentadas curvas teóricas obtidas a partir da equação 28 da variação do $\mathrm{pH}$ em função da fração volumétrica quando é aplicado o processo de variações contínuas à titulação. As curvas da Figura 8 mostram a variação do valor calculado de $\mathrm{pH}$ com a fração volumétrica para titulações de soluções de ácido forte (HX) com base forte $(\mathrm{YOH})$, ambas na mesma concentração. Como pode ser verificado na Figura 8, os perfis das curvas se assemelham as obtidas nos processos convencionais de titulação, reduzindo a transição do $\mathrm{pH}$ na vizinhança do ponto estequiométrico. Uma diferença clara entre as curvas advindas do processo proposto e as obtidas pelo método convencional está 
relacionada com a existência do ponto correspondente à fração volumétrica da solução do titulante é igual a unidade.

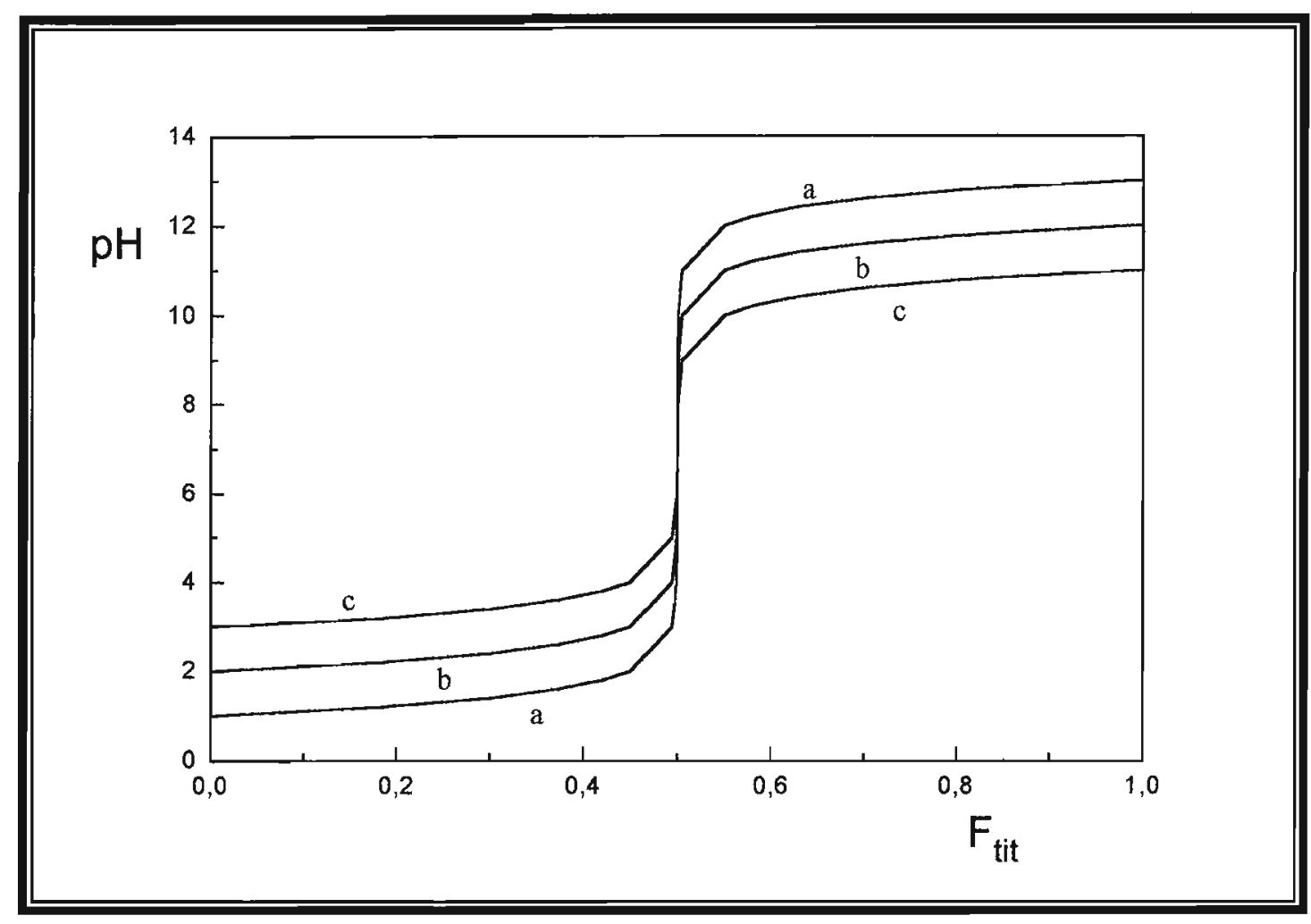

Figura 8. Variação do $\mathrm{pH}$ com a fração volumétrica da solução do titulante para titulações de soluções equimolares de ácido forte (HX) com base forte $(\mathrm{YOH})$, seguindo o processo das variações contínuas. a) $\mathrm{C}_{\mathrm{HX}}=$ $0,1 \mathrm{Me} \mathrm{C}_{\mathrm{YOH}}=0,1 \mathrm{M}$, b) $\mathrm{C}_{\mathrm{HX}}=0,01 \mathrm{Me} \mathrm{C}_{\mathrm{YOH}}=0,01 \mathrm{M}$, a) $\mathrm{C}_{\mathrm{HX}}=0,001$

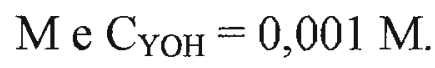

O comportamento das curvas do processo de titulação baseado no método proposto por Job, para o caso em que é mantida a concentração de apenas uma das espécies (titulante ou titulando) e variando a concentração da solução da espécie complementar é apresentada na Figura 9. As curvas 
foram obtidas aplicando a equação 28 para concentração da solução do ácido igual a $0,01 \mathrm{M}$ e para as concentrações de $0,01 \mathrm{M}, 0,02 \mathrm{M}$ e $0,05 \mathrm{M}$ da solução de base forte.

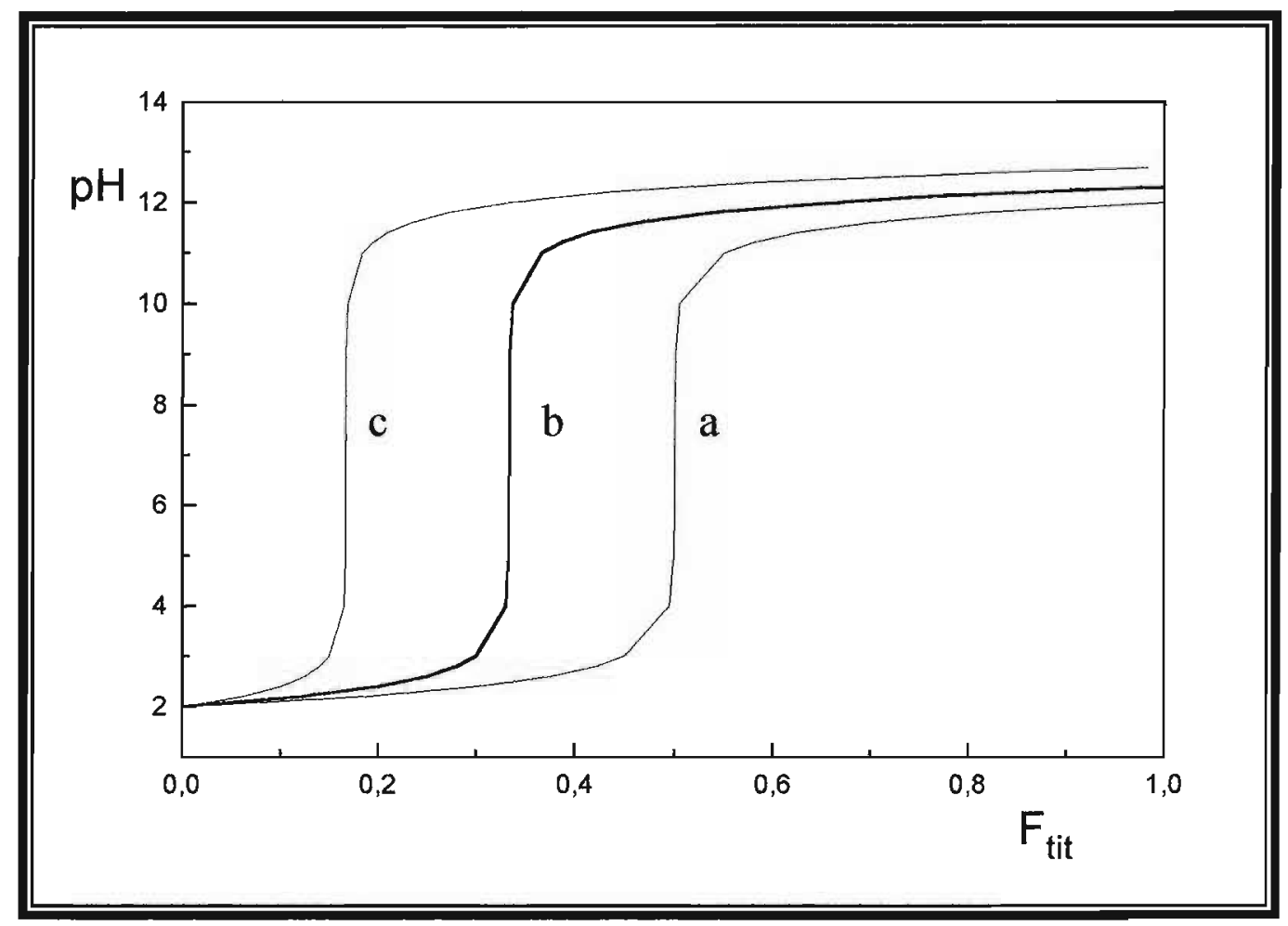

Figura 9. Curvas teóricas de titulação baseadas no processo das variações contínuas. Ácido forte $0,01 \mathrm{M}$ com base forte a) $0,01 \mathrm{M}$, b) $0,02 \mathrm{M}$ e c) $0,05 \mathrm{M} . \mathrm{F}_{\text {tit }}=$ fração volumétrica da solução de base forte.

Pelas curvas da Figura 9 é possível constatar que os valores de fração volumétrica da solução da base correspondente ao ponto estequiométrico para as titulações de solução de $\mathrm{HX}$ 0,01 M com YOH $0,01 \mathrm{M}, 0,02 \mathrm{M}$ e $0,05 \mathrm{M}$ são iguais a $0,5,0,33$ e 0,17 , respectivamente.

Um sistema em titulação pode ser monitorado por qualquer detector ou indicador sensível a variação de acidez do meio. A variação do $\mathrm{pH}$ com 
o volume adicionado da solução do titulante para um processo convencional de titulação de ácido fraco monoprótico com base forte é apresentado na Figura 10. A adição de titulante à solução de amostra é feita até que seja alcançado o ponto final da titulação. Como na curva de titulação da Figura 10, o ponto final deve estar contido na zona de inflexão da curva, de forma que o repentino aumento do valor da variável de controle, por exemplo o $\mathrm{pH}$, com a adição da solução do titulante induza ao operador que o ponto final da titulação tenha sido atingido. Similarmente, ao ser empregado um corante indicador, este deve apresentar variação de coloração na mesma faixa de $\mathrm{pH}$ que o sistema em análise. Assim, o corante indicador deve ser escolhido de acordo com a espécie que se deseja determinar e com as características intrínscicas do mesmo. Os corantes indicadores para titulações de ácidos ou bases, são ácidos ou bases fracas que apresentam colorações diferenciadas quando presentes predominantemente na forma associada ou dissociada. 


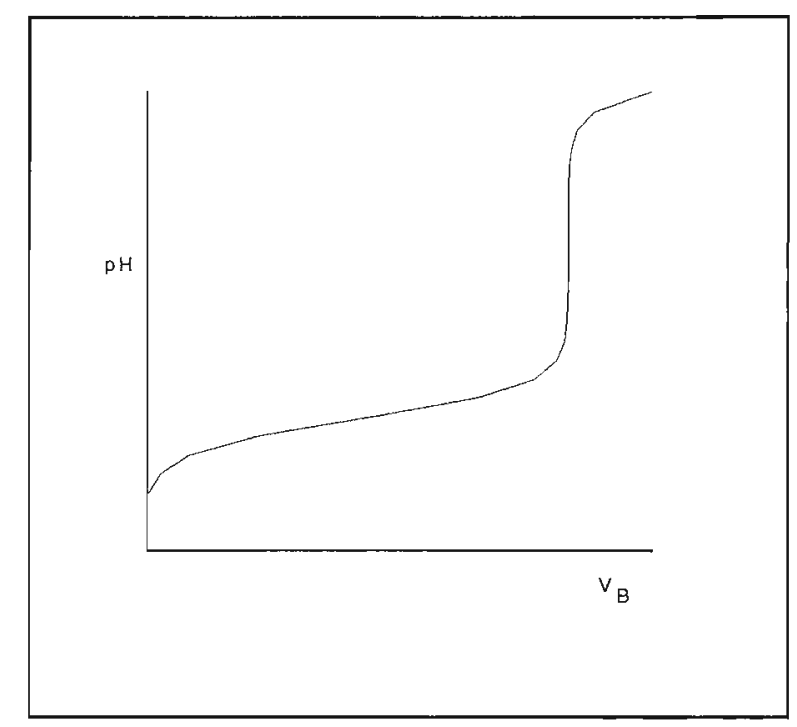

Figura 10. Representação de curva teórica da variação de $\mathrm{pH}$ com volume adicionado de titulante, para um sistema de titulação de um ácido fraco monoprótico com base forte.

2.2. Consumo de Reagentes na Titulação por Procura Binária

Sendo $\mathbf{V}$ a soma do volume das alíquotas de titulante e da solução da amostra, o volume de $x$, para qualquer tentativa de busca $k$, para $k$ maior que 2, pode ser calculado pela equação 29.

$$
\mathrm{V}_{x, \mathrm{k}}=\mathrm{V} \cdot\left[2^{-1} \pm 2^{-2} \pm 2^{-3} \pm 2^{-4} \pm \ldots . \pm 2^{-(k-1)}\right]
$$

$$
\mathrm{V}, \mathrm{k}=\mathrm{V} \sum_{=1}^{-1} \pm 2^{-}
$$


O consumo total de reagentes para o processo de titulação por busca binária é muito baixo, podendo ser expresso pelo produto do número total de tentativas de procura pelo volume de uma sequência $\left(\mathrm{V}_{x, \theta}\right)$.

A técnica de análise química por titulação volumétrica, em sistemas de fluxo contínuo, aplicando o processo de busca binária para a localização do ponto final, é realizada de modo descontínuo. Uma grande vantagem da aplicacão deste processo descontínuo de análise em fluxo contínuo é que, por princípio, a soma dos volumes das alíquotas de amostra e titulante introduzidas no percurso analítico é sempre constante. Desta forma, como o percurso analítico e a zona de amostra não são alteradas durante uma análise, a dispersão desta zona de amostra também permanece constante. 


\section{CAPÍTULO 3. CONDIÇÕES EXPERIMENTAIS}

As condições de experimentação são apresentadas em três módulos distintos, visto que é composto de um sistema de fluxo, um programa para executar o processo de procura binária e um conjunto de soluções utilizadas para os testes desta metodologia de titulação em estudo.

\subsection{Instrumentação e Diagrama de Fluxo}

Para a operacionalização do sistema de titulação em fluxo contínuo aplicando o conceito de procura binária foi empregado como detector um espectrofotômetro de feixe simples Femto, modelo 432, (SP, Brasil), equipado com célula de fluxo. A célula de fluxo utilizada foi construída em vidro, apresentando capacidade igual a $200 \mu \mathrm{L}$ e caminho ótico de 12 $\mathrm{mm}$. O espectrofotômetro fornecia sinal analógico de saída igual a 100 $\mathrm{mV}$ para uma unidade de absorvância.

A corrente de fluxo do sistema apresentado no diagrama de fluxo da Figura 11 foi gerada por uma bomba peristáltica Ismatec - modelo IPN-2. O sistema de fluxo proposto para a execução das titulações por procura binária utilizou um único canal, pelo qual foram aspiradas as soluções. Assim, proporcionando as condições para que bombas peristálticas mais simples, com um número menor de canais, possam ser empregadas para o mesmo fim. 
Um microcomputador 386 foi empregado para a aquisição e processamento de dados, bem como para controle da introdução de volumes variados das alíquotas das soluções da amostra e do titulante. $O$ sistema foi elaborado para microcomputadores contendo microprocessador da família 80286, ou mais recentes (80386 ou 80486), equipados com a interface PCL - 711S, produzida pela American Advantech Co. (San Jose, CA, USA).

A interface PCL - $711 \mathrm{~S}^{47}$ apresenta 5 níveis de ganho, selecionáveis por programação, permitindo melhorar a resolução das medições, dado que a faixa de diferença de potencial pode ser limitada, pelo programa, entre $\pm 5 \mathrm{~V}, \pm 2,5 \mathrm{~V}, \pm 1,25 \mathrm{~V}, \pm 0,625 \mathrm{~V}$ ou $\pm 0,3125$ V. Para esta interface, que apresenta 8 canais individuais de entrada, o processo de conversão de sinais analógicos em digitais pode ser inicializado de três modos distintos: (i) através de um programa de controle desenvolvido; (ii) empregando o temporizador, contido na própria interface; ou, (iii) por algum evento externo. A transferência de dados foi realizada por programação e, por sua vez, a conversão do sinal analógico para sinal digital, com precisão de $\pm 1 \mathrm{LSB}$, é executada a cada período de $25 \mu$ s. O conversor de sinal analógico para digital (conversor A/D), presente na interface, é estruturado em 12 digitos binários (bits), garantindo sensibilidade suficiente para detecção espectrofotométrica. A rotina desenvolvida, para titulações por procura binária, assumia nível de ganho igual a $4\left(16=2^{4}\right)$, assim limitando a faixa de diferença de potencial entre $-0,3125 \mathrm{~V}$ e $+0,3125 \mathrm{~V}$. Sendo empregado conversor A/D de 12 bits, o número de unidades digitais é igual a $2^{12}$ (4096). Para nível de ganho igual a 4, uma unidade digital é acrescida a cada incremento de $0,153 \mathrm{mV}$ na diferença de potencial 
aplicada sobre o conversor A/D. Como citado anteriormente, o espectrofotômetro empregado produz uma diferença de potencial igual a $100 \mathrm{mV}$ para uma unidade de absorvância. Assim, uma unidade de absorvância produz sinal digital igual a 2703, e consequentemente o acréscimo de uma unidade digital a cada incremento de 0,0015 em absorvância.

As soluções foram introduzidas no percurso analítico através do acionamento de válvulas solenóides de 3 vias, modelo 161T031, produzidas pela Neptun Research Co. (Stow, MA, USA). Durante o processo de titulação as válvulas eram acionadas através da porta de saída da interface PCL-711S. Uma interface eletrônica desenvolvida, no Centro de Energia Nuclear na Agricultura da Universidade de São Paulo $^{48}$, foi empregada para fornecer a diferença de potencial de $12 \mathrm{~V}$, suficiente para que as válvulas solenóides pudessem ser acionadas. A mesma interface de potência foi empregada também para a sincronização do início da etapa de amostragem com a pulsação da bomba peristáltica.

Um sistema de fluxo, como representado no diagrama de fluxo da Figura 11, foi empregado para a execução do processo de titulação por procura binária. O sistema de fluxo era consistuído de três válvulas solenóides de 3 vias, bobina de reação, ponto de junção, tubos em polietileno com diâmetro interno de $0,8 \mathrm{~mm}$, uma bomba peristáltica e um detector espectrofotométrico. 


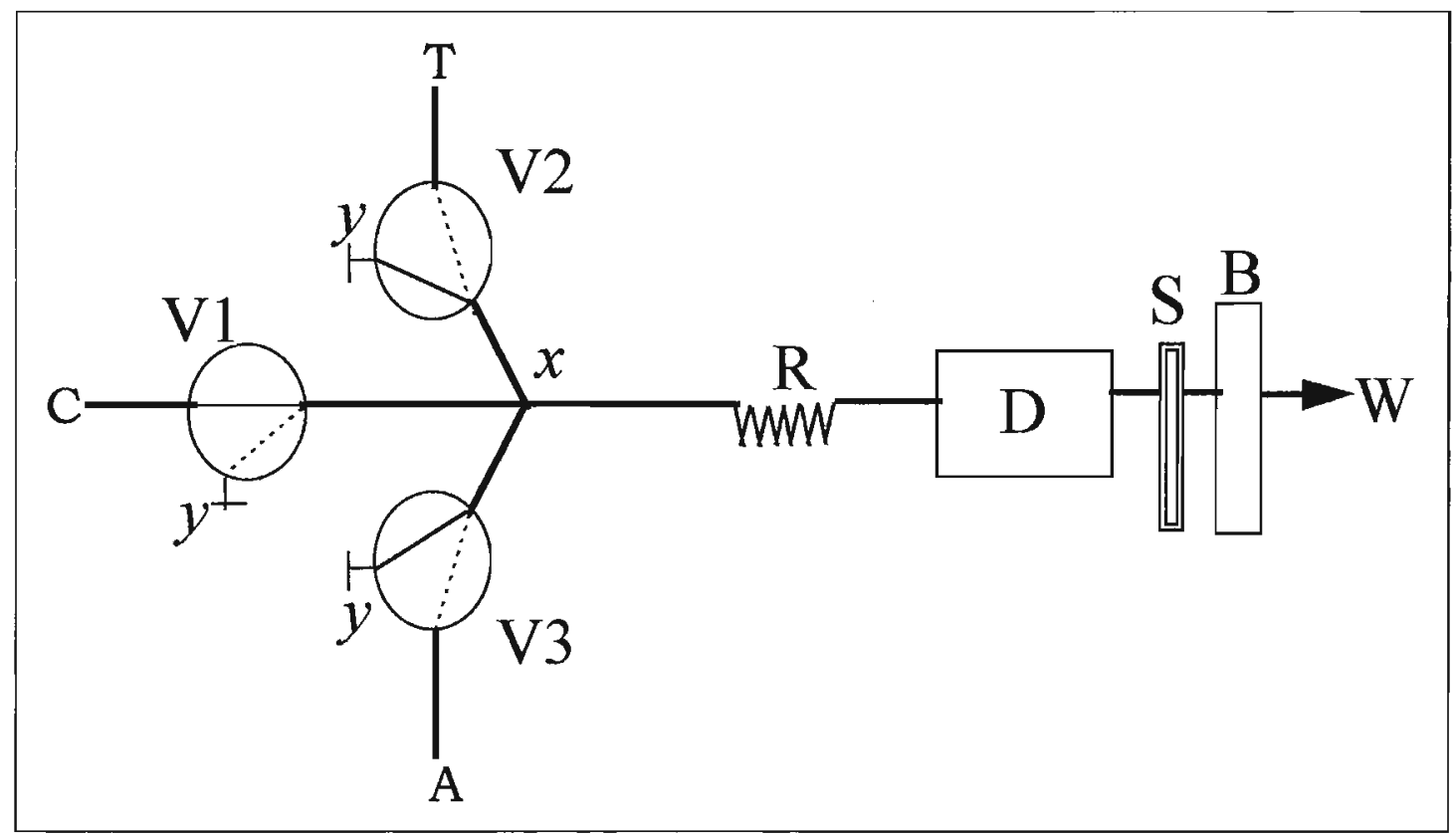

Figura 11. Diagrama de fluxo empregado para o processo de titulação por procura binária. $\mathrm{A}=$ amostra; $\mathrm{T}=$ titulante; $\mathrm{C}=$ carregador. $\mathbf{V 1}, \mathrm{V} 2 \mathrm{e}$ $\mathbf{V 3}=$ válvulas solenóides; $\mathrm{R}=$ reator; $\mathrm{D}=$ detector espectrofotométrico; $\mathrm{S}=$ supressor de pulsos; $\mathrm{B}=$ bomba peristáltica; $\mathrm{W}=$ descarte. $x=$ ponto de junção; $y=$ obstrução do fluxo.

A sincronização do início da etapa de amostragem foi realizada através da leitura da porta de entrada digital da interface PCL-711S acoplada ao microcomputador ${ }^{49}$. Ao sistema foi associado uma célula supressora de pulsos ${ }^{50}$, para atenuar a pulsação da vazão, comum quando são empregadas bombas peristálticas para impulsionar as correntes pelo percurso analítico. 


\subsection{Sistema FIA e Variáveis Experimentais}

No diagrama de fluxo apresentado na Figura 11, todas as válvulas estão desativadas. Nestas condições somente a solução carregadora flui pelo percurso analítico. Acionando ao mesmo instante as válvulas solenóides V1 e V2, uma alíquota do titulante começa a ser introduzida no percurso analítico. De outro modo, com o acionamento simultâneo das válvulas solenóides $\mathbf{V} 1$ e V3, é inserida a solução da amostra no mesmo percurso. Repetições sucessivas destas ações: acionamento de V1 e V2, mantendo V3 desativada, seguido do acionamento de V1 e V3, desativando $\mathbf{V} 2$, gera uma sequência de pulsos alternados das soluções da amostra e do titulante. A cada sequência produzida é contabilizado um novo passo, ou tentativa, de procura.

Sempre que a válvula solenóide V1 é acionada, o fluxo da solução carregadora é interrompido. Sabendo que a válvula solenóide V1 sempre é acionada conjuntamente ou com a válvula solenóide $\mathbf{V} 2$, para a inserção da solução do titulante, ou com a válvula V3, quando se deseja introduzir um dado volume da solução da amostra no percurso analítico, o volume de uma sequência é proporcional ao intervalo de tempo que a válvula solenóide V1 permanece acionada. O volume da sequência de alíquotas das soluções da amostra e do titulante introduzido no percurso analítico (v) é, portanto, calculado pelo produto entre o valor da vazão de aspiração ( $\phi)$, imposta pela bomba peristáltica, e o intervalo de tempo que a válvula solenóide $\mathrm{V} 1$ permanece acionada $\left(\mathrm{t}_{\mathrm{V} 1}\right)$, como expressa a equação 30.

$$
\mathbf{v}=\phi \cdot \mathrm{t} \mathrm{V} 1
$$


Uma seqûencia é composta por uma ou mais alíquotas das soluções da amostra e do titulante, introduzidas sucessiva e consecutivamente no percurso analítico. Cada alíquota da solução da amostra e do titulante que compõe uma sequência é denominada de segmento. Para a execução do processo de titulação por procura binária proposto, o volume inserido no percurso analítico é uma constante. Portanto, a soma dos intervalos de tempo que as válvulas solenóides V2 e V3 permanecem acionadas deve ser mantida para todos os passo da procura. Após a introdução da sequência de volume $\mathbf{v}$ no percurso analítico, esta é transportada pela solução carregadora para o detector, uma vez desativada todas as válvulas solenóides (V1, V2 e V3).

Como descrito anteriormente, para garantir volumes iguais, o tempo que a válvula V1 permanece acionada, deve ser o mesmo para todas as tentativas de busca. $\mathrm{O}$ volume $\mathbf{v}$ da sequência de alíquotas, expresso em $\mathrm{cm}^{3}$, é dado por $\phi \cdot \mathbf{t}_{\mathrm{Vl}}$, como na equação 30 , onde $\phi$ é expressa $\mathrm{em} \mathrm{cm}^{3} \cdot \mathrm{s}^{-1}$ $\mathrm{e}, \mathbf{t}_{\mathrm{V} 1}$ expresso em segundos.

Para a primeira tentativa de busca, é inserido no percurso analítico uma alíquota de volume $\mathbf{v}$ da solução do titulante. Para tanto, as válvulas V1 e V2 são mantidas acionadas durante o intervalo de tempo $\Delta t$. Como o processo de amostragem é baseado no intervalo de tempo que as válvulas permanecem acionadas, a precisão do volume inserido no percurso analítico é função (I) do tempo de resposta do sistema às ordens de acionamento e desativação das válvulas, (ii) da capacidade do sistema em reproduzir intervalos de tempo, (iii) da sensibilidade do sistema em distingüir pequenas variações de intervalos de tempo; e, (iv) da constância da vazão durante a etapa de amostragem. 
A constância da vazão é sensivelmente prejudicada, quando são empregadas bombas peristálticas para gerar 0 fluxo. As bombas peristálticas produzem um perfil de fluxo pulsante em função do tempo, afetando a precisão da amostragem, principalmente quando devem ser inseridos pequenos volumes. Com o objetivo de minimizar este problema, foram acoplados ao sistema um sincronizador de pulsos e uma célula supressora de pulsação ${ }^{49}$.

O processo de titulação por busca binária pode também ser definido como um sistema automatizado de determinação da concentração de espécies químicas através de aproximações sucessivas. Cada tentativa de localização do ponto final de uma titulação é denominada de passo ou ciclo. Para o primeiro passo, as frações volumétricas da solução da amostra e do titulante são iguais a 0 e 1 , respectivamente. Assim, no primeiro ciclo de procura é inserida no percurso analítico uma alíquota da solução do titulante, mantendo as válvulas solenóides V1 e V2 acionadas durante o período de tempo $\mathrm{t}_{\mathrm{Vl}}$, previamente selecionado. Uma vez introduzida a alíquota do titulante, as válvulas solenóides V1 e V2 são desativadas e o carregador flui novamente pelo percurso transpostando a alíquota da solução do titulante no sentido do detector.

Desativando as válvulas V1 e V2, o sistema lê, através da interface PCL-711S, o sinal analógico gerado na saída do espectrofotômetro, armazenando o sinal máximo produzido nesta primeira tentativa em $\mathrm{S}_{0}$. $\mathrm{O}$ procedimento aplicado para a determinação do sinal máximo gerado pelo detector é apresentado no diagrama de blocos da Figura 12. 


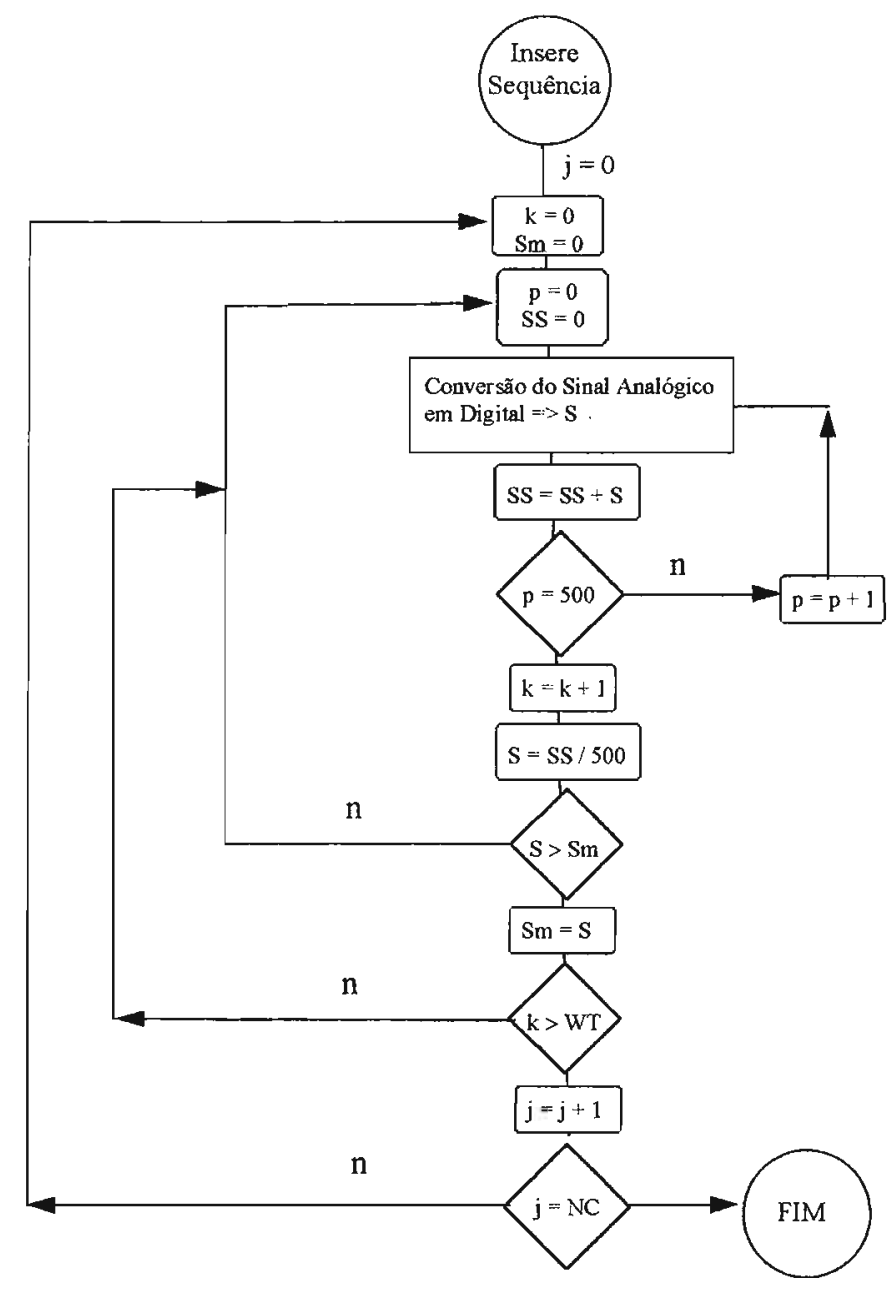

Figura 12. Diagrama de blocos correspondente ao processo leitura dos sinais transientes e estabelecimento do sinal máximo. Por defeito o número de conversões (n) do sinal analógico para digital igual a 500. $\mathrm{S}=$ sinal gerado. $\mathrm{Sx}=$ sinal máximo referente a sequência $\mathrm{x} . \mathrm{WT}=$ tempo de espera para a leitura dos sinais. $\mathrm{k}=$ contador do tempo de espera.

O segundo ciclo é realizado acionando simultaneamente V1 e V3, interrompendo o fluxo do carregador e iniciando o escoamento da solução da amostra pelo percurso analítico durante o mesmo intervalo de tempo préviamente selecionado $\left(\mathrm{t}_{\mathrm{v} 1}\right)$. $\mathrm{O}$ sinal máximo gerado pelo espectrofotômetro é armazenado como $S_{1}$. Com os valores de $S_{0}$ e $S_{1}$, o 
sistema calcula a diferença entre $S_{1}$ e $S_{0}$, para estabelecer o valor limiar, $\mathrm{S}_{\mathrm{C}}$. Dependendo dos valores de $\mathrm{S}_{0}$ e $\mathrm{S}_{1}$, o cálculo de $\mathrm{S}_{\mathrm{C}}$ é realizado pela equação 12 ou 13. A partir do terceiro passo de busca do ponto final são geradas sequências compostas de alíquotas de ambas as soluções. As sequências são constituídas de pequenas alíquotas da solução titulante e da solução da amostra, inseridas alternada e consecutivamente no percurso analítico. $O$ processo de geração das sequências segue o conceito da multicomutação ${ }^{48,51,52}$, proposto nos laboratórios do CENA - USP. O volume total das sequências é o mesmo estabelecido para os dois ciclos iniciais, uma vez que o intervalo de tempo que a válvula solenóide V1 permanece acionada é igual para qualquer tentativa da procura.

No terceiro ciclo, uma sequência é gerada amostrando alternadamente alíquotas de igual volume das soluções do titulante e do titulando. Isto é realizado acionando por intervalos de tempo iguais, simultaneamente, V1 e V2, seguido do acionamento simultâneo das válvulas solenóides $\mathbf{V} 1$ e V3. O ciclo é repetido até completar o volume total estipulado pelo operador ao iniciar a titulação por procura binária. $\mathrm{O}$ número de repetições, ou número de pulsos, é também um dado de entrada, que o operador deve selecionar antes de iniciar a titulação. Durante a execução desta análise é calculado, pelo computador, o intervalo de tempo que as válvulas permanecem acionadas, para a inserção de alíquotas da solução de amostra e do titulante. O cálculo do tempo que os 2 conjuntos de válvulas solenóides (V1-V2 e V1-V3) persistem acionados, é baseado, por sua vez, no volume total da sequência, no número de pulsos, e na vazão. Estes parâmetros devem ser fornecidos pelo operador antes de iniciar uma rotina de titulações. Uma vez completado o passo de amostragem, todas as válvulas solenóides são desativadas e a 
corrente da solução do carregador fluí novamente pelo percurso analítico, transportando a sequência no sentido do detector. Enquanto a sequência é transportada no percurso analítico, ocorre a dispersão mútua nas interfases das alíquotas das soluções de amostra e do titulante. A dispersão favorece o desenvolvimento das reações químicas. $O$ processo de introdução dos segmentos que compõe a sequência de alíquotas na tentativa $j$ maior ou igual a 2 é apresentada esquematicamente na Figura 13.

O sinal gerado pelo detector na terceira tentativa é lido pelo microcomputador como $S_{2}$. O valor de $S_{2}$ é comparado com $S_{C}$ para estabelecer se o volume da alíquota da solução da amostra ou do titulante deve ser aumentada em $50 \%$ na tentativa seguinte da procura. Como o volume introduzido de uma das soluções no percurso analítico será incrementado em $50 \%$ no ciclo seguinte, e o volume da sequência não é alterado, independentemente do ciclo de procura, o volume da solução complementar será reduzido na mesma proporção. Para operacionalizar a variação de $50 \%$ nos volumes das alíquotas, é acrescido em $50 \%$ o intervalo de tempo de acionamento de um dos pares de válvulas (V1-V2 ou V1-V3), e consequentemente reduzido na mesma proporção o intervalo de tempo de acionamento do outro par de válvulas solenóides. $O$ procedimento de busca do ponto final segue o algorítmo desenvolvido, variando o ciclo de trabalho das válvulas. Uma visão geral do processo de titulação por procura binária é apresentada, na forma de diagrama de blocos, na Figura 14.

Para todas as tentativas da procura, os segmentos são inseridos no percurso analítico pelo ponto de junção $x$ até que toda a sequência seja introduzida. Desta forma pode ser dito que a sequência é construída passoa-passo por uma série de alíquotas, cujo volume destas é estabelecido 
indiretamente pelo sistema de controle do processo. Idealmente, para garantir a coalescência das alíquotas das soluções de amostra e titulante que compõe a sequência, deve ser estipulado que o comprimento da sequência não deve superar o comprimento do percurso analítico.

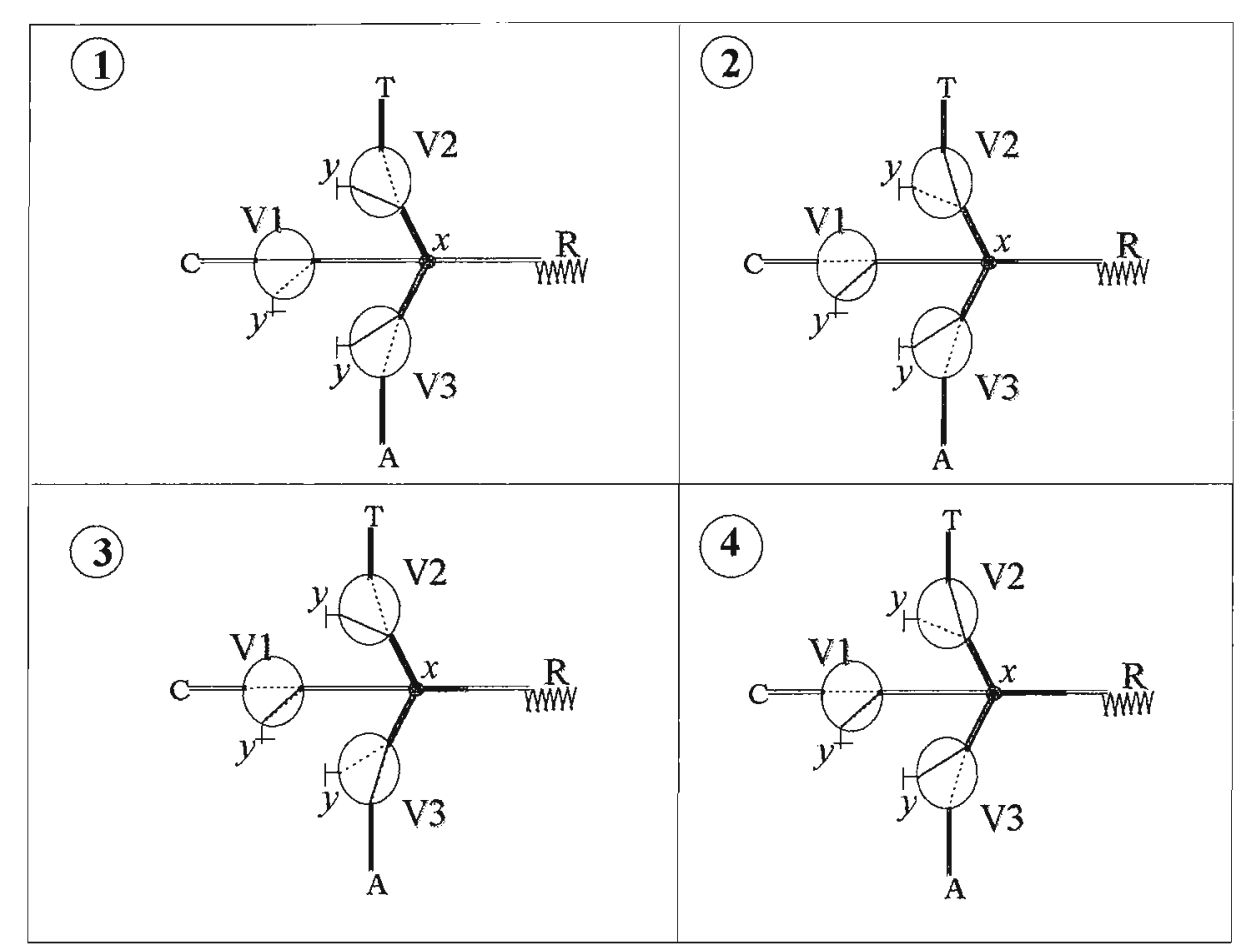

Figura 13. Esquema do processo de geração de uma sequência baseado no conceito de amostragem por multicomutação. V1, V2 e V3 = válvulas solenóides. $\mathrm{C}=$ carregador. $\mathrm{T}=$ solução titulante. $\mathrm{A}=$ solução da amostra. $\mathrm{R}=$ reator. $y=$ obstruidor de fluxo. $x=$ ponto de junção. 1) Fluindo carregador pelo percurso analítico; 2) Iniciando a construção de uma sequência, através da introdução de uma alíquota da solução do titulante; 3) Interrupção da adição do titulante e introdução de alíquota da solução da amostra; 4) Interrupção da adição da solução da amostra e início da adição de nova alíquota do titulante. 


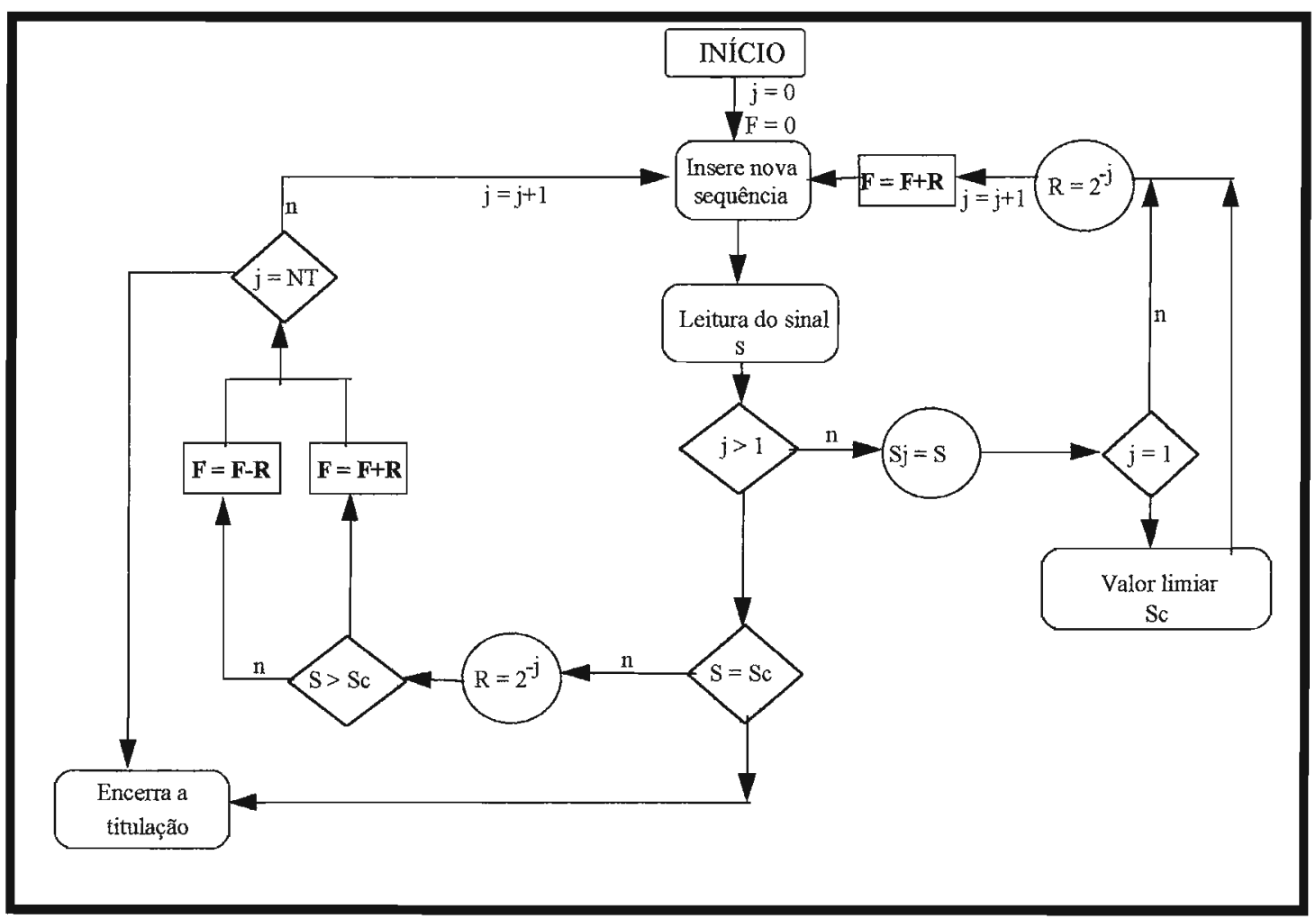

Figura 14. Diagrama de blocos global do processo de titulação por busca binária. $\mathrm{F}=$ fração volumétrica. $\mathrm{NT}=$ número de passos de busca. $\mathrm{j}=$ passo de busca em execução.

\subsection{Método de Preparo das Soluções}

Todas as soluções foram preparadas empregando água destilada e deionizada. Solução estoque de $\mathrm{NaOH}$ de concentração $10 \mathrm{M}$ foi preparada partindo do reagente sólido (Merck), em grau de pureza analítico. As diluições necessárias desta solução foram feitas diariamente com água destilada e deionizada, para manter as soluções sempre com suas concentrações conhecidas. Soluções de $\mathrm{NaOH}$ de concentração 0,1 e $0,01 M$ de hidróxido de sódio foram padronizadas empregando ftalato ácido de potássio (Merck), com grau analítico de pureza, como padrão 
primário. A padronização das soluções de $\mathrm{NaOH}$ foram realizadas empregando fenolftaleína como indicador. Uma amostra de ftalato ácido de potássiom, sempre que necessário, foi levada a estufa e mantida em dessecador. As massas foram determinadas em balanças analíticas.

Soluções de ácido clorídrico (Merck) foram preparadas partindo de solução $1 M$ de ácido clorídrico. Sempre que necessário as soluções diluídas foram padronizadas com solução de $\mathrm{NaOH}$ de concentração adequada e conhecida.

Soluções de fenolftaleína, azul de bromotimol e alaranjado de metila foram preparadas ${ }^{53}$ e usadas como soluções indicadoras para as titulações convencionais e pelo processo de procura binária. A solução de fenolfateína foi preparada em meio aquoso-alcoólico (1:1), em concentração de 1 e $0,5 \%(\mathrm{~m} / \mathrm{v})$. A solução de azul de bromotimol foi preparada em meio alcalinizado com $\mathrm{NaOH}$, para garantir a solubilização da mesma. Solução de alaranjado de metila $0,05 \%(\mathrm{~m} / \mathrm{v})$ foi preparada dissolvendo o sal de sódio em solução aquosa de ácido clorídrico de forma que a concentração final em cloreto após a diluição estivesse em torno de $0,001 \mathrm{M}$.

Soluções de ácido acético foram prepradas dissolvendo anidrido acético em água, e fazendo as diluições adequadas para obter soluções 0,2 , 0,1 e $0,05 M$.

Solução $0,1 M$ de cloreto de magnésio foi preparada dissolvendo aparas de magnésio metálico em solução diluída de ácido clorídrico e ajustando o pH com solução de $\mathrm{NaOH}$. Solução de EDTA foi preparada dissolvendo o sal dissódico em água destilada e deionizada. A solução foi padronizada contra carbonato de cálcio ${ }^{54}$. Solução tampão amoniacal foi preparada dissolvendo 3,2 g de cloreto de amônio em $28 \mathrm{~mL}$ de hidróxido 
de amônio concentrado e diluindo para $1 \mathrm{~L}$. O indicador negro de eriocromo- $\mathrm{T}$ foi preparado triturando $0,2 \mathrm{~g}$ deste reagente com $50 \mathrm{~g}$ de nitrato de potássio.

\subsection{Programa para a Execução das Titulações por Procura Binária}

O programa para realizar titulações por procura binária foi desenvolvido em linguagem QuickBASIC, versão 4.5. O corpo principal do programa e uma série de sub-rotinas associadas a este corpo é apresentado no Apêndice 1. O programa desenvolvido é executável em qualquer computador baseado no padrão IBM-PC ou compativel, desde que esteja acoplada a placa principal deste computador a interface PCL711S (ou PCL-711) da Advantech Co.

O processo de amostragem das alíquotas das soluções de amostra e titulante no processo de titulação por procura binária é baseado em tempo. O controle do intervalo de tempo para o acionamento das válvulas solenóides é decisivo para o bom andamento da análise. As possibilidades de programação de rotinas de contagem de tempo são variadas: i) estabelecer uma base de tempo e fazer a contagem dos múltiplos inteiros desta base; e, ii) empregar o comando TIMER.

Quando é empregado o comando TIMER, a incerteza no período de tempo transcorrido é elevada e a precisão é reduzida o suficiente para desconsiderar esta possibilidade uma vez que os intervalos de tempo são sempre pequenos. Ao ser aplicado este comando o computador deve i) acessar a referência de tempo do microcomputador no momento do acionamento de uma válvula solenóide (t0); ii) acessar novamente este contador de tempo (t); iii) determinar o tempo transcorrido $(\mathbf{d t}=\mathbf{t}-\mathbf{t} \mathbf{0})$; iv) 
comparar com o valor definido pela rotina (te); e, caso $\mathbf{d t}<\mathbf{t e}$, o processo é repetido para o mesmo valor de t0 e novo valor de $\mathbf{t}$, por sua vez se te é menor ou igual a dt, a rotina é então liberada. Para situações nas quais o intervalo de tempo estipulado pelo operador te é da ordem de alguns segundos, o erro associado com a aplicação deste procedimento é desprezível.

O estabelecimento de uma base de tempo por sua vez implica que durante um período de tempo o computador estará disponível apenas para contagens. Supondo que o processador ao realizar a contagem de 1 até 120 transcorra 100 milisegundos, qualquer múltiplo $\mathrm{n}$ de $0,1 \mathrm{~s}$ pode ser obtido se e a contagem de 1 até 120 se repetir $n$ vezes. A base de tempo é normalmente obtida através da força bruta, acionando um cronômetro ao iniciar o processo de contagem. Uma vez estabelecida a base de tempo, esta é especifica para o equipamento no qual foi realizada a contagem, não podendo transferir a base estabelecida em um computador para outro instrumento sem executar testes prévios.

Em uma das versões do programa para executar a procura binária foi associada uma rotina que minimiza este problema. Esta aciona simultaneamente o contador e o TIMER por um período de 10 segundos. Decorrido o intervalo de tempo de 10 segundos, a rotina assume o valor final do contador, calcula o número de contagens por segundo e sequencialmente o número de contagens para a base de tempo desejada. Desta forma o programa adequou-se a computadores das linhas $386 \mathrm{DX}$ e $386 \mathrm{SX}$, com referência de tempo de 25,33 e $40 \mathrm{Mhz}$, permitindo a execução da titulação sem maiores problemas.

Outras questões relativas ao programa desenvolvido, como o algorítmo desenvolvido e o processo de determinação do sinal máximo 
para cada sequência produzida, são apresentados respectivamente nos diagramas de blocos das Figuras 14 e 12. Outras questões pertinentes ao programa desenvolvido, apresentado no Apêndice 1, são discutidas no decorrer desta tese.

Ualversidade de São Paulo 


\section{CAPÍTULO 4. RESULTADOS E DISCUSSÃO}

A curva apresentada na Figura 15 mostra uma titulação de ácido clorídrico com hidróxido de sódio obtida pelo método da busca binária, empregando solução alcoólica de fenolftaleína como indicador. O estudo deste procedimento de titulação foi realizado investigando os parâmetros que afetam a exatidão, precisão e a faixa de operação. Para esta titulação, os parâmetros selecionados para esta operação são apresentados na tabela 2.

Tabela 2. Valores selecionados para as variáveis operacionais na titulação de solução de ácido clorídrico com hidróxido de sódio pelo processo de procura binária.

\begin{tabular}{l|c}
\hline Variáveis & Valores Selecionados \\
\hline Número de Tentativas de Procura & 11 \\
Número de Pares de Alíquotas & 5 \\
Vazão $\left(\mathrm{cm}^{3} \mathrm{~min}^{-1}\right)$ & 2 \\
Número de Réplicas das Sequências & 5 \\
Volume de uma Sequência de Alíquotas $\left(\mathrm{mm}^{3}\right)$ & 283 \\
\hline
\end{tabular}

$\mathrm{Na}$ tabela 3 são apresentados os dados relacionados com o processo de procura na titulação de neutralização, cuja curva está apresentada na Figura 15. Nesta tabela são mostrados os valores médios dos sinais gerados e os desvios para 5 réplicas de uma mesma tentativa de procura do ponto final. $\mathrm{O}$ aumento do desvio padrão nas proximidades 
do ponto final, é devido as características do indicador selecionado e a sensibilidade do equipamento a pequenas variações de absorvância. A variação do desvio com a fração volumétrica da solução do titulante é apresentada na Figura 16.

Tabela 3. Comportamento de uma titulação de $\mathrm{HCl}$ com $\mathrm{NaOH}$ pelo método da busca binária.

\begin{tabular}{c|c|c}
\hline $\begin{array}{c}\text { Fração } \\
\text { Volumétrica da } \\
\text { Solução de }\end{array}$ & $\begin{array}{c}\text { Média dos Sinais } \\
\text { Máximos Gerados } \\
\text { pelo Detector }\end{array}$ & $\begin{array}{c}\text { Desvio Padrão das } \\
\text { Médias dos Sinais } \\
\text { MaOH 0,1 M }\end{array}$ \\
$\begin{array}{c}\text { Máximos } \\
\text { (unidades digitais) }\end{array}$ & (unidades digitais) \\
\hline 0,00 & 2055,0 & 0 \\
50,00 & 2055,2 & 0,45 \\
62,50 & 2055,4 & 0,55 \\
68,75 & 2183,4 & 5,55 \\
69,14 & 2199,6 & 7,09 \\
69,53 & 2199,4 & 3,36 \\
69,94 & 2183,2 & 13,16 \\
70,31 & 2219,2 & 3,03 \\
71,88 & 2256,8 & 3,27 \\
75,00 & 2273,8 & 2,39 \\
100,00 & 2305,0 & 0,71 \\
\hline
\end{tabular}

*número de réplicas $=5$ 


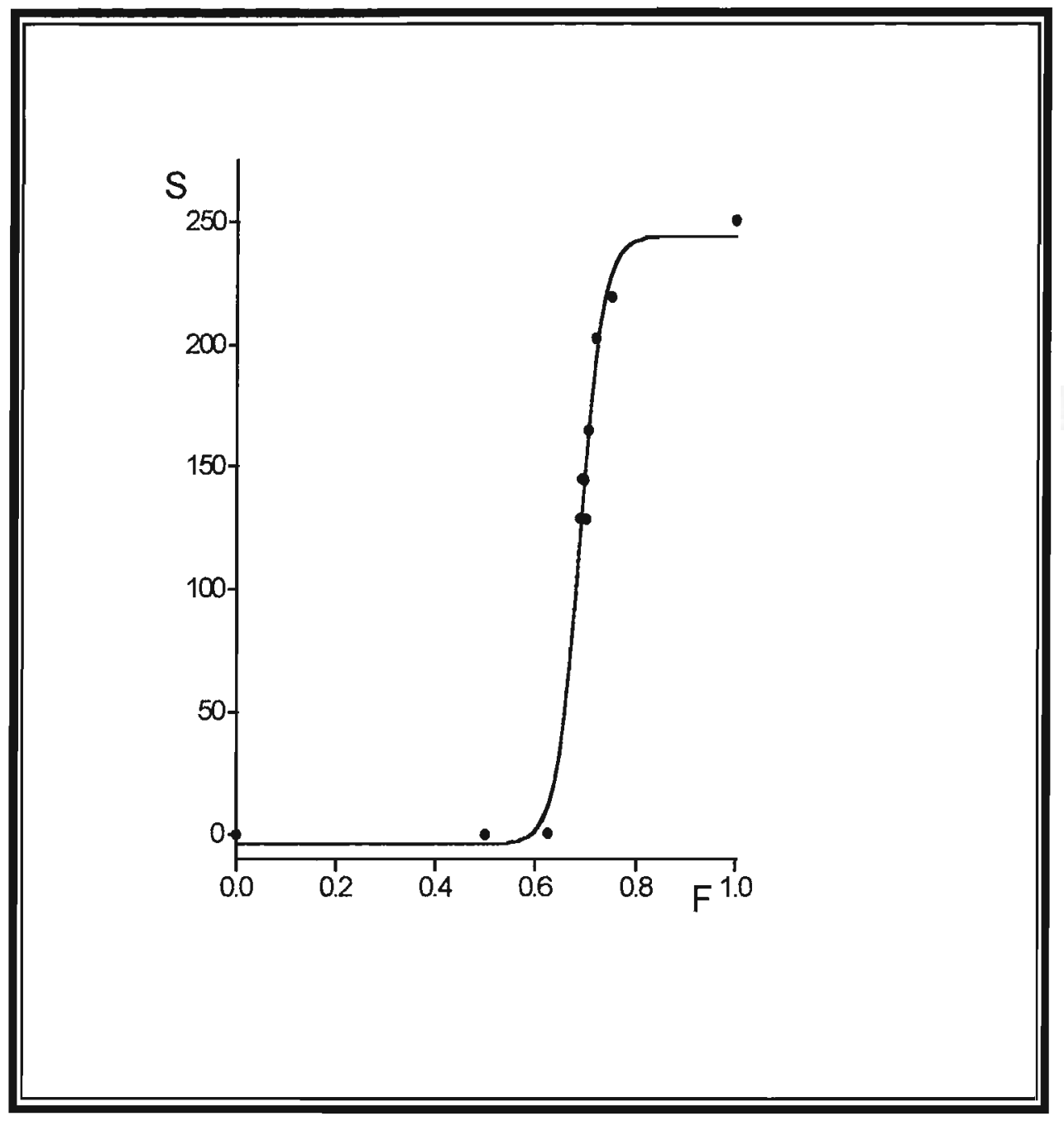

Figura 15. Curva típica de titulação por busca binária de uma solução de ácido clorídrico $0,02 \mathrm{M}$ com solução padronizada $0,0100 \mathrm{M}$ de hidróxido de sódio, e fenolftaleína como corante indicador. $\mathrm{S}=$ sinal; $\mathrm{F}=$ fração volumétrica do titulante, $\mathrm{NaOH}$. Volume da sequência $=283 \mathrm{~mm}^{3}$; e número de pulsos $=5$. 


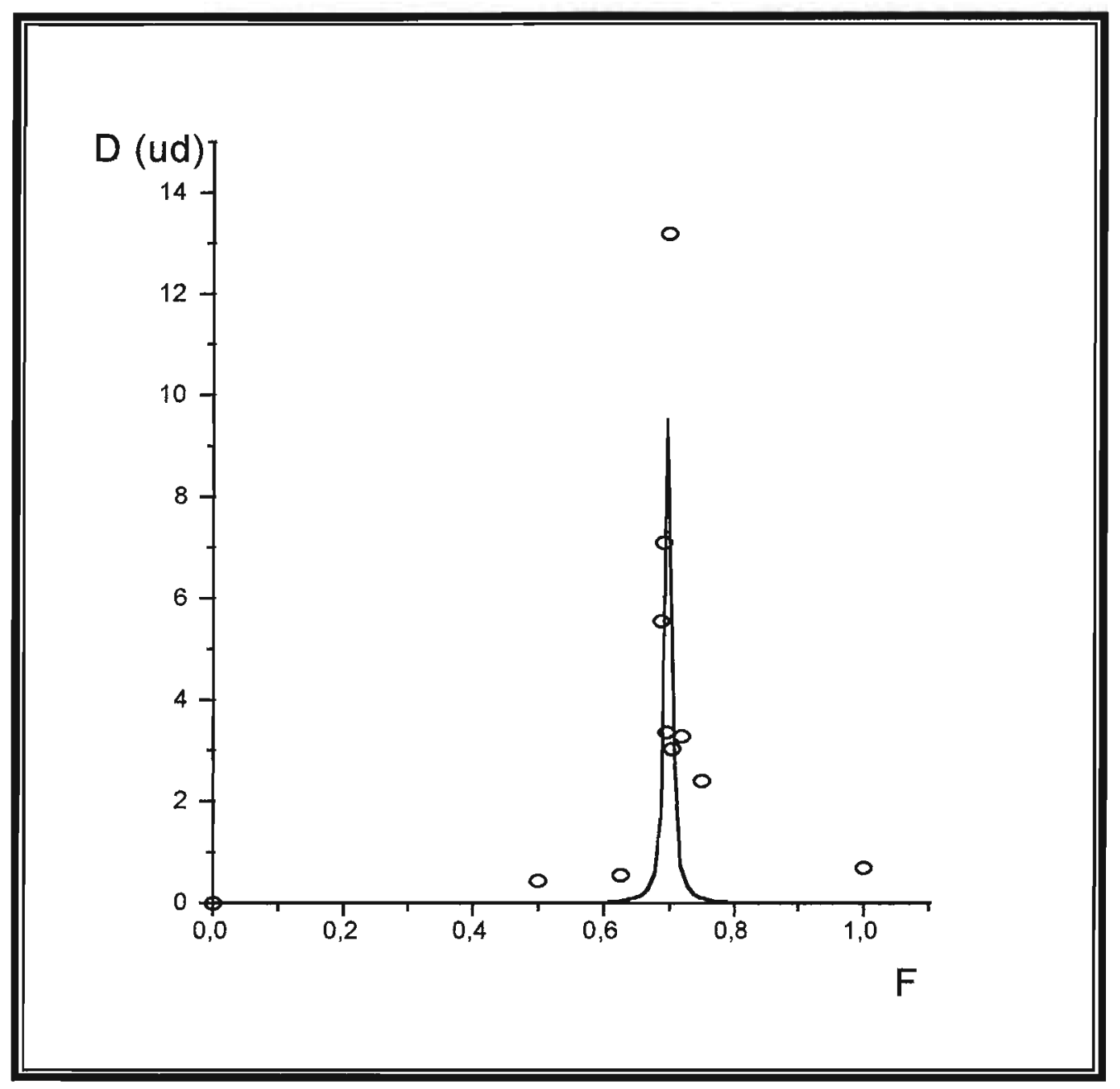

Figura 16. Variação do desvio padrão da média do sinal máximo obtido com a fração volumétrica do titulante em cada tentativa da procura, para a titulação de $\mathrm{HCl}$ 0,02 M com $\mathrm{NaOH} 0,0100 \mathrm{M}$, utilizando fenolftaleína como indicador. $\mathrm{D}=$ desvio padrão em unidades digitais. $\mathrm{F}=$ fração volumétrica da solução de $\mathrm{NaOH}$. Variáveis operacionais apresentadas na tabela 2. 


\subsection{Fatores que Afetam o Processo de Titulação por Procura Binária}

O principal fator que afeta a precisão e exatidão do método é capacidade do sistema em reproduzir os volumes nas tomadas de alíquotas. A reprodutibilidade é afetada tanto pelo comportamento pulsante da vazão, como pelo tempo de resposta do sistema global.

O tempo de resposta do sistema é o menor intervalo de tempo necessário para iniciar o escoamento de um dado volume pelo percurso analítico. Considerando os fatos, os parâmetros primordiais a serem investigados são a vazão, a dimensão ou volume da sequência, o número de alíquotas do titulante e da solução da amostra que formam a sequência, o número de tentativas de procura do ponto final e o tempo de amostragem.

\subsubsection{Número de Passos de Busca do Ponto Final}

O termo $2^{-(j-1)}$ da equação 13 decresce com o aumento do número de passos de busca $j$, tornando o processo tão mais exato quanto maior o número de sequências formadas, ou ainda, quanto maior o número de tentativas selecionadas para a procura.

$$
\mathrm{F}_{j}=\mathrm{F}_{j-1}+(-1)^{z} \cdot 2^{-(j-1)}, \text { para } j \geq 3 \quad \text { (Eq. 13) }
$$

As restrições experimentais inerentes ao sistema construído tornam impossível diminuir na prática o valor do termo $2^{-(j-1)}$ à magnitude teórica desejada para o mesmo após um determinado número de tentativas de 
procura. Experimentalmente foi determinado que para o sistema de fluxo empregado, o menor intervalo de tempo de acionamento das válvulas solenóides, que garanta o escoamento para o percurso analítico de um volume proporcional, não deve ser inferior a $80 \mathrm{~ms}$. Nestas condições, o menor volume de uma alíquota que pode ser inserido no percurso analítico com confiabilidade é proporcional a este intervalo de tempo. Para uma vazão de aspiração constante durante a etapa de introdução da alíquota igual a $2 \mathrm{~cm}^{3} \mathrm{~min}^{-1}$, o volume mínimo possível de ser inserido no meio de análise seria de $2,6 \mathrm{~mm}^{3}$.

Para o processo de titulação por procura binária, a variação da fração volumétrica de uma das soluções (titulante ou amostra), entre dois passos consecutivos é apresentada na Figura 17. Ao serem selecionados 11 passos de busca do ponto final, a variação da fração volumétrica é da ordem de 0,001 , quando o último passo é executado. Caso o volume total selecionado para a sequência seja de $283 \mathrm{~mm}^{3}$, a variação de volume correspondente para o décimo primeiro passo de busca seria de 0,283 $\mathrm{mm}^{3}$. Logicamente este valor é inferior aos $2,6 \mathrm{~mm}^{3}$ calculado como o volume mínimo que pode ser introduzido com segurança no percurso analítico. Porém estes dois valores são independentes, uma vez que o tempo mínimo de resposta de uma válvula solenóide se refere ao tempo que a válvula muda da condição desativada para a ativada, e não deve ser comparado ao intervalo de tempo a mais, ou a menos, que uma válvula solenóide deve ser mantida ativada para carregar um determinado volume no percurso analítico. Assim, o tempo de resposta de uma válvula solenóide e a capacidade de diferenciação de pequenos incrementos nos intervalos de tempo são parâmetros distintos. 
O intervalo de tempo mínimo de acionamento de uma válvula solenóide define os limites da faixa de concentração de uma amostra, possível de ser determinada por este procedimento volumétrico, a partir de uma solução de concentração conhecida do titulante.

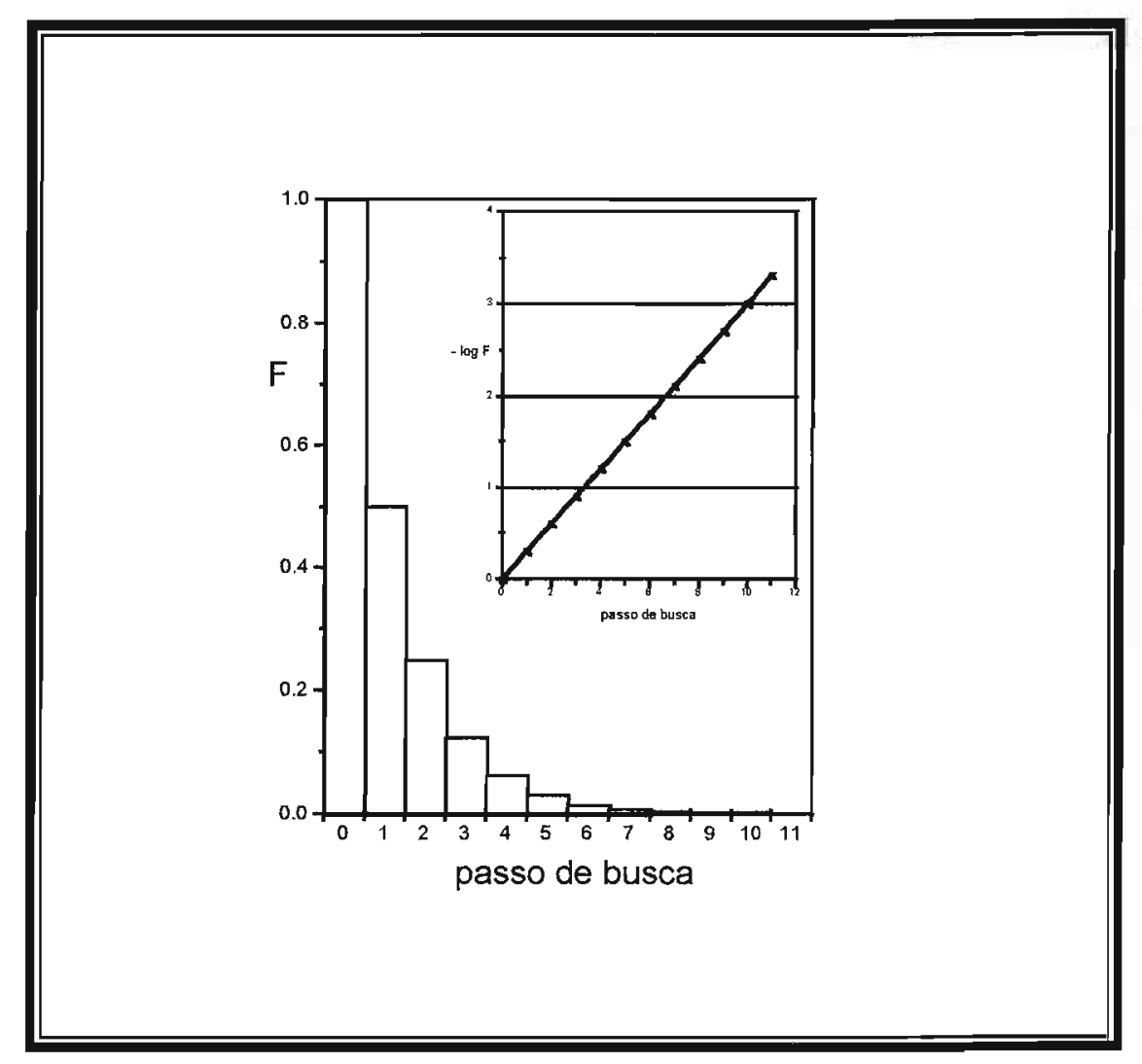

Figura 17. Variação do incremento na fração volumétrica em função dos passos de busca. Em detalhe a variação do antilogarítmo do incremento da fração volumétrica com o aumento do número de passos de busca.

Exemplificando, se a taxa de fluxo é de $2,0 \mathrm{~cm}^{3} \min ^{-1}\left(33,3 \mathrm{~mm}^{3}\right.$ $\mathrm{s}^{-1}$ ), volume da sequência igual a $200 \mathrm{~mm}^{3}$, número de pares de alíquotas igual a 5 e concentração do titulante (por exemplo, $\mathrm{NaOH}$ ) igual a $0,0100 \mathrm{M}$, o tempo que a válvula V1 permanece acionada para gerar as 
sequências é de 6 segundos. Na Figura 18 é apresentado um esquema da variação do intervalo de tempo que um conjunto de válvulas permanece acionado para as tentativas da procura. Para o terceiro passo da procura os intervalos de tempo que os conjuntos de válvulas solenóides V1-V2 e V1-V3 permanecem acionadas são iguais. Sabendo que serão adicionados 5 pares de alíquotas das soluções da amostra e do titulante, o intervalo de tempo necessário para adição de cada alíquota da solução de amostra e do titulante será de $600 \mathrm{~ms}$. No sexto passo da busca, um dos conjuntos de válvulas pode necessitar permanecer acionado por $75 \mathrm{~ms}$, valor este inferior ao limiar de $80 \mathrm{~ms}$ estabelecido previamente. A fração volumétrica correspondente a uma das soluções para esta sexta tentativa de procura do ponto final seria de 0,9375 . Como $F x+F y=1$, a fração volumétrica da solução correspondente seria 0,0625 .

Como a relação estequiométrica da reação entre $\mathrm{HCl}$ e $\mathrm{NaOH}, x$ e $y$, é $1: 1$, a concentração da espécie de interesse na solução em análise no ponto de equivalência pode ser expressa por

$$
\mathrm{V} x \cdot \mathrm{C} x=\mathrm{V} y \cdot \mathrm{C} y
$$

ou, em termos das frações volumétricas,

$$
\text { Fx.V.Cx = Fy.V.Cy }
$$

Portanto, se $\mathrm{F} x=0,9375, \mathrm{~F} y=0,0625$ e $x=$ solução padronizada de $\mathrm{NaOH}$ de concentração $0,01 \mathrm{M}$, a concentração de ácido clorídrico na solução em análise poderia ser até $0,15 \mathrm{M}$. Para o caso de $\mathrm{F} x=0,0625$, $\mathrm{F} y=0,9375$ e $x=$ solução de $\mathrm{NaOH} 0,01 \mathrm{M}$, a concentração mínima de 
íons $\mathrm{H}^{+}$na solução original de ácido clorídrico, que poderiam ser determinados empregando o processo de titulação por procura binária seria de $6,7 \cdot 10^{-4} \mathrm{M}$. Portanto, partindo de uma solução do titulante de concentração conhecida, empregando o processo desenvolvido sem a necessidade de efetuar diluições prévias ou preparar nova solução do titulante, é possível determinar, diretamente por titulação, concentrações do analito em soluções até 15 vezes mais concentradas ou diluídas que a do titulante, assumindo sequências de $283 \mathrm{~mm}^{3}, 5$ pulsos e vazão de 2,0 $\mathrm{cm}^{3} \min ^{-1}$. 


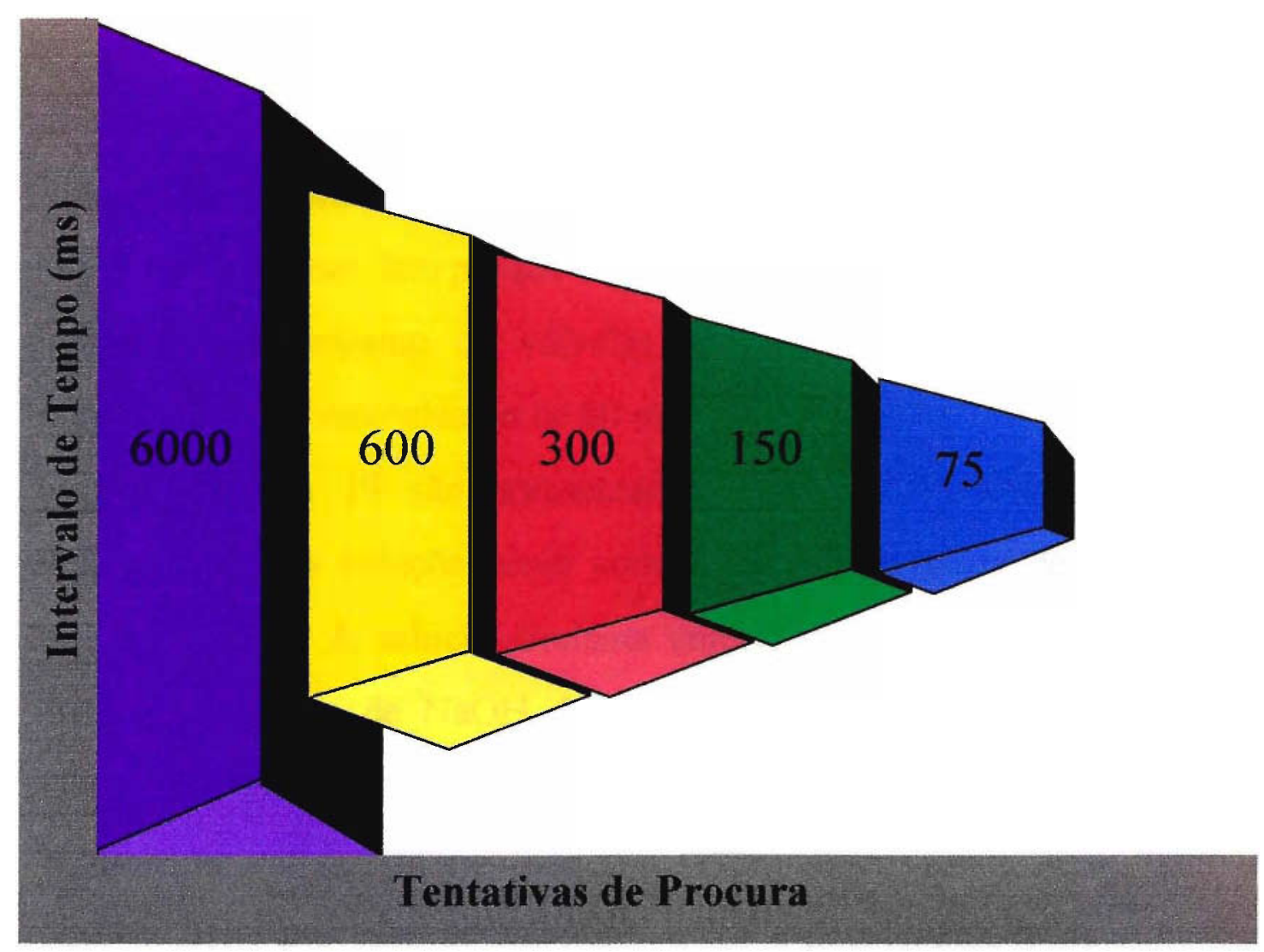

Figura 18. Apresentação esquemática da variação do intervalo de tempo de acionamento de um conjunto de válvulas (V1-V2 ou V1-V3) solenóides com a tentativa de procura. Vazão $=2,0 \mathrm{~cm}^{3} \mathrm{~min}^{-1}$. Volume da sequência de alíquotas $=200 \mathrm{~mm}^{3}$. Número de pares de alíquotas $=5$.

A razão entre as concentrações das soluções da amostra e do titulante pode ainda ser expandida. Tal expansão nos limites de razão das concentrações ocorre (i) aumentando o volume da sequência, (ii) reduzindo a taxa de fluxo ou (iii) diminuindo o número de pulsos. Se o volume da sequência do exemplo anterior fosse duplicado, os limites permissíveis para aplicar o processo de titulação por procura binária também seria duplicada. Assim, permitindo determinar por titulação, sem alterações no sistema de fluxo, soluções da amostra até 30 vezes mais concentradas ou diluídas. 
Além desta proporção de concentração e, sabendo que o processo de procura seria interrompido na sétima tentativa de busca do ponto final de titulação, o sistema atuaria com baixa precisão levando o operador a conclusões errôneas. Isto porque o intervalo de tempo mínimo determinado para que um conjunto de válvulas solenóides permaneça acionado é inferior ao limiar estabelecido de $80 \mathrm{~ms}$.

$\mathrm{Na}$ Figura 19 são apresentadas 3 curvas relacionadas com as titulações de três soluções com concentrações diferentes de $\mathrm{HCl}, 0,15$, 0,01 e 0,001 M. A solução titulante empregada nas três titulações foi a mesma de solução de $\mathrm{NaOH}$ de concentração $0,01002 \mathrm{M}$. O indicador selecionado para estas titulações foi uma mesma solução alcoólica de fenoftaleína $0,5 \%(\mathrm{~m} / \mathrm{v})$. Os resultados obtidos demostram tanto a robustez deste processo de titulação, como a potencialidade da aplicação desta metodologia em laboratórios de análises químicas e para controle de processos industriais.

O parâmetro número de passos também deve ser avaliado, quanto ao nível de exatidão desejado para a análise. Supondo uma titulação de soluções de mesma concentração, $0,01 \mathrm{M}$, de $\mathrm{HCl}$ e $\mathrm{NaOH}$, processada nas mesmas condições de volume da sequência, vazão e número de pulsos apresentados no exemplo anterior, pode ser avaliado o efeito deste processo de aproximações sucessivas através da diminuição da incerteza com o aumento do número de passos de busca do ponto final. A tabela 4 mostra os valores teóricos desta titulação, supondo a utilização de solução alcoólica de fenolftaleína como corante indicador.

$\mathrm{O}$ indicador fenolftaleína apresenta variação de coloração na faixa de $\mathrm{pH}$ entre 8,2 e 9,6. Assim a resposta do indicador foi estabelecida tomando como base as características da corante fenolftaleína. 


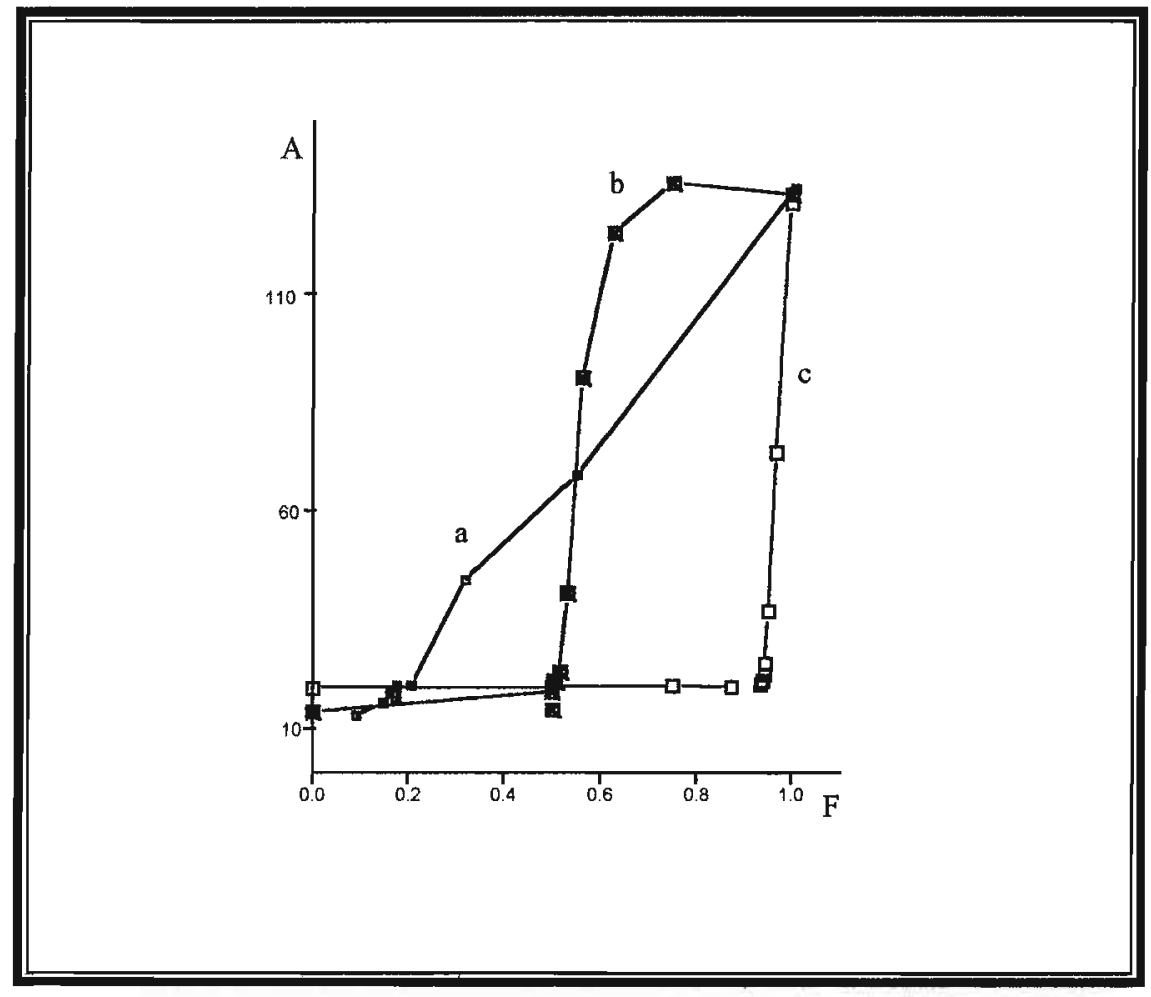

Figura 19. Representação gráfica da variação do sinal gerado pelo detector em função da fração volumétrica da solução $0,01002 \mathrm{M}$ de $\mathrm{NaOH}$, para titulações por procura binária de soluções de $\mathrm{HCl}$ (a) $0,15 \mathrm{M}$, (b) $0,01 \mathrm{M} \mathrm{e} \mathrm{(c)} \mathrm{0,001} \mathrm{M.} \mathrm{F} \mathrm{=} \mathrm{fração} \mathrm{volumétrica} \mathrm{de} \mathrm{NaOH}$. A = sinal em unidade arbitrária. 
A coluna referente a resposta do indicador indica a coloração que a sequência deveria adquirir no $\mathrm{pH}$ calculado nas diferentes proporções volumétricas das soluções de amostra e titulante preparadas a cada passo de busca. A última coluna apresenta os valores calculados de $\mathrm{pH}$ para as tentativas de procura do ponto final de titulação. $\mathrm{O}$ pH em cada passo da procura foi calculado levando em consideração as frações volumétricas de ambas soluções, a constante de auto protólise da água e as concentrações de $\mathrm{H}^{+}$e $\mathrm{OH}^{-}$nas respectivas soluções originais ${ }^{53}$.

Tabela 4. Andamento presumível do processo de procura binária na titulação de $\mathrm{HCl} \quad 0,01 \mathrm{M}$ com $\mathrm{NaOH} \quad 0,01 \mathrm{M}$, usando solução de fenolftaleína como indicador.

\begin{tabular}{cccccc}
\hline $\begin{array}{c}\text { Passo } \\
\text { de } \\
\text { Busca }\end{array}$ & $\begin{array}{c}\text { Fração } \\
\text { Volumétrica do } \\
\text { Titulante }\end{array}$ & $\begin{array}{c}\text { Resposta } \\
\text { do } \\
\text { Indicador }\end{array}$ & $\begin{array}{c}\text { Concentração } \\
\text { presumível de } \\
\text { HCl } \\
\left(\text { moles.L } \text { - }^{-1}\right.\end{array}$ & $\begin{array}{c}\text { Erro } \\
\text { Previsto } \\
(\%)\end{array}$ & $\begin{array}{c}\mathrm{pH} \\
\text { Calculado }\end{array}$ \\
\hline 0 & 0,00000000 & - & - & - & 2,0 \\
1 & 1,00000000 & + & 0,01 & $\infty$ & 12,0 \\
2 & 0,50000000 & - & 0,03 & 200 & 7,0 \\
3 & 0,75000000 & + & 0,017 & 70 & 11,7 \\
4 & 0,62500000 & + & 0,013 & 30 & 11,4 \\
5 & 0,56250000 & + & 0,011 & 10 & 11,1 \\
6 & 0,531250000 & + & 0,0106 & 6 & 10,8 \\
7 & 0,515625000 & + & 0,0103 & 3 & 10,5 \\
8 & 0,507812500 & + & 0,0102 & 2 & 10,2 \\
9 & 0,503906250 & + & 0,01008 & 0,8 & 9,9 \\
10 & 0,501953125 & + & 0,01003 & 0,3 & 9,6 \\
\hline
\end{tabular}


Para determinadas situações, o nível de exatidão alcançado com 11 passos de busca $(99,8 \%$, em fração volumétrica) pode não ser suficiente, sendo necessário um aumento no número de tentativas de procura do ponto final da titulação. A variação da exatidão do processo com o número de passos é representada na Figura 20.

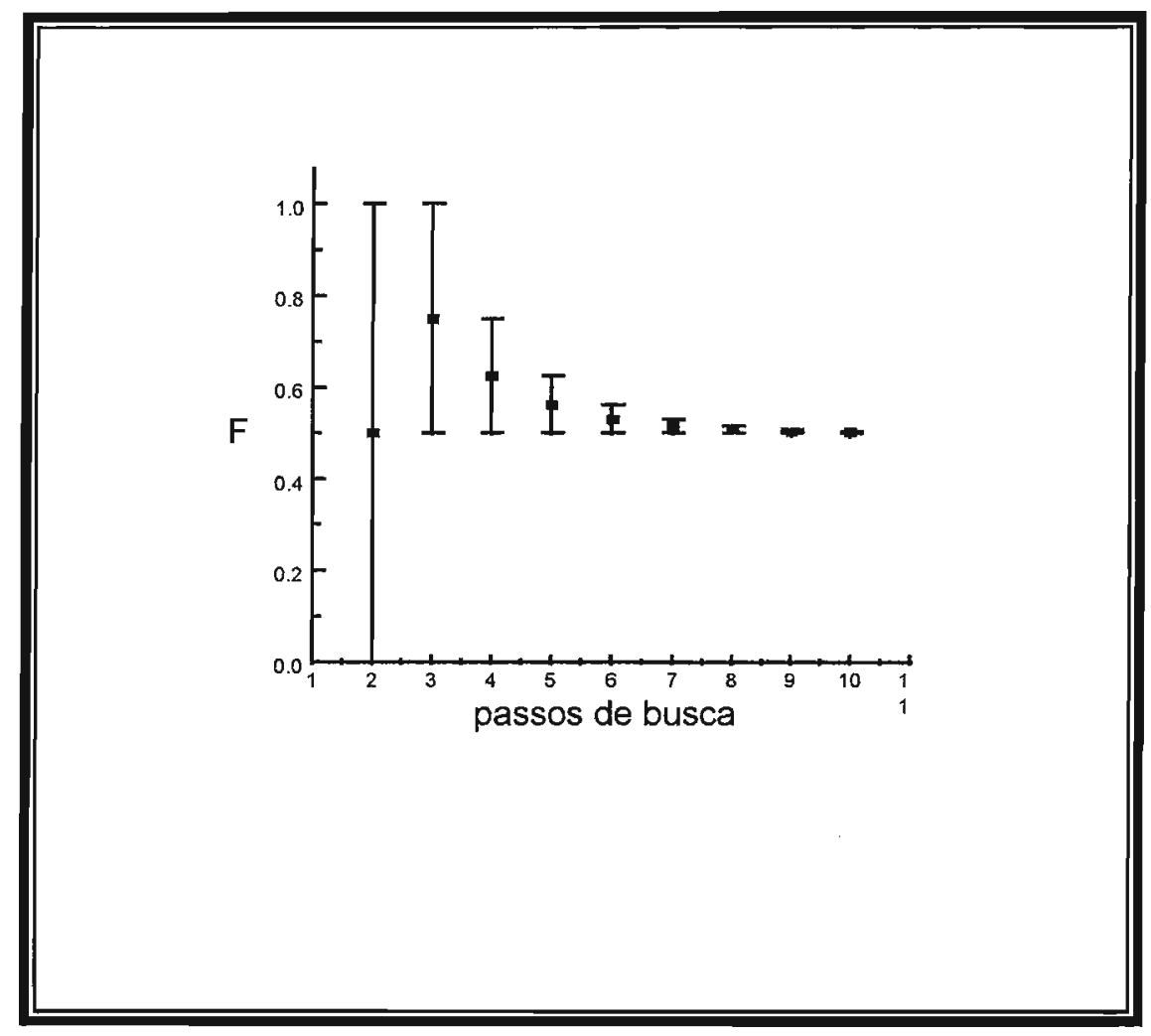

Figura 20. Variação do intervalo de fração volumétrica de $\mathrm{NaOH}$, que contém a proporção de equivalência, em função do número de passos de busca. $E$ = fração volumétrica do titulante. As barras indicam o erro máximo expresso em fração volumétrica. Concentrações das soluções e passos de busca como na tabela 4. Exemplificando titulação de soluções de mesma concentração de ácido e base. 
Conceitualmente, para atingir um nível de incerteza ainda mais reduzido, bastaria aumentar o número de tentativas de busca do ponto final do processo de titulação por procura binária. Contudo, o aumento indiscriminado do número de ciclos de procura pode resultar em sérias dificuldades operacionais, que acarretariam na perda de precisão no processo de tomada das alíquotas.

Uma vez aumentado o número de passos de busca são reduzidos os incrementos nos intervalos de tempo de acionamento das válvulas solenóides, de tal modo a ser obedecida a equação 10. Assim, o aumento no número de passos resultará, em algum ciclo, na incapacidade de discriminação pelo sistema da variação no intervalo de tempo em que as válvulas devem permanecer acionadas. Apesar deste sistema ser suficientemente automatizado, sendo o gerenciamento do processo da análise efetuada por um microcomputador, sempre existirão limites a serem respeitados.

\subsubsection{Formação de uma Sequência}

A eficiência de qualquer processo de titulação depende da capacidade da reação se completar à cada adição de um volume do titulante. Em procedimentos convencionais de titulação são adicionadas alíquotas do titulante em um sistema estacionário contendo o titulando. O sistema permanece sobre constante agitação, a fim de garantir a interação entre as espécies reativas das soluções.

Por princípio, um sistema de análise química em fluxo não é estacionário. A garantia de que a reação será completada no percurso 
analítico, depende tanto da eficiência de mistura das soluções antes de ser alcançado o detector como da cinética da reação.

$\mathrm{Na}$ titulação por procura binária foi empregado o método da amostragem binária $^{48,49,51}$, para favorecer a mistura entre as soluções. Neste processo de amostragem, são inseridas no percurso analítico pequenas alíquotas da solução de amostra alternada e consecutivamente com alíquotas da solução do titulante. Utilizando esta técnica de amostragem, enquanto a sequência é transportada no sentido do detector, ocorrem dispersões mútuas nas diversas interfaces líquidolíquido, como mostrado na Figura 21.

Atingir a total coalescência entre as alíquotas é imprescindível para assegurar a eficácia da mistura, bem como para fornecer condições essenciais para que a reação se complete. No processo de titulação por procura binária, os parâmetros que afetam a garantia da coalescência das alíquotas são o volume das alíquotas (comprimento dos segmentos), o número de pulsos, a vazão e o comprimento da bobina de reação.

O efeito causado sobre as concentrações determinadas pelo processo de titulação por procura binária quando a mistura das soluções de amostra e do titulante não é adequada foi avaliado. Os resultados obtidos em uma série de titulações por busca binária foram comparados com as concentrações determinadas através de titulação em sistema estacionário e empregando procedimento convencional. O sistema que serviu de base para o estudo, foi a titulação de uma solução de $\mathrm{HCl}$ com uma solução padronizada de $\mathrm{NaOH}$, empregando como indicador solução alcoólica de fenoftaleína. Para a avaliação do efeito do volume das alíquotas, foi mantida a vazão $\left(2 \mathrm{~cm}^{3} \mathrm{~min}^{-1}\right)$, o volume da sequência 
e o comprimento da bobina de reação $(50 \mathrm{~cm})$, sendo variado o volume das alíquotas através da mudança do número de pulsos. Os resultados da variação do erro em função do número de pulsos é apresentada na Figura 22.

Como pode ser verificado, os melhores resultados são encontrados para o número de repetições das alíquotas entre 5 e 10 . A causa dos erros nos valores de concentração determinados, quando foram selecionados menos que 5 ou mais de 10 pulsos, devem ser considerados separadamente.

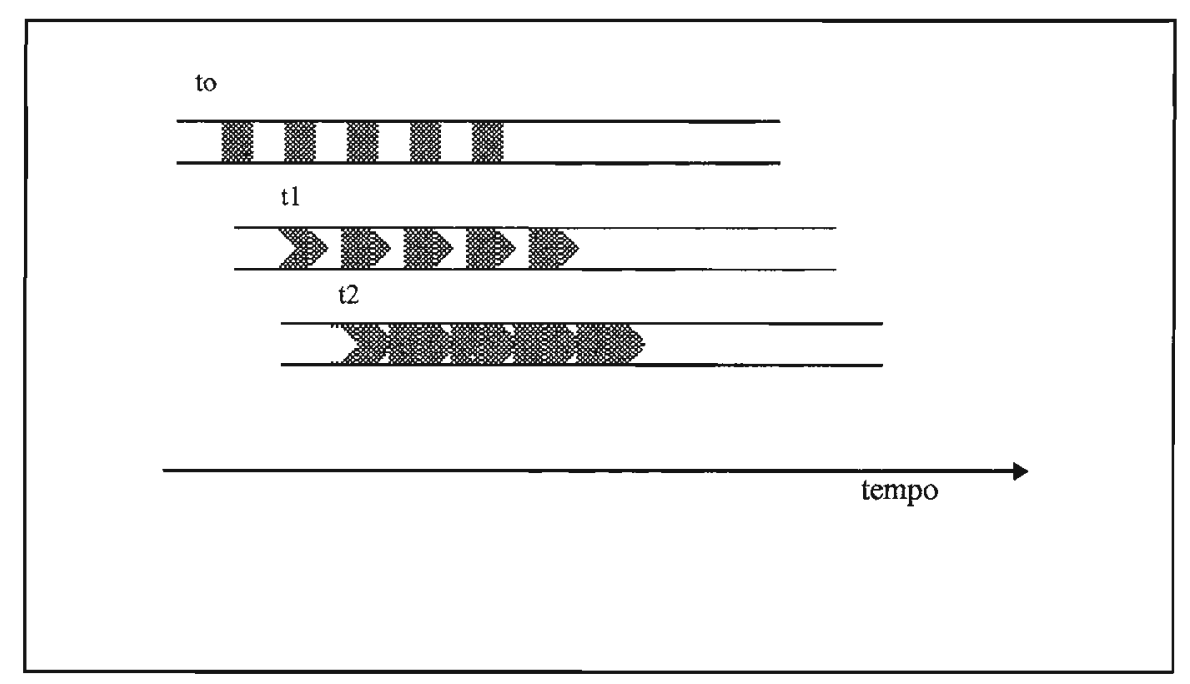

Figura 21. Esquematização do processo de dispersão mútua no percurso analítico, quando é empregado o conceito de amostragem binária. 


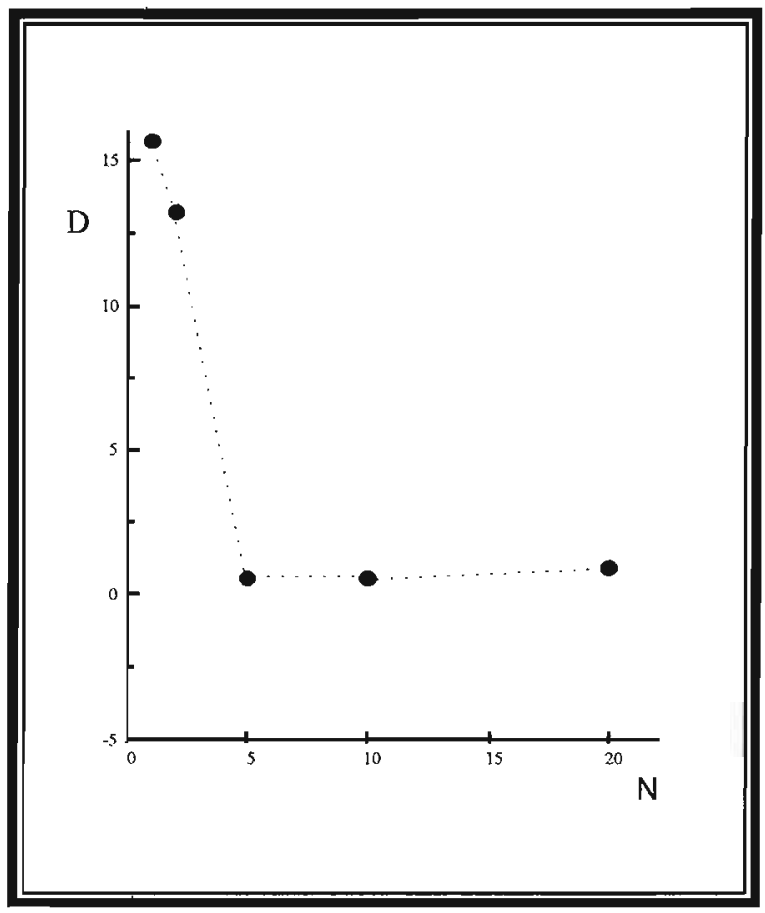

Figura 22. Variação do erro analítico em função do número de pulsos. $\mathrm{N}=$ número de pulsos; $\mathrm{D}=$ erro em percentagem. Vazão $=2 \mathrm{~cm}^{3} \min ^{-1}$; volume da sequência $=283 \mathrm{~mm}^{3}$; e comprimento da bobina de reação $=$ $50 \mathrm{~cm}$.

Selecionando um número pequeno de pulsos, o volume das alíquotas é elevado, e por consequência são inseridas no percurso analítico alíquotas de grandes volumes, afetando na coalescência completa entre as alíquotas das soluções para as dimensões do percurso analítico selecionado. Naturalmente, este efeito pode ser minimizado, através do aumento do comprimento do reator e/ou diminuindo o volume da sequência.

Aumentando o comprimento da bobina de reação, ou em outras palavras o percurso analítico, ocorre uma diminuição na magnitude dos sinais gerados pelo detector para as sequências com excesso de íons $\mathrm{OH}^{-}$. Este resultado se deve a maior dispersão da sequência no percurso 
analítico, uma vez que o sistema de fluxo proposto é fortemente diluidor. Para as sequências com prótons em excesso, a fenoftaleína permanece na forma associada, assim não apresentando variação de absorvância no comprimento de onda de $520 \mathrm{~nm}$, selecionado para o monitoramento do sinal transiente. A variação do sinal de absorvância gerado pelo espectrofotômetro, quando são adicionados alíquotas de mesmo volume de fenolftaleína em meio alcalino, com as dimensões do percurso analítico é apresentada na Figura 23.

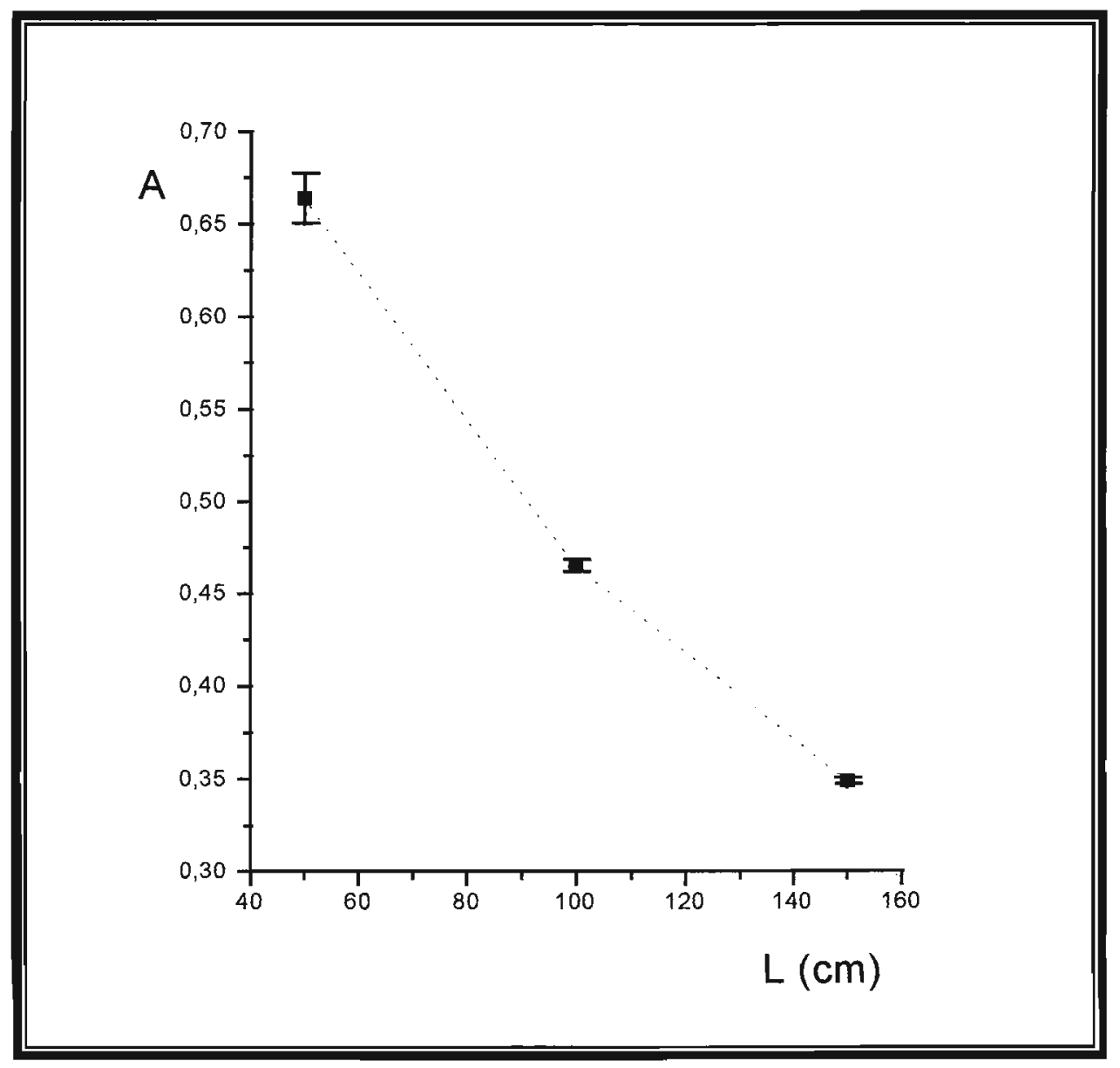

Figura 23. Variação do sinal de absorvância gerado pelo espectrofotômetro com o comprimento do percurso analítico. Volume da sequência $=183 \mathrm{~mm}^{3}$. Vazão $=2,15 \mathrm{~cm}^{3} \cdot \mathrm{min}^{-1} \cdot \lambda=520 \mathrm{~nm}$. 
Uma consequência inerente ao aumento do percurso analítico é a redução no valor de $S_{C}$, devido ao aumento da dispersão da zona de amostra, tornando o processo mais sensível a ruídos.

Por sua vez a diminuição do volume da sequência gerou uma diminuição na precisão da análise, visto que a diminuição no volume da sequência acarreta em intervalos de tempo mais reduzidos de acionamento das válvulas solenóides para a finalização do processo de titulação.

O erro encontrado na localização do ponto final de titulação pelo processo de busca binária, para mais de 10 pulsos e volume da sequência de $283 \mathrm{~mm}^{3}$ (Figura 22), pode ser explicado pela diminuição a metade nos tempos de acionamento das válvulas solenóides, afetando a precisão da amostragem das alíquotas nas últimas tentativas da procura binária. Para contornar esta situação, o recurso mais simples seria aumentar o volume da sequência. Porém, garantindo para qualquer passo da procura, a eficiência de mistura entre as alíquotas das soluções de amostra e do titulante.

De maneira geral, pode ser afirmado que o sucesso do processo de titulação por procura binária em fluxo contínuo é dependente da capacidade de todo o sistema tanto em amostrar, com alto grau de confiabilidade, pequenas alíquotas alternadas e consecutivas das soluções da amostra e do titulante, e da eficiência de mistura das soluções no percurso analítico estabelecido.

Pelos resultados obtidos pode ser afirmado que a aplicação deste processo de titulação em fluxo contínuo seria inviável, caso não tivesse sido empregado o conceito de amostragem binária. Como pode ser 
visualizado na Figura 22, é muito mais simples contornar a deficiência da metodologia quando são introduzidas um grande número de alíquotas no meio de análise.

Ao ser introduzido no percurso analítico apenas um par de alíquotas das soluções da amostra e do titulante, a titulação por procura binária em fluxo contínuo poderia ser executada, porém com grandes restrições. A viabilização deste processo de titulação em fluxo induziria ao emprego de outro conceito, certamente atrelado concomitantemente aos fenômenos de dispersão e reação.

Desenvolver este processo seria realizar uma variação no primeiro processo de titulação em FIA, desenvolvido por Ruzicka e colaboradores $^{11}$. Além do mais, este processo de titulação fatalmente requisitaria uma curva de calibração, o que redundaria em uma pseudotitulação, como discutido anteriormente ${ }^{13-15}$.

\subsubsection{Relevância da Sincronização da Pulsação da Bomba Peristáltica}

Garantir a precisão na etapa de amostragem é fundamental para o sucesso do processo da titulação por procura binária em sistema de fluxo. Além do tempo de resposta da válvula, a variação da vazão de aspiração durante o processo de amostragem influe negativamente sobre a precisão nos volumes das alíquotas amostradas.

Idealmente a vazão deveria ser uma constante a qualquer tempo. Contudo, ao serem empregadas bombas peristálticas para o estabelecimento do fluxo, o comportamento da vazão ao longo do tempo segue uma função de onda completa, tal como apresentada na Figura 24. 
A minimização do comportamento pulsante da vazão foi efetivada fazendo uso de um atenuador de pulsação. O emprego do atenuador foi primeiramente reportado por Bergamin e colaboradores ${ }^{50}$.

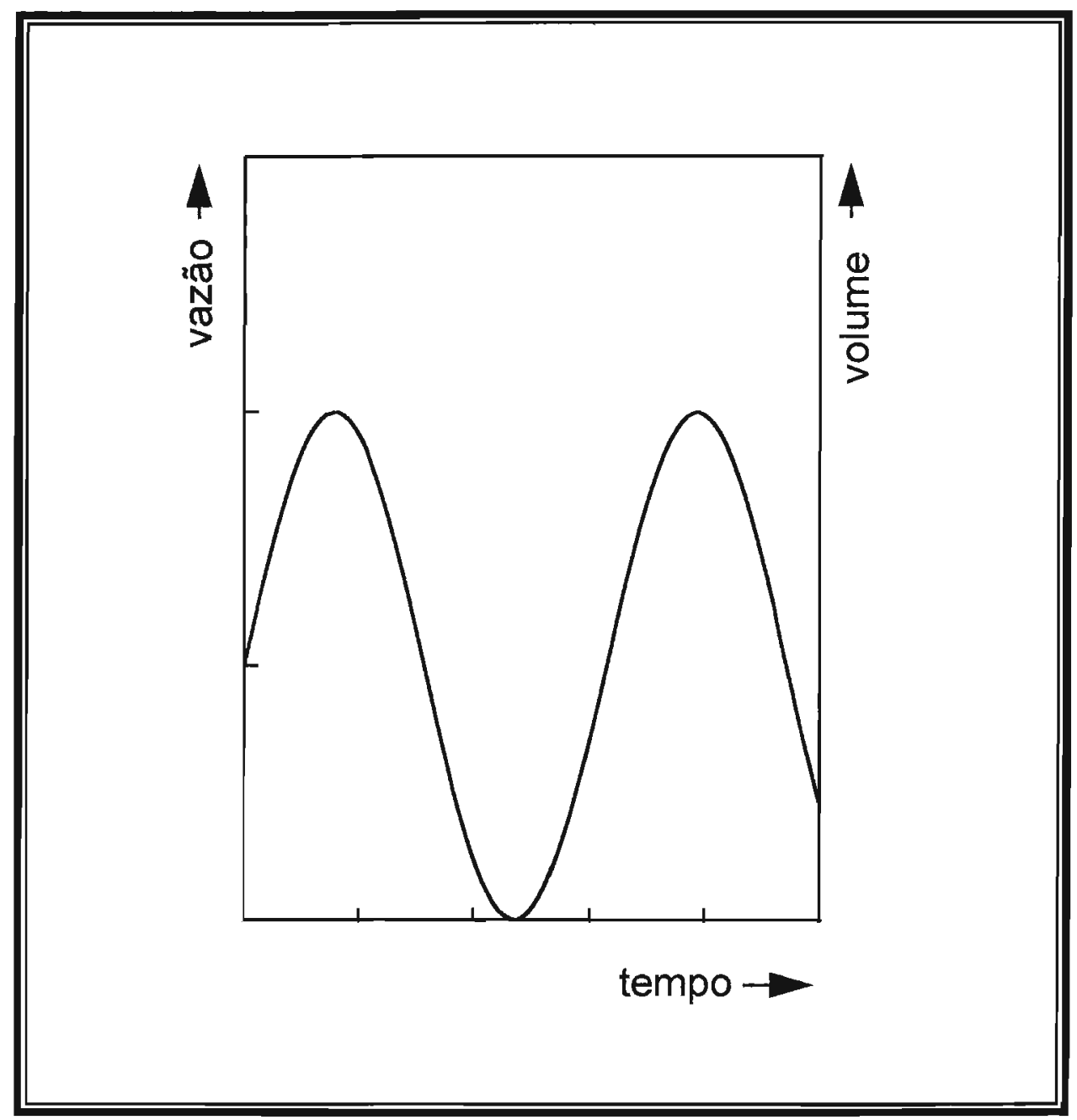

Figura 24. Variação da vazão produzida por uma bomba peristáltica em função do tempo.

Apesar da melhora considerável na estabilidade da vazão ao longo do tempo ao ser incorporado o atenuador ao sistema de fluxo foi necessário associar um sincronizador à bomba peristáltica. A posição em que se encontram os roletes da bomba em relação ao tubo de tygon no 
momento da amostragem modificam significativamente o volume amostrado da solução. Pelo esquema apresentado na Figura 25 pode ser visualizada a dependência do volume amostrado em um dado intervalo de tempo com a posição dos roletes da bomba peristáltica, no momento em que é iniciada a amostragem.

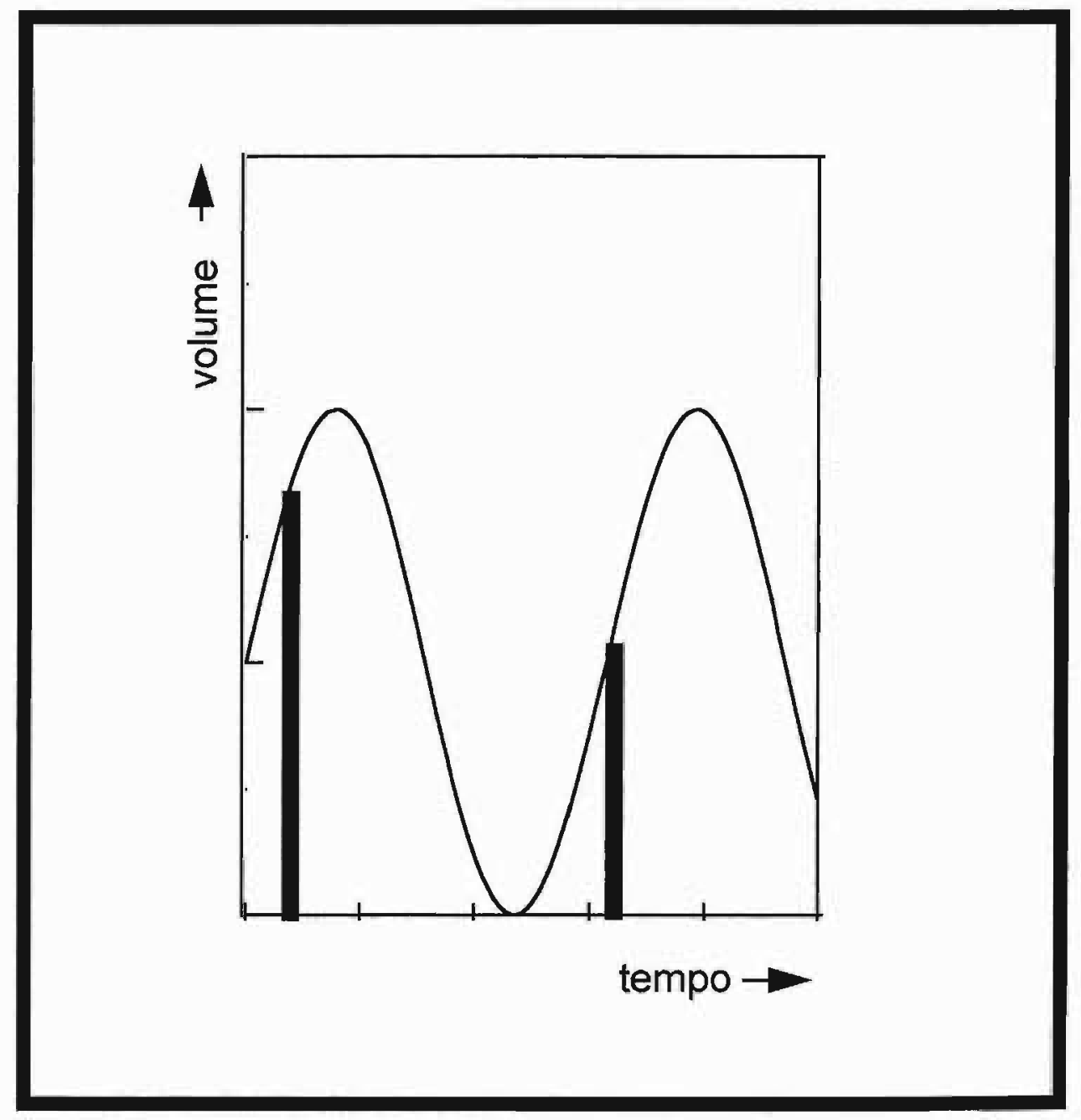

Figura 25. Variação do volume amostrado em função da posição do rolete, expresso em tempo, no início da amostragem.

Desta forma foi incorporada à bomba peristáltica um sincronizador de pulsação que libera o início da amostragem quando o rolete atinge 
uma posição definida. Para um processo baseado em tempo é extremamente importante a sincronização do início da amostragem das alíquotas com a pulsação da bomba peristáltica, para garantir que o volume amostrado seja sempre o mesmo enquanto o intervalo de tempo em que a válvula solenóide estiver acionada não for alterado.

\subsubsection{O Fator de Comparação}

O fator de comparação empregado para o cálculo do valor limiar, após a execução dos dois passos iniciais da procura, foi selecionado partindo do mesmo conceito que define a faixa de $\mathrm{pH}$ em que ocorre a transição de coloração de um indicador visual. Assim, foi estabelecido que o ponto final é alcançado se a absorvância atingir a 1/10 da diferença entre as absorvâncias máximas nas duas tentativas iniciais da procura.

Para outra situação, na qual o objetivo é uma exploração teórica do conceito de procura, conhecendo as espécies presentes na solução da amostra e as concentrações das soluções de amostra e titulante, o fator de comparação poderia assumir o valor de 0,5. Desta forma seria fundamental que o operador selecionasse um indicador cuja constante de dissociação fosse igual ao $\mathrm{pH}$ no ponto estequiométrico. Naturalmente, apesar da beleza do conceito apresentado, a aplicação deste procedimento não seria aceitável nos laboratórios de análise química. 


\subsection{Critérios para a Viabilização da Titulação por Procura Binária}

Os métodos de titulação necessitam de um sistema para monitorar o andamento da análise, de modo a permitir que o operador possa estabelecer o momento no qual deve ser interrompida a adição do titulante à solução da amostra, uma vez constatada alteração em algum sinal proveniente do sistema de detecção que seja pertinente ao sistema em análise.

Ao ser empregado o processo de titulação por procura binária o sistema tem que interpretar os sinais provenientes do detector para estabelecer a melhor rota da procura até o menor intervalo de frações volumétricas que contenha a transição esperada (ponto estequiométrico). $\mathrm{O}$ processo de titulação por procura binária pode ser empregado sempre que i) ocorra alguma alteração abrupta no sinal gerado pelo detector ao ser variada a fração volumétrica de uma das soluções $\left(F_{x}\right)$ no ponto estequiométrico, ii) quando os sinais produzidos pelo detector nas duas tentativas iniciais da procura $\left(\mathrm{F}_{\mathrm{x}}=0\right.$ e $\left.\mathrm{F}_{\mathrm{x}}=1\right)$ sejam nitidamente diferentes, e iii) se a variação do sinal gerado pelo detector com a variação da fração volumétrica da espécie controle corresponder a uma função monótona. Em princípio não existe restrição específica quanto aos sistemas de detecção empregados, sendo viáveis a aplicação de detectores fotométricos, potenciométricos ou outros, desde que as premissas que garantam a aplicação da lógica de procura binária sejam respeitadas. 


\subsubsection{Modos de Interpretação dos Sinais Gerados pelo Detector}

Os valores da tabela 4 apresentados para exemplificar uma titulação por procura binária de um ácido forte com uma base forte, empregando solução de fenolftaleína como indicador, podem ser tratados de três formas distintas. O processo poderia monitorar com a variação da fração volumétrica (i) o $\mathrm{pH}$, caso seja empregado um detector potenciométrico, (ii) a absorvância, se o detector empregado for fotométrico, ou (iii) através da interpretação logística do estado em que se encontra a solução. Na Figura 26 é apresentada a variação do pH com a fração volumétrica, enquanto que na Figura 27 é apresentada a resposta do sistema relacionada com a presença, ou ausência, de cor, em cada solução preparada com diferente fração volumétrica durante o processo de procura binária.

A busca binária aplicada diretamente a variação do $\mathrm{pH}$ em função da fração volumétrica do titulante, requer que o programa seja informado sobre o $\mathrm{pH}$ no ponto estequiométrico para que seja viabilizada a execução do processo. Para titulações de ácidos ou bases completamente dissociadas este problema é facilmente contornável, uma vez que o $\mathrm{pH}$, no ponto estequiométrico, é sempre igual a 7 . Porém para os casos das titulações de ácidos ou bases parcialmente dissociadas, o pH no ponto estequiométrico é função tanto da constante de dissociação desta espécie química, como das concentrações das soluções da amostra e do titulante. Desta forma, o sistema precisa ser informado sobre as características da solução em análise para poder inicializar o processo de titulação por procura binária. 
Independentemente do sistema de detecção, a interpretação dos dados feita pelo sistema, idealmente segue a mesma lógica apresentada na Figura 27, convertendo o sinal gerado pelo detector em digito binário ( 0 ou 1) através da comparação deste sinal com um valor limiar previamente estabelecido. Este conceito pode ser "ensinado" para um computador, para que este instrumento atue como qualquer operador para a definição do prosseguimento, ou não, da operação de introdução de alíquotas da solução do titulante. O fluxo de informações durante o processo de titulação por procura binária é apresentado na Figura 28.

A curva apresentada na Figura 27 mostra uma curva ideal para a execução do processo de procura binária. Este tipo de curva é similar a resultante da variação do sinal digital com a diferença de potencial aplicada sobre um circuito TTL ("transistor-transistor-logic"), apresentada na Figura 29.

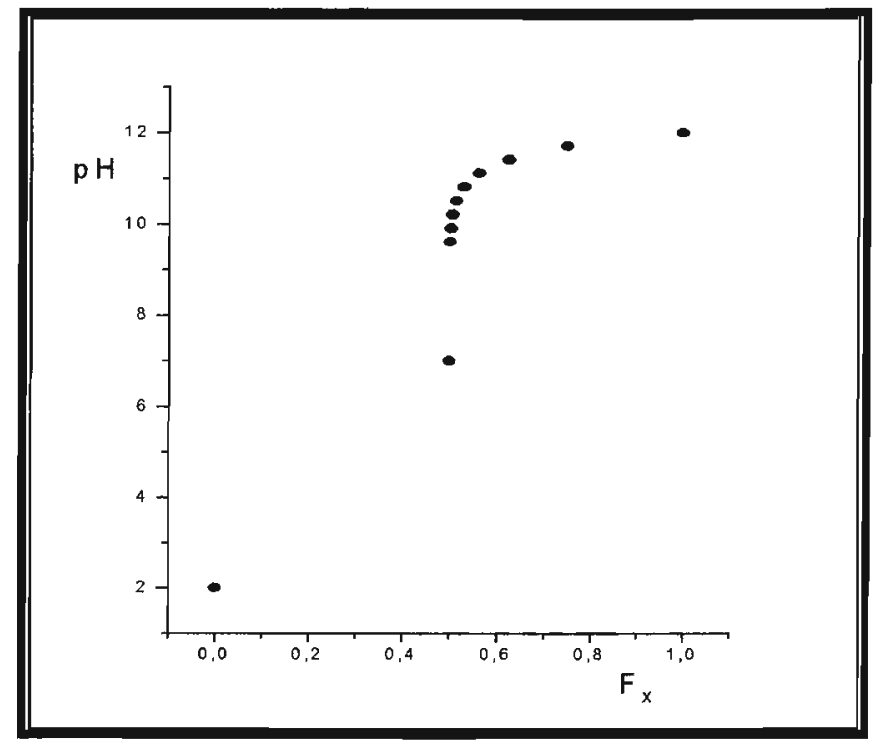

Figura 26. Variação do $\mathrm{pH}$ com a fração volumétrica para titulação de neutralização. $F_{x}=$ fração volumétrica de solução $0,01 \mathrm{M}$ de $\mathrm{NaOH}$. 


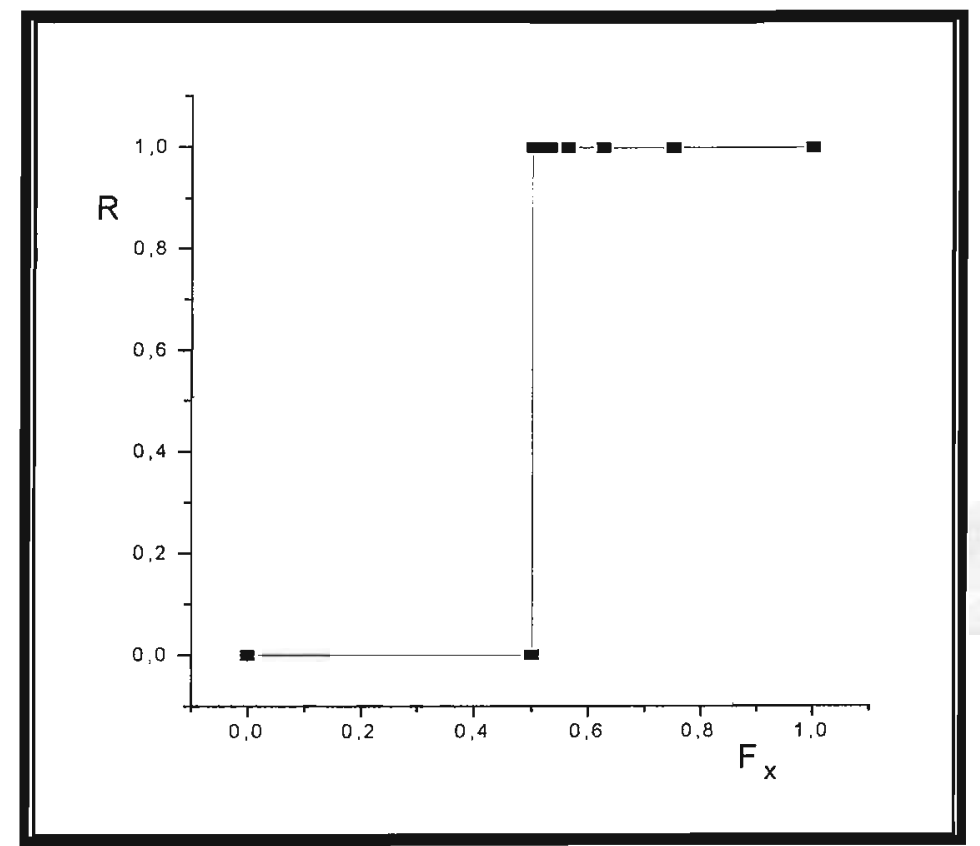

Figura 27. Resposta do sistema sobre a presença ou ausência de coloração em função da fração volumétrica do titulante para o processo de titulação de solução de $0,01 \mathrm{M}$ em $\mathrm{HCl}$ por procura binária. $\mathrm{F}_{\mathrm{x}}=$ fração volumétrica de solução $0,01 \mathrm{M}$ de $\mathrm{NaOH}$. $\mathrm{R}$ é a resposta, $0=$ ausência de cor e 1 = presença de cor . 


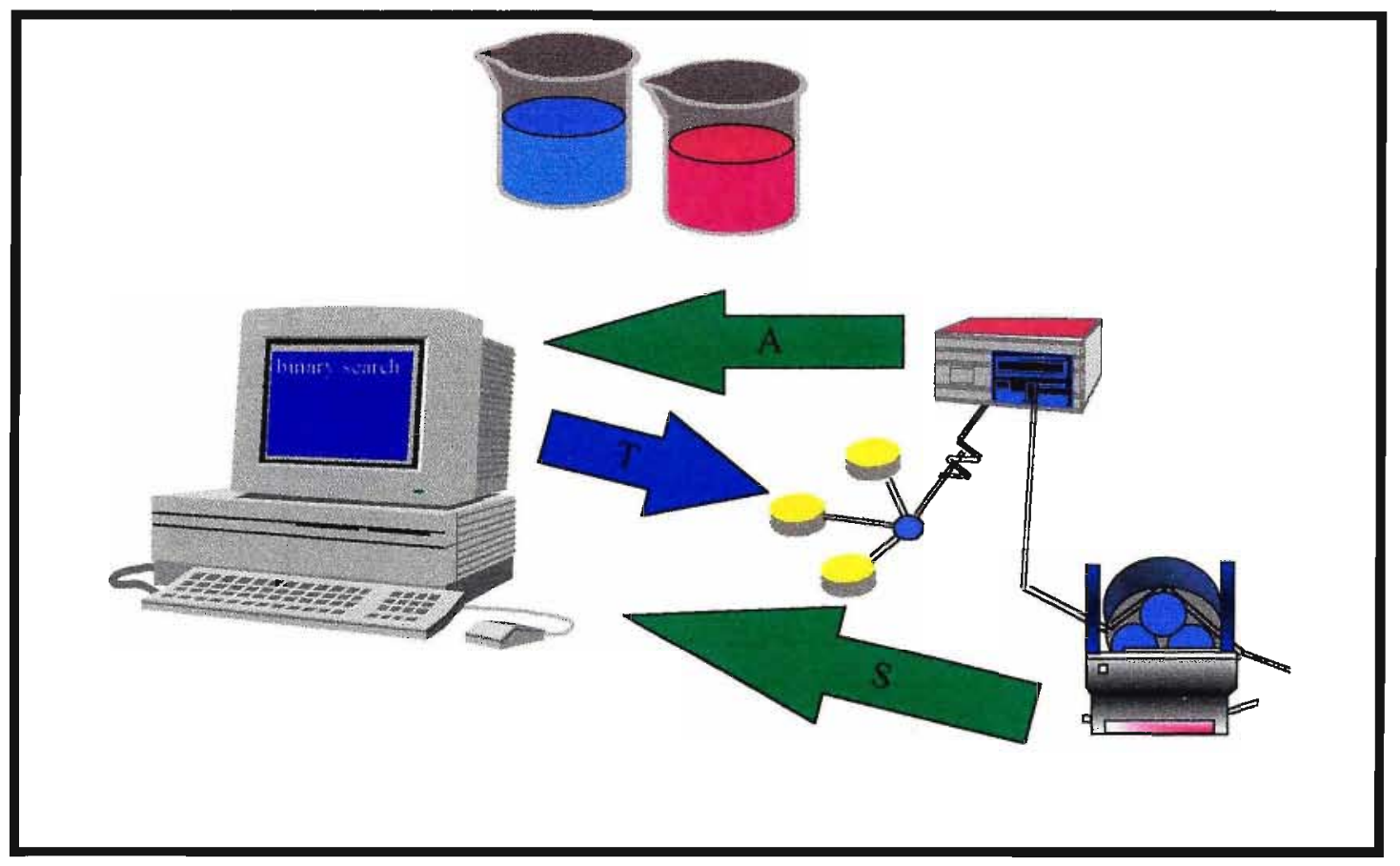

Figura 28. Trânsito de informações entre as partes componentes do sistema de titulação por procura binária. $\mathrm{T}=$ tempo de acionamento das válvulas. $\mathrm{S}=$ sinal do sincronizador. $\mathrm{A}=$ absorvância. 


$$
\text { d.d.p aplicada na entrada }
$$

Figura 29. Função limiar aplicada comumente em circuitos digitais. Se d.d.p. aplicada na entrada $<0,8 \mathrm{~V}$, o digito binário assume valor 0 . Caso d.d.p. aplicada na entrada do circuito $>2,4 \mathrm{~V}$, o digito binário assume valor 1 .

A função que representa as curvas das figuras 27 e 29 são denominadas de monótonas. Esta classe de função também é empregada para descrever o comportamento de um neurônio.

Um neurônio tem múltiplas conexões de entrada, e de várias formas pode somar os sinais provenientes das diversas conexões. Se a soma dos sinais de entrada é inferior ao valor limiar, o neurônio é mantido no estado desativado. Caso a soma atinja o nível do limiar, o neurônio é ativado e a mensagem segue avante.

No processo de procura binária o sistema recebe primeiramente as informações sobre os limites extremos da função resposta, iniciando o processo de busca. O sistema gera um nó $\left(F_{2}=0,5\right)$, que é uma 
possível solução. Testa se este nó é de fato a solução. Caso a solução tenha sido encontrada, então informa e interrompe o processo. Caso contrário, volta a gerar uma nova possível solução. O método gera e testa de busca é uma forma de resolução de problemas, sendo normalmente associado a outros métodos de busca.

A forma mais simples de resolver um problema é através da força. $\mathrm{Na}$ computação, usar a força, implica na repetição exaustiva de um procedimento que garanta a solução, caso exista uma solução. Segundo Rabuske ${ }^{33}$, esta forma de proceder pode requisitar muito tempo, sendo útil recorrer a estratégias para reduzir o espaço de busca. Para atingir este efeito, pode ser implementado algum método heurístico que para acelerar a busca da solução de um problema recorre a quaisquer informações disponíveis. A aplicação de métodos heurísticos aumenta a eficiência de resolução de um problema, contudo, não garantindo a solução ótima.

Na procura binária, o intervalo é reduzido à metade a cada passo de busca. Gerando, após 11 tentativas de procura, o mesmo resultado que o sistema obteria, no caso de ser utilizada a força para a resolução do problema. Ao ser empregada a força bruta para a resolução do mesmo problema, determinação do ponto final de uma titulação pela variação das frações volumétricas, o número de tentativas seria no máximo igual a 2049.

Para a titulação de solução $0,01 \mathrm{M}$ de $\mathrm{HCl}$ com solução $0,01 \mathrm{M}$ de $\mathrm{NaOH}$, exemplificada na tabela 4 , o processo de procura pode ser entendido como o menor intervalo de frações volumétricas, cujas nos extremos do qual as respostas sobre o aparecimento de coloração sejam opostas. Assim, o intervalo de fração volumétrica que contém o ponto 
final é aquele definido entre o maior valor de fração volumétrica correspondente a uma resposta é negativa, e o menor valor de fração volumétrica que resulte em uma resposta positiva. A Figura 30 mostra graficamente a lógica de busca exemplificada na tabela 4; os pontos em preto representam as tentativas não testadas, e os pontos abertos, as tentativas testadas. Como discutido previamente o intervalo que contém o ponto final é reduzido a metade, a cada nova tentativa da procura, e o processo de busca é unidirecional não retroagindo, com o avanço da procura, a um valor de fração volumétrica gerado e testado anteriormente.

As prerrogativas básicas sendo atendidas, o processo vai restringindo os limites superior ou inferior do intervalo de fração volumétrica dentro do qual existe o ponto final da titulação. $\mathrm{Na}$ terminologia usual de sistemas inteligentes, o sistema inicia o processo gerando duas pilhas que apresentam os valores que limitam o intervalo que contém a fração volumétrica relativa ao ponto final da titulação. A tabela 5 apresenta a sucessão dos limites superior e inferior a cada tentativa da procura, para os resultados apresentados no exemplo da tabela 4. 


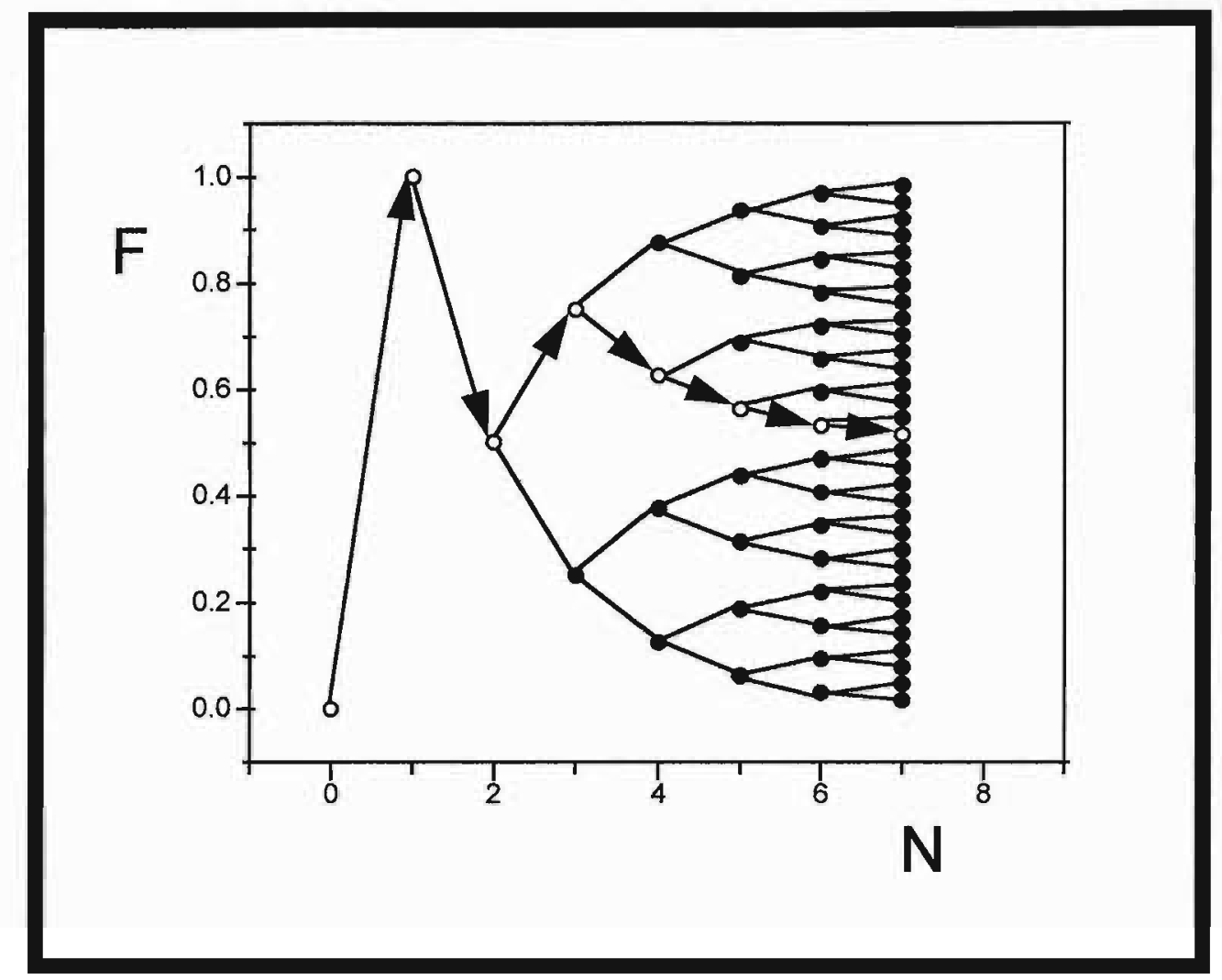

Figura 30. Processo de busca implementado para a titulação por procura binária, conforme tabela 4 , de solução $0,01 \mathrm{M}$ de $\mathrm{HCl}$ com solução $0,01 \mathrm{M}$ em $\mathrm{NaOH}$, empregando fenolftaleína como indicador. Pontos pretos $=$ frações volumétricas não testadas. Pontos abertos $=$ frações volumétricas testadas. Setas = rota de procura. 
Tabela 5. Variação do intervalo do conjunto verdade com o avanço do método de busca, para a titulação de solução $0,01 \mathrm{M}$ de $\mathrm{HCl}$ com solução $0,01 \mathrm{M}$ de $\mathrm{NaOH}$, empregando fenolftaleína como indicador.

\begin{tabular}{c|cccc}
\hline $\begin{array}{c}\text { Passo } \\
\text { de } \\
\text { Busca }\end{array}$ & $\begin{array}{c}\text { Fração } \\
\text { Volumétrica da } \\
\text { solução de } \\
\text { NaOH }\end{array}$ & $\begin{array}{c}\text { Resposta } \\
\text { do } \\
\text { Indicador }\end{array}$ & $\begin{array}{c}\text { Limite } \\
\text { Mínimo }\end{array}$ & $\begin{array}{c}\text { Limite } \\
\text { Máximo }\end{array}$ \\
\hline 0 & 0,00000000 & - & n.d. & n.d. \\
1 & 1,00000000 & + & 0 & 1 \\
2 & 0,50000000 & - & 0,5 & 1 \\
3 & 0,75000000 & + & 0,5 & 0,75 \\
4 & 0,62500000 & + & 0,5 & 0,625 \\
5 & 0,56250000 & + & 0,5 & 0,5625 \\
6 & 0,531250000 & + & 0,5 & 0,53125 \\
7 & 0,515625000 & + & 0,5 & 0,515625 \\
8 & 0,507812500 & + & 0,5 & 0,5078125 \\
9 & 0,503906250 & + & 0,5 & 0,503890625 \\
10 & 0,501953125 & + & 0,5 & 0,501953125 \\
\hline n.d. $=$ não definido & & &
\end{tabular}

4.2.2. Titulação Fotométrica e Titulação com Detecção Fotométrica do Ponto Final

Ao ser eleito o sistema de deteç̧ão fotométrica para monitorar uma dada titulação, o operador pode ter como espécie controle do ponto final tanto uma das soluções reagentes (amostra ou titulante), caso um destas soluções absorvam radiação eletromagnética na região 
do visível, o produto da reação envolvida na titulação, ou ainda, fazendo uso de uma espécie externa a reação principal (corante indicador) que seja sensível ao excesso da solução titulante.

Ao ser selecionado o procedimento de titulação baseado na adição de um corante indicador adequado para a detecção do ponto final é esperada pelo menos uma mudança abrupta na coloração da solução em análise, para poder ser aplicado o algorítmo de procura binária. Em outras palavras, o processo de titulação fotométrica ${ }^{55,56}$ que emprega a adição de uma solução indicadora externa para a localização do ponto final pode ser aplicado, porém com sérias restrições. Idealmente, com a adição de um certo volume do titulante à solução do titulando, esta última solução deverá apresentar um novo máximo de absorção, que possa ser medido com o detector selecionado.

Em princípio, nos procedimentos tradicionais de titulação empregando detector espectrofotométrico para o monitoramento do ponto final, qualquer das opções mencionadas para a indicação da completação da reação podem ser aplicadas. Assim, caso uma das espécies reagentes, ou o produto da reação entre as espécies, absorverem a radiação em um dado comprimento de onda, o acompanhamento da titulação pode ser realizado tomando como base a variação do sinal gerado pelo detector fotométrico (absorvância) com o volume de titulante adicionado à solução da amostra.

Uma vez que a absorvância é diretamente proporcional a concentração em solução da espécie indicadora, indiretamente é avaliada a variação da concentração desta espécie com a adição do titulante, independentemente da espécie em monitoramento ser um indicador interno ou externo da titulação. 
O emprego da lógica de procura binária quando é utilizada uma das soluções reagentes como indicadora do ponto final (indicador interno $^{57}$ ), é exemplificada através da titulação de uma solução contendo íons $\mathrm{Cu}$ (II) com EDTA a pH 10 em tampão amoniacal. Os íons cobre estão na forma colorida do complexo amoniacal e durante a titulação ocorre um deslocamento no equilíbrio, favorecendo a formação do complexo com EDTA. Porém, a concentração do tampão amoniacal e do íon $\mathrm{Cu}\left(\mathrm{NH}_{3}\right)_{4}{ }^{+2}$ afetam significativamente o grau de dissociação do tetramin-complexo e a razão entre as constantes de estabilidade dos dois complexos, o que resulta em uma variação discreta na absorvância medida nas vizinhanças do ponto final. A curva produzida pela variação da absorvância com a fração volumétrica, para as titulações por procura binária de solução de íons $\mathrm{Cu}^{+2}$ em tampão amoniacal a pH 10 com solução 0,05 M em EDTA, é apresentada na Figura 31. Para o sistema proposto foram selecionadas as seguintes variáveis: percurso analítico de $100 \mathrm{~cm}$, vazão igual a $2,15 \mathrm{~cm}^{3} \mathrm{~min}^{-1}$, comprimento de onda igual a $620 \mathrm{~nm}$. Os dados obtidos no sistema estudado foram comparados com o valor conhecido de concentração de íons $\mathrm{Cu}$ (II), 0,10 M, apresentando desvio surprendentemente grande (maior que $80 \%$ ) entre o valor esperado e o valor encontrado pelo sistema. Tal diferença pode ser explicada pelos fatos: (i) a reação de deslocamento não é instantânea; (ii) nas proximidades do ponto estequiométrico a competição entre o $\mathrm{NH}_{3}$ e o EDTA pelos íons $\mathrm{Cu}(\mathrm{II})$ é intensa; (iii) a concentração do tampão amoniacal foi extremamente elevada (0,05 M); e, (iv) o complexo Cu(II)-EDTA absorve também no comprimento de onda selecionado. 


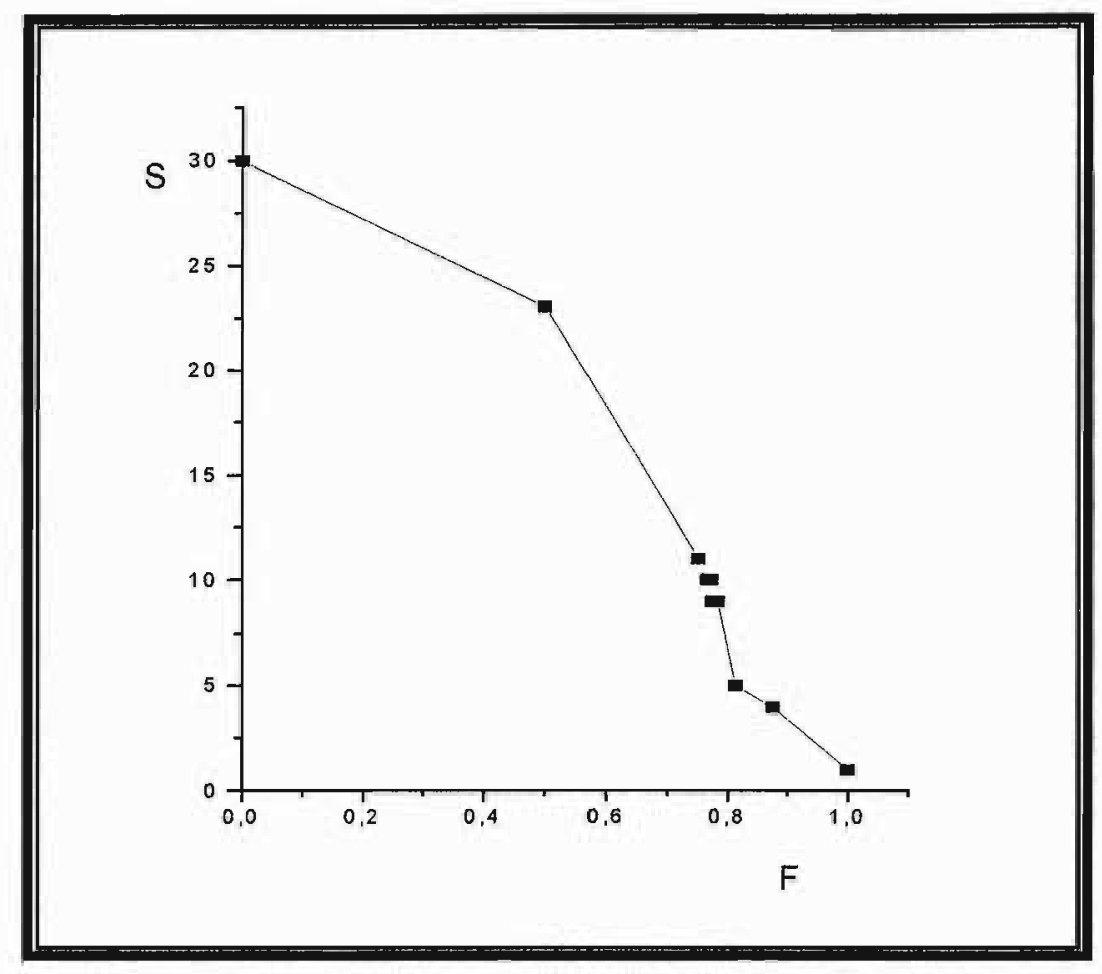

Figura 31. Variação da absorvância na titulação por procura binária de solução amoniacal $0,1 \mathrm{M}$ de $\mathrm{Cu}(\mathrm{II})$ com a fração volumétrica da solução $0,050 \mathrm{M}$ de EDTA. $\mathrm{S}=$ sinal digital. $\mathrm{F}=$ fração volumétrica de EDTA. $\lambda=620 \mathrm{~nm}$.

4.3. Seleção de Indicadores para o Processo de Titulação por Procura Binária

A utilização de indicadores externos para a detecção do ponto final de titulações foi exemplificada anteriormente para o sistema $\mathrm{HCl}$ e $\mathrm{NaOH}$, quando solução de fenolftaleína foi empregada como indicador. Conforme discutido anteriormente, o operador deve ter previamente, o conhecimento de alguns dados sobre a solução da amostra. Tanto para o preparo da solução padronizada do titulante, como para a escolha de 
um indicador adequado para o procedimento analítico. Este fato é evidenciado através de uma série de titulações consecutivas de uma mesma solução de ácido acético $0,1 \mathrm{M}$ com solução padronizada de $\mathrm{NaOH}$ com concentração $0,09338 \mathrm{M}$, empregando em cada titulação indicadores com transições de coloração em faixas distintas de $\mathrm{pH}$. As variáveis do sistema selecionadas para esta série de titulações são apresentadas na tabela 6. Os indicadores selecionados foram fenolftaleína, azul de bromotimol e alaranjado de metila. Os valores de concentração obtidos são apresentados na tabela 7.

Tabela 6. Valores selecionados para as variáveis operacionais nas titulações de solução de ácido acético com hidróxido de sódio pelo processo de procura binária, empregando diferentes indicadores.

\begin{tabular}{l|c}
\hline Variáveis & Valores Selecionados \\
\hline Número de Tentativas de Procura & 11 \\
Número de Pares de Alíquotas & 5 \\
Vazão $\left(\mathrm{cm}^{3} \mathrm{~min}^{-1}\right)$ & 2,15 \\
Número de Réplicas das Sequências & 5 \\
Volume de uma Sequência de Alíquotas $\left(\mathrm{mm}^{3}\right)$ & 366,9 \\
\hline
\end{tabular}

$\mathrm{O}$ pH calculado para o ponto de equivalência no sistema proposto ácido acético e $\mathrm{NaOH}$ é de 8,57. Os valores de $\mathrm{pH}$ em que predominam as formas ácidas e básicas dos indicadores selecionados e as respectivas colorações são apresentados na tabela 8. Entre os indicadores selecionados para a avaliação o mais adequado é a fenolftaleína, dado que o valor de sua constante de dissociação é 
bastante próximo ao $\mathrm{pH}$ calculado para o ponto de equivalência do sistema proposto.

Tabela 7. Concentrações determinadas de ácido acético aplicando o processo de titulação por procura binária com solução padronizada de $\mathrm{NaOH}$ 0,09338 M, empregando diferentes indicadores.

\begin{tabular}{c|cc}
\hline Indicador & $\begin{array}{c}\text { Fração } \\
\text { volumétrica } \\
\text { de NaOH }\end{array}$ & $\begin{array}{c}\text { Concentração } \\
\text { Calculada } \\
(\mathrm{M})\end{array}$ \\
\hline fenolftaleína & 50,59 & 0,09561 \\
azul de bromotimol & 46,48 & 0,08110 \\
alaranjado de metila & 8,79 & 0,00900 \\
\hline
\end{tabular}

Tabela 8. Características dos indicadores ácido - base selecionados.

\begin{tabular}{c|cc|cc}
\hline \multirow{2}{*}{ Indicador } & \multicolumn{2}{|c|}{ Coloração } & \multicolumn{2}{c}{$\begin{array}{c}\text { Intervalo de } \\
\text { Transição de } \mathrm{pH}\end{array}$} \\
\cline { 2 - 5 } & forma & forma & forma & forma \\
& ácida & básica & ácida & básica \\
\hline fenolftaleína & incolor & rosa & 8,2 & 9,6 \\
azul de bromotimol & amarela & azul & 6,0 & 7,6 \\
alaranjado de metila & vermelha & amarela & 3,1 & 4,4 \\
\hline
\end{tabular}

Nos sistemas convencionais de titulação a seleção imprópria de um indicador faz com que a mudança de cor não seja abrupta. Esta informação não pode ser dada ao operador, pelo sistema, durante o 
processo de titulação por procura binária. Desta forma é clara a necessidade do conhecimento prévio a respeito da espécie química em titulação e de sua possível concentração na solução de amostra, fornecendo as condições para que sejam escolhidas a solução titulante e $\mathrm{o}$ indicador adequados.

\subsection{Adicionando Indicadores nas Titulação por Busca Binária}

O comportamento do processo de titulação por procura binária foi avaliado quanto à adição da solução contendo o indicador nas soluções da amostra, titulante ou em ambas as soluções. A avaliação foi realizada partindo da titulação de solução de ácido forte $(\mathrm{HCl})$, com solução de base forte $(\mathrm{NaOH})$ e usando solução alcoólica de fenolftaleína como indicador. O comprimento de onda selecionado para o monitoramento do sinal transiente foi de $520 \mathrm{~nm}$.

Quando a titulação pelo processo de procura binária é realizada adicionando à solução alcoólica do indicador exclusivamente na solução de $\mathrm{HCl}$, o processo não apresenta condições de tomar decisões para os passos subsequentes, pois não existiram condições para a diferenciação dos sinais gerados nos dois primeiros passos de procura do ponto final.

A impossibilidade de diferenciação nos dois passos iniciais da titulação por procura binária occorre devido ao fato de que o indicador, em meio ácido, não absorve radiação no comprimento de onda selecionado. O mesmo acontecendo com a solução alcalina, sem que se tenha a adição deste corante indicador. $\mathrm{O}$ parâmetro de comparação $\mathrm{S}_{\mathrm{C}}$ 
foi igual ao sinal gerado pelo detector em $\mathrm{S}_{0}$. O programa desenvolvido denuncia para o operador que ocorreu igualdade entre $S_{0}$ e $S_{C}$, suspendendo automaticamente a rotina de análise e, requisitando do operador a verificação do comprimento de onda selecionado no espectrofotômetro e das condições globais do sistema de fluxo.

No caso em que o indicador é adicionado somente na solução de $\mathrm{NaOH}$, a concentração analítica da espécie indicadora é necessariamente alterada em cada sequência de alíquotas introduzidas no percurso analítico. Isto se deve ao fato do volume das alíquotas de $\mathrm{NaOH}$ variarem para cada sequência gerada. Este efeito foi fortemente sentido na titulação de uma solução $0,001 \mathrm{M}$ de $\mathrm{HCl}$ com solução 0,01 $\mathrm{M}$ de $\mathrm{NaOH}$. A fração volumétrica da solução de $\mathrm{NaOH}$ no ponto de equivalência seria aproximadamente de 0,11. Como foram adicionados $50 \mathrm{~mm}^{3}$ de solução $1 \%(\mathrm{~m} / \mathrm{v})$ de fenolftaleína à $25 \mathrm{~cm}^{3}$ da solução do titulante $(\mathrm{NaOH})$, a concentração final do indicador após a diluição foi de $0,002 \%(\mathrm{~m} / \mathrm{v})$.

Efeito semelhante ao encontrado na titulação de $\mathrm{HCl}$ com $\mathrm{NaOH}$, quando a solução indicadora foi adicionada exclusivamente na solução da base forte, se deu na titulação de íons $\mathrm{Cu}^{+2}$ com solução padronizada de EDTA em tampão amoniacal a $\mathrm{pH} 10$, discutida no ítem anterior.

A adição da mesma quantidade do indicador em ambas as soluções, foi a opção que apresentou os melhores resultados para o processo de busca binária. Isto porque a concentração do indicador permanece inalterada para qualquer passo da busca, já que a soma das 
frações volumétricas da solução de amostra e do titulante é sempre igual a unidade.

Outra opção testada foi a condição de análise quando era efetuado o acoplamento de uma nova válvula solenóide ao sistema de fluxo, com a função específica de inserir o mesmo volume da solução contendo o corante indicador, a cada tentativa da procura. $\mathrm{O}$ diagrama de fluxo proposto para o sistema é apresentado na Figura 32. Para o caso específico da solução de fenolftaleína, o resultado obtido com este procedimento não foi satisfatório. Partículas residuais de fenolftaleína ocasionaram obstrução no escoamento de líquido através da válvula solenóide durante a jornada de trabalho.

\subsection{Aplicando o Conceito de Titulação por Busca Binária}

Conceitualmente, o mesmo sistema de fluxo pode ser empregado para titulações de soluções em uma ampla faixa de concentração. Isto foi comprovado pela titulação de uma série de soluções de concentrações variáveis de $\mathrm{HCl}$ com a mesma solução de $\mathrm{NaOH}$, como está apresentado na Figura 19. As frações volumétricas correspondentes ao ponto final da procura binária, para os três casos apresentados foram de 0,090820 , para a solução solução $0,001 \mathrm{M}$ de $\mathrm{HCl} ; 0,50098$, para a solução solução $0,01 \mathrm{M}$ de $\mathrm{HCl}$; e 0,944335 , para a solução solução $0,15 \mathrm{M}$ em $\mathrm{HCl}$. As concentrações determinadas para as soluções foram de $9,989 \times 10^{-4} \mathrm{M}, 1,004 \times 10^{-2} \mathrm{M}$ e $1,696 \times 10^{-1} \mathrm{M}$, respectivamente. Os desvios calculados entre os valores de concentração obtidos e os valores esperados, sugerem uma variação máxima da ordem de $13 \%$ para o caso no qual a solução da amostra 
apresentava concentração em $\mathrm{H}_{3} \mathrm{O}^{+} 15$ vezes maior que a concentração de íons $\mathrm{OH}^{-}$na solução do titulante.

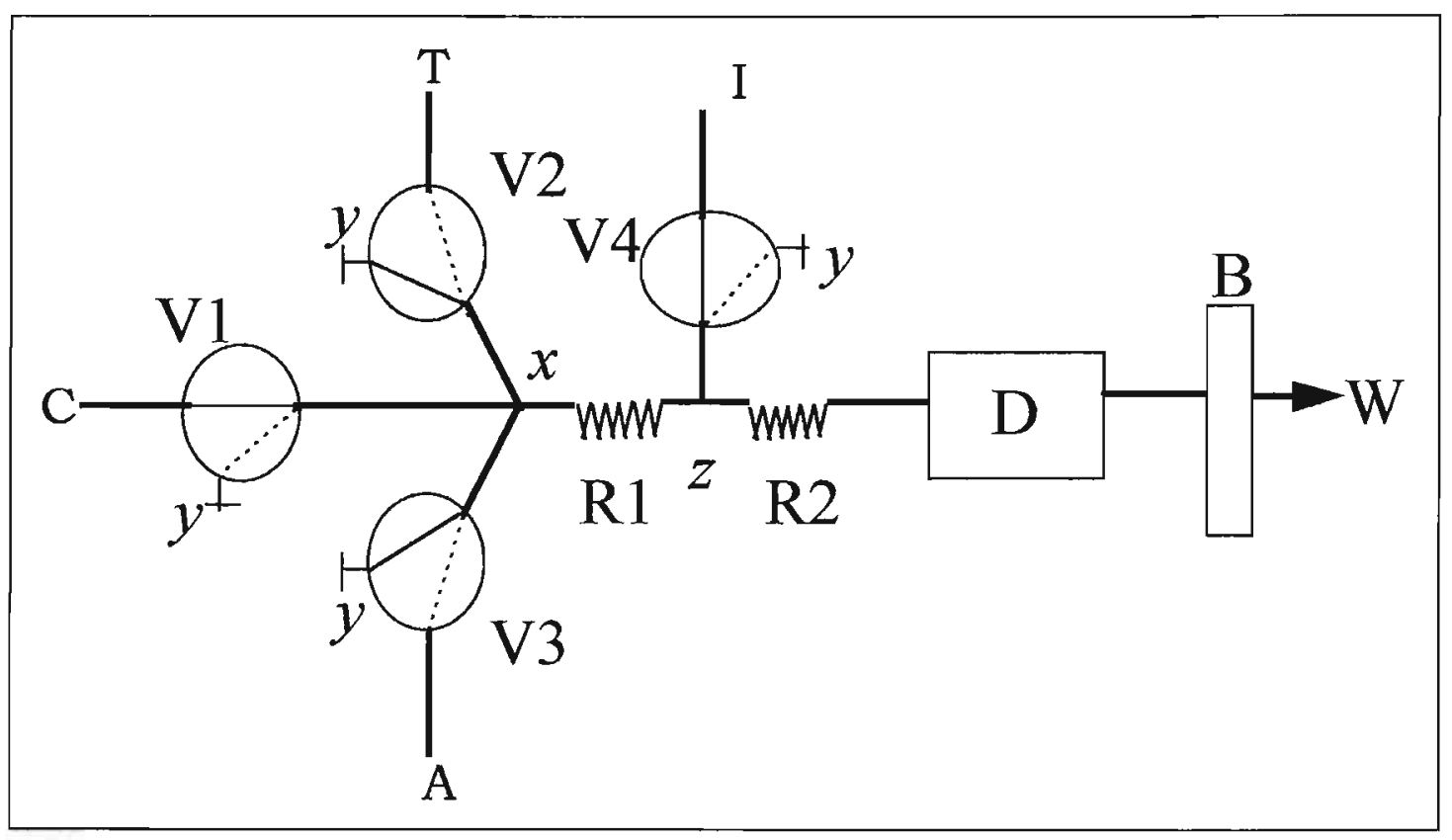

Figura 32. Diagrama de fluxo opcional para o sistema de titulação por procura binária com linha independente para introdução do indicador. $\mathrm{C}=$ solução carregadora. $\mathrm{A}=$ solução da amostra. $\mathrm{T}=$ solução titulante. $\mathrm{I}=$ solução do indicador. $\mathrm{R} 1 \mathrm{e} \mathrm{R} 2=$ bobinas de reação. $x \mathrm{e} z=$ pontos de junção. $y=$ obstruidor de fluxo. V1, V2, V3 e V4 = válvulas solenóides de três vias. $\mathrm{D}=$ detector. $\mathrm{B}=$ bomba peristáltica. $\mathrm{W}=$ descarte.

A robustez do método proposto pode ser verificada através da ampla faixa de concentração de uma espécie de interesse presente em uma solução que pôde ser determinada fazendo uso de uma mesma solução do titulante.

Outro ponto a ser abordado é relacionado com as condições para a viabilização da implementação do processo. O processo de titulação por 
busca binária sendo executado manualmente, a partir do terceiro passo de busca, as misturas para o passo seguinte devem ser preparadas de acordo com o sinal gerado pelo detector. Este procedimento deveria ser mantido até a definição do menor intervalo de fração volumétrica que contenha a fração volumétrica relativa ao ponto final da titulação.

Outra possibilidade de implementar o processo de busca binária para a localização do ponto final sem empregar recursos de automação, seria através do preparo antecipado de todas as possíveis misturas entre as soluções da amostra e do titulante. Na tabela 9 é indicado o número total de soluções que devem ser preparadas para cada passo de busca. Este seria um trabalho duro e tedioso para o analista, uma vez que seria necessário preparar mais de mil misturas das soluções reagentes com proporções volumétricas diferentes.

A duração de uma determinação de concentração empregando o sistema automatizado proposto é de cerca de 3 minutos, requerendo do operador apenas o preparo e a padronização da solução original do titulante. 
Tabela 9. Número de soluções a serem preparadas para a realização de uma titulação por busca binária caso o sistema não fosse automatizado.

\begin{tabular}{c|cc}
\hline $\begin{array}{c}\text { Passo } \\
\text { de }\end{array}$ & Número de & Quantidade \\
Busca & parcões & Total de \\
& Soluções \\
& docução & \\
\hline 0 & 1 & 1 \\
1 & 1 & 2 \\
2 & 1 & 3 \\
3 & 2 & 5 \\
4 & 4 & 9 \\
5 & 8 & 17 \\
6 & 16 & 33 \\
7 & 32 & 65 \\
8 & 64 & 129 \\
9 & 128 & 257 \\
10 & 256 & 513 \\
11 & 512 & 1025 \\
12 & 1024 & 2049 \\
\hline
\end{tabular}




\subsection{O Programa Desenvolvido para Procura Binária}

O programa desenvolvido para a execução das titulações por busca binária, foi escrito em linguagem QuickBASIC (MicroSoft), versão 4.5, é apresentado de forma sumária no apêndice A. Este programa foi concebido em arranjo modular, sendo composto por cerca de 40 sub programas e funções, podendo ser implementado em microcomputadores 286, 386 ou 486, conectados à interface PCL-711S ${ }^{47}$.

O módulo principal do programa compreende 7 diferentes janelas com funções específicas:

- teste das válvulas solenóides;

- seleção da base de tempo, considerando a frequência de transmissão de informações no microcomputador; seleção do disco, rigído ou não, e do diretório para o armazenamento dos dados de análise;

- estabelecimento da linha de base, do zero em absorvância e de sua variância, ajustando a absorvância do detector para zero;

- seleção dos parâmetros para a titulação;

- sincronização opcional do início das etapas de amostragem com o pulso gerado pela bomba peristáltica;

- e, uma tela para início do processo de busca, através da introdução das alíquotas da solução de amostra e do titulante no percurso analítico.

Os sinais gerados pelo espectrofotômetro são transmitidos para a interface de controle e aquisição de dados, e consecutivamente processados, como apresentado no diagrama de blocos da Figura 12. 
Durante a execução da titulação é estabelecida uma região no monitor de vídeo, onde podem ser acompanhados, através de uma curva, os pontos relacionados com os sinais transientes gerados pelo detector. Em outra área do monitor é indicado para o operador o valor máximo do sinal transiente obtido para uma dada sequência, bem como o intervalo de fração volumétrica que contém a transição de coloração do corante indicador.

Caso o número de soluções de amostras a serem tituladas seja maior que dois, o sistema de fluxo pode sofrer uma pequena modificação, como apresentado no diagrama de fluxo da Figura 33, onde uma válvula solenóide é associada ao ponto de junção $y$, de forma a alterar a direção do fluxo durante a troca da solução de amostra. A rotina para acionamento das válvulas solenóides, para este sistema, segue o diagrama de blocos da Figura 34. Com o acoplamento de uma nova válvula solenóide a etapa de troca de amostra é tremendamente facilitada, visto que ao serem acionadas conjuntamente as válvulas $\mathrm{V} 2$ e V4 a amostra fluí em direção a bomba peristáltica, sem passar pelo detector. Em outras palavras, durante a troca de amostras, as possíveis bolhas de ar que podem ser introduzidas no percurso analítico são desviadas da cela de fluxo, sendo aspiradas diretamente para a bomba peristáltica. 


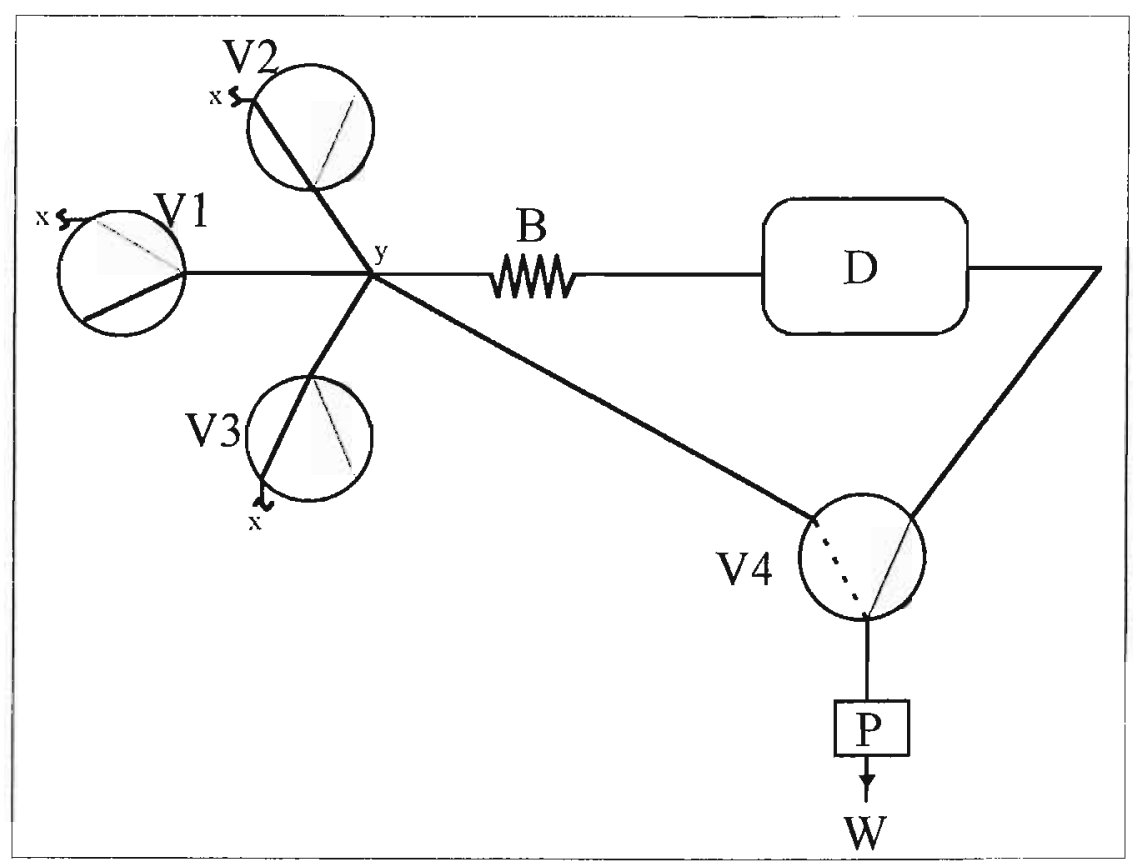

Figura 33. Diagrama de fluxo alternativo para titulações de uma série de soluções de amostras aplicando o conceito de procura binária. $\mathrm{B}=$ bobina de reação; $\mathrm{D}=$ detector; $\mathrm{P}=$ bomba peristáltica; $\mathrm{W}=$ despejo; $\mathrm{V} 1, \mathrm{~V} 2, \mathrm{~V} 3$ e V4 $=$ válvulas solenóides. $x=$ obstruidor de fluxo e $y=$ ponto de junção. 


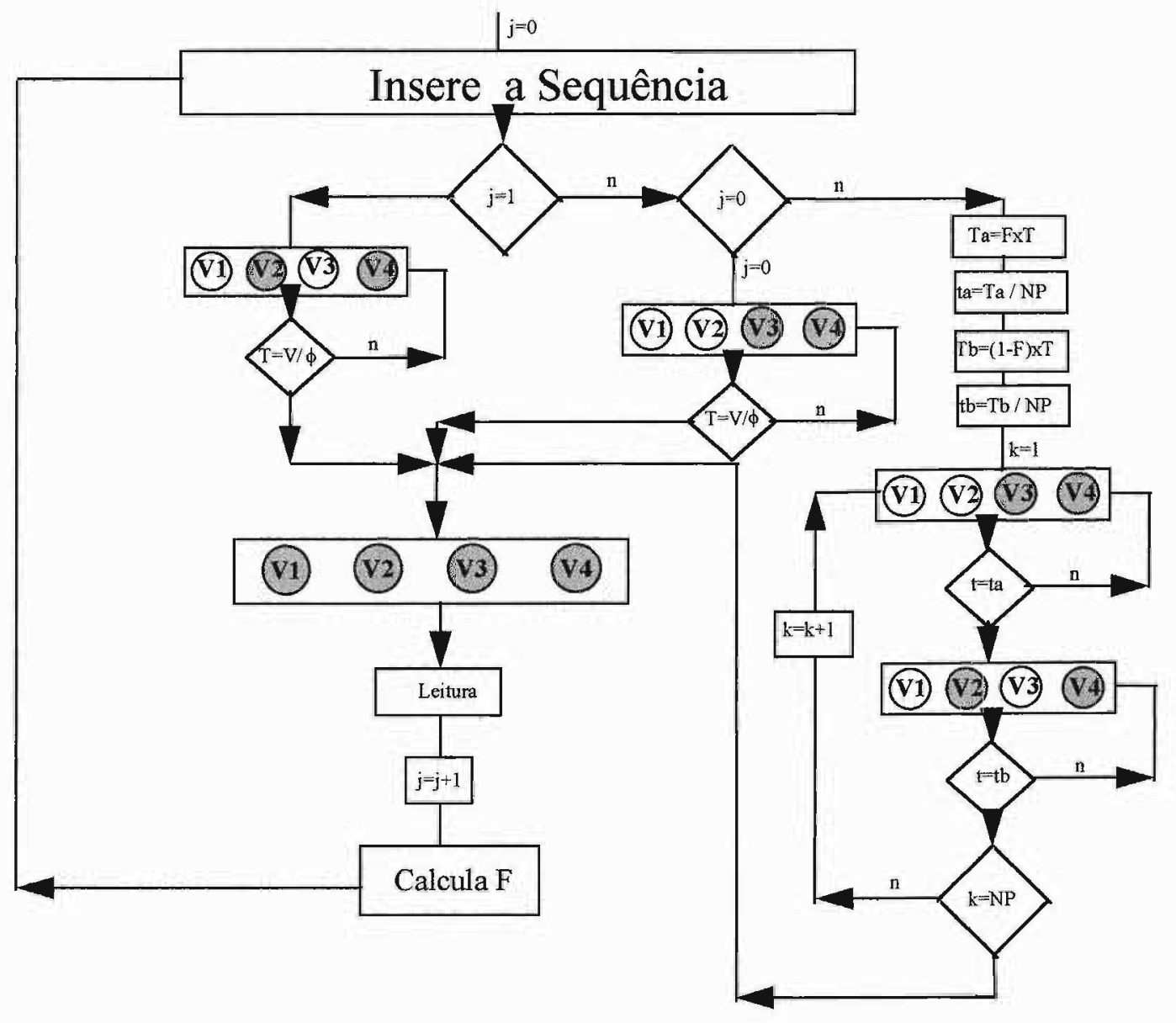

Figura 34. Diagrama de blocos simplificado para o processo alternativo de busca binária, correspondente. $\mathrm{NP}=$ número de pulsos; V1, V2, V3 e $\mathrm{V} 4=$ válvulas solenóides. $\mathrm{T}=$ tempo de acionamento; $\Phi=$ vazão; $\mathrm{F}=$ fração volumétrica; $a$ e $b=$ soluções do titulante e da amostra. $\bigcirc$ = válvula ativada e $\bigcirc$ =válvula desativada. 
Outra opção deste programa é a possibilidade de acionamento de uma rotina para estabelecimento do espectro de uma ou mais soluções, utilizando a qualidade de aquisição e processamento de dados da interface de controle. A varredura da faixa definida de comprimentos de onda é realizada manualmente. A curva referente ao espectro de absorção é obtida através de algum pacote gráfico ou estatístico, por exemplo o Origin 3.0 (MicroCal).

Um motor de passo poderia ser associado ao seletor de comprimento de ondas do espectrofotômetro, permitindo a automatização deste processo de varredura. Este seria um investimento bastante elevado para um equipamento com sistema óptico mediano (banda larga).

A rotina do programa desenvolvido gera uma matriz, onde são relacionados os comprimentos de onda com os sinais gerados pelo detector. A planilha é armazenada no disco rígido em ASCII.

A aplicação deste procedimento sugere que primeiramente sejam definidos os sinais de referência, para cada comprimento de onda. Estes, são obtidos fazendo escoar pelo percurso analítico a solução carregadora. O espectro de absorção das soluções de amostra e do titulante, com ou sem a adição do indicador, são obtidos relacionando o sinal obtido com o sinal de referência, para cada comprimento de onda selecionado.

\subsection{Outras Aplicações do Processo de Titulação por Busca Binária}

Todos os testes iniciais de maleabilidade, robustez e confiabilidade no processo de titulação por procura binária foram realizados com uma bateria de titulações em sistema convencional de titulação de ácido forte com base forte. A metodologia de titulação desenvolvida nesta tese foi 
aplicada com sucesso nos laboratórios do CENA-USP para uma série de outros sistemas que relatamos a seguir a título de informação.

A titulação de solução $0,2 \mathrm{M}$ de $\mathrm{HCl}$ com solução padronizada de $\mathrm{NaOH}, 0,1002 \mathrm{M}$, foi realizada em tréplica usando solução de verde de bromocresol como corante indicador. Nas três titulações consecutivas a fração volumétrica de $\mathrm{NaOH}$, correspondente à transição de coloração do indicador, foi de 0,664 , para 9 passos de busca. A concentração de $\mathrm{HCl}$ determinada pelo método de titulação por procura binária foi de 0,1980 M. Comparando com o método convencional de titulação através da aplicando do teste $t$-pareado o resultado obtido pelo processo de procura binária não mostrou diferença significativa para $95 \%$ de confiabilidade.

O processo também foi aplicado para a determinação da acidez em amostra de bebida alcoólica (Cachaça Cayuba, Ceará), titulando esta amostra com solução padronizada $0,009978 \mathrm{M} \mathrm{NaOH}$, e usando fenolftaleína como indicador. $O$ interesse nesta determinação esteva relacionado com a possibilidade do processo em executar a titulação de soluções parcialmente homogeneizáveis. $\mathrm{O} \mathrm{pH}$ encontrado para a amostra foi de 3,8 .

O método foi aplicado com sucesso para a determinação da concentração de solução de ácido bórico por titulação de neutralização. O método utilizado empregava a adição de uma massa conhecida de manitol à solução de ácido bórico, e titulava a solução resultante com solução padronizada de $\mathrm{NaOH}$, empregando fenolftaleína como indicador. A faixa de concentração de ácido bórico possível de ser determinada pelo método da busca binária era relacionada com o volume das alíquotas e com a quantidade de manitol adicionado na solução. 
Este método vem sendo alterado de forma a permitir sua aplicação na determinação de teores de frutose em adoçantes. Para tal objetivo, uma alíquota de volume conhecido de solução de ácido bórico é misturada com uma massa conhecida do adoçante. A mistura é, então, levada para a determinação da concentração de íons $\mathrm{H}^{+}$livres. A quantidade de $\mathrm{H}^{+}$livre é proporcional ao número de moles de frutose existente no adoçante. $O$ processo poderia ser aplicado para a determinação sequencial de frutose e glucose, associando ao sistema de fluxo uma coluna contendo enzimas que permitam a inversão da glucose.

O método também foi aplicado para a determinação por volumetria de íons $\mathrm{Mg}^{+2}$ com solução padronizada de EDTA. Para esta titulação a solução carregadora foi uma solução tampão amoniacal $(\mathrm{pH}=10)$ e o indicador empregado foi o negro de eriocromo - T. Neste procedimento foram adicionadas nas soluções de magnésio e do quelante massas iguais da mistura do indicador com nitrato de potássio. Os limites inferior e superior de concentração do íon metálico são estabelecidos como para a titulação de neutralização de ácido clorídrico com hidróxido de sódio. Os resultados obtidos quando comparados ao método convencional de titulação com o mesmo indicador não apresentou diferenças significativas.

Outra aplicação a ser ressaltada é a titulação de uma solução contendo mistura dos ácidos acético e clorídrico. Para este sistema são realizados dois processos de busca, relacionados com os dois indicadores selecionados para as determinações, alaranjado de metila e fenolftaleína. A determinação da concentração de ácido clorídrico foi realizada com alaranjado de metila e a determinação da concentração de ácido acético na solução da amostra empregando solução de fenolftaleína como 
indicador. Aplicando o teste $t$-pareado, os resultados obtidos pelo método convencional e por procura binária mostraram-se comparáveis para nível de confiabilidade de $95 \%$. 


\section{CONCLUSÕES}

Os resultados obtidos aplicando o método de titulação por busca binária indicam a potencialidade deste procedimento para executar análises volumétricas. Porém, a precisão do processo é fortemente dependente da precisão nas amostragens das alíquotas e, consequentemente das variações de vazão decorrentes da bomba peristáltica.

O método pode ser aplicado fazendo uso de várias classes de detectores, além do fotométrico. Para um detector ser empregado com sucesso, três premissas devem ser respeitadas: i) os sinais gerados nos dois primeiros passos de busca sejam diferentes; ii) a função relacionada com a variação do sinal gerado pelo detector com a fração volumétrica deve ser monótona e; iii) a variação no parâmetro físico sobre investigação deve ocorrer no ponto estequiométrico.

$\mathrm{O}$ desenvolvimento desta metodologia de titulação baseada no processo das razões molares resultou em um processo bastante elegante de análise com um espectro de aplicação muito amplo. A dificuldade relatada para a titulação de ácido clorídrico com solução de hidróxido de sódio, quando a solução do indicador é adicionada apenas na solução contendo a base, pôde ser verificada também no processo de titulação fotométrica, como na titulação de cobre com EDTA. Esta mácula seria eliminada se o processo de procura binária fosse desenvolvido com base no método das razões molares. Isto ocorreria dada a possibilidade de 
construir sequências ternárias de amostra, titulante e diluente, onde o volume da alíquota da amostra seria mantido durante todas as tentativas da procura, variando os volumes das alíquotas de titulante e diluente. Este método permitiria a determinação da concentração de espécies químicas de interesse em meios bastante adversos, como por exemplo a determinação do $\mathrm{pH}$ em amostras de vinhos tintos ou leite.

O programa desenvolvido foi testado por outros operadores com excelente resposta. $O$ processo de procura binária abre uma perspectiva muito interessante de aplicação de algorítmos para gerenciar procedimentos de análises químicas.

Apenas quem já realizou uma quantidade enorme de titulações e por falta de habilidade, ou desleixo, não conseguiu detectar o ponto final, consegue entender a beleza deste processo.

\subsection{Trabalhos Futuros}

O sistema futuramente deve ser redefinido para ambiente Windows, afim de expandir os limites de memória liberadas para o sistema operacional. Uma vez que este titulador, ou gerenciador de análises, necessitará de bibliotecas e bancos de dados específicos. Para tanto será empregado o contador de tempo da interface PCL - 711S para garantir a introdução de alíquotas precisas das soluções de amostra e titulante.

O processo de titulação por procura binária pode ser implementado em tituladores automáticos estacionários baseado no preparo de um número pequeno de misturas das soluções de amostra e titulante e, comandado por computador. Para tal objetivo seriam necessárias noções 
de robótica e a estruturação de um sistema preciso de tomadas de alíquotas, independente de bombas peristálticas.

O método da multicomutação pode ser facilmente adaptado para gerar curvas analíticas partindo de uma única solução de concentração conhecida. $\mathrm{O}$ mesmo pode, também ser empregado para processos que necessitem de adição de padrão. Não seriam necessárias modificações ou adequações no sistema de fluxo empregado na titulação por busca binária, para que este realize estas outras atividades. 
1. Ziegel, H., Z. Anal. Chem., 53 (1914) 755.

2. Whitnah, C.H., Ind. Eng. Chem. Anal. Ed., 5 (1933) 352.

3. Shenk, W.E.; Fenwick, F., Ind. Eng. Chem. Anal. Ed., 7 (1935) 194.

4. Berhenke, L.F.; Britton, E.C., Ind. Eng.Chem., 38 (1946) 544.

5. Lingane, J.J., Anal. Chem., 20 (1948) 285.

6. Zimmerli, F.H., Anal. Instrum., 5 (1967) 1.

7. Blaedel, W.J.; Laessig, R.H., Anal. Chem., 36 (1964) 1617.

8. Ruzicka, A.J.; Hansen, E.H., Anal. Chim. Acta, 78 (1975) 145.

9. Blaedel, W.J.; Hicks, G.P., Anal.Chem., 34 (1962) 388.

10. Fleet, B.; Ho, A.Y.W., Anal. Chem., 46 (1974) 9.

11. Ruzicka, A.J.; Hansen, E.H.; Mosbaek, H., Anal. Chim. Acta, 98 (1977) 235.

12. Ramsing, A.U.; Ruzicka, A.J.; Hansen, E.H., Anal. Chim. Acta, 129 (1981) 1 .

13. Stewart, K.K.; Rosenfeld, A.G., Anal. Chem., 54 (1982) 2368.

14. Pardue, H.L.; Fields, B., Anal. Chim. Acta, 124 (1981) 39.

15. Stewart, K.K., Anal. Chem., 55 (1983) 931A.

16. Blaedel, W.J.; Laessig, R.H., Anal. Chem., 37 (1965) 332.

17. Martínez-Calatayud, J.; Campíus, P.; Micó, R., Analyst, 112 (1987) 1063. 
18. Marcos, J.; Ríos, A.; Valcárcel, M., Anal. Chim. Acta, 261 (1992) 489.

19. Marcos, J.; Ríos, A.; Valcárcel, M., Anal. Chim. Acta, 261 (1992) 495.

20. Yarnitzky, C.N.; Klein, N.; Cohen, O., Talanta, 40 (1993) 1937.

21. Yarnitzky, C.N.; Klein, N.; Cohen, O., J. Anal. Instr., 40 (1993) 1937.

22. Bartrolí, J.; Alerm, L., Anal. Chim. Acta, 269 (1992) 29.

23. Bartrolí, J.; Alerm, L.; Garcia-Raurich, J.; Masip, J., Quim. Anal., 13 (1994) 31.

24. Agudo, M.; Marcos, T.; Rios, A.; Valcarcel, M., Anal. Chim. Acta, 239 (1990) 211.

25. Sagara, F.; Kobayashi, T.; Tajima, T.; Ijyuin, H.; Yoshida, I.; Ishii, D.; Ueno, K., Anal. Chim. Acta, 261 (1992) 505.

26. Korn, M.; Gouveia, L.F.; de Oliveira, E.; Reis, B.F., Anal. Chim. Acta, 313 (1995) 177.

27. Fuhrmann, B.; Spohn, U., Anal. Chim. Acta, 282 (1993) 397.

28. Fuhrmann, B.; Spohn, U., J. Autom. Chem., 15 (1993) 209.

29. Nagy, G.; Toth, K.; Pungor, E., Anal. Chem., 47 (1975) 1460.

30. Petty, J.D.; Petty, D.A.; Peachey, R.M.; Smith, T.K.; Krieger, B.L., Talanta, 41 (1994) 359.

31. Blaedel, W.J.; Laessig, R.H., Ad. Anal. Chem. and Instrum., 5 (1966) 69.

32. Olim, A.; Wikmark, G., Anal. Chem., 55 (1983) 1402.

33. Rabuske, R.A., "Inteligência Artificial", Editora da UFSC, Florianópolis, Brasil, 1995.

34. Liscouski, J.G., Anal. Chem., 54 (1982) 849A. 
35. Maj, S.P., "The Use of Computer for Laboratory Automation", Ed. Royal Society of Chemistry, Cambridge, UK, 1993.

36. Wikmark, G., Anal. Instrum., 13 (1984) 145.

37. Job, P., Ann. Chim., 9 (1928) 113.

38. Vorburgh, W.C.; Cooper, G.R., J. Am. Chem. Soc., 63 (1941) 437.

39. Harvey, A.E.; Manning, D.L., J. Am. Chem. Soc., 72 (1950) 4438.

40. Harvey, A.E.; Manning, D.L., J. Am. Chem. Soc., 74 (1952) 4744.

4.1. Ríos, A.; Luque de Castro, D.; Valcárcel, M., J. Chem. Educ., 63 (1986) 552.

42. Christian, G.D., "Analytical Chemistry", Ed. John Willey \& Sons, $4^{\circ}$ ed., 1986.

43. Johansson, A., Anal. Chim. Acta, 206 (1988) 97.

44. Underwood, A.L., Ad. Anal. Chem. Instrum., 3 (1964) 31.

45. Lastman, G.J.; Sinha, N.K., "Microcomputer-Based Numerical Methods for Science and Engineering", Saunders College Publishing 1989.

46. Martinho, E.J.C., Oliveira, J.C.; Fortes, M.A., "Matemática Para o Estudo da Física", Fundação Calouste Gubenkian, Lisboa, Portugal, 1985 .

47. Documento Técnico, "PCL-711S interface card user manual", Advantech Co., Taiwan, 1992.

48. Reis, B.F.; Giné, M.F.; Zagatto, E.A.G.; Lima, J.L.F.C.; Lapa, R.A., Anal. Chim. Acta, 293 (1994) 129. 
49. Martelli, P.B.; Reis, B.F.; Kronka, E.A.M.; Bergamin Fo, H.; Korn, M.; Zagatto, E.A.G.; Lima, J.L.F.C; Araújo, A.N., Anal. Chim. Acta, 308 (1995) 397.

50. Bergamin Fo, H.; Reis, B.F.; Zagatto, E.A.G., Anal. Chim. Acta, 97 (1978) 427.

51. Kronka, E.A.M.; Korn, M; Reis, B.F., Anal. Chim. Acta, no prelo.

52. Basset, J.; Denney, R.C.; Jeffrey, G.H.; Mendham, J., "Vogel's Textbook of Quantitative Inorganic Analysis", Longman Group Limited, Análise, Londres, UK, 1978.

53. Hargis, L.G., "Analytical Chemistry”, Prentice-Hall Inc., NJ, USA, 1988.

54. Headridge, J.B., Talanta, 1 (1958) 293.

55. Higushi, T.; Rehm, C.; Barnstein, C., Anal. Chem., 28 (1956) 1506.

56. Johansson, A., Anal. Chim. Acta, 61 (1972) 285.

57. Flashka, H., Talanta, 8 (1961) 381. 


\section{APÊNDICE 1}

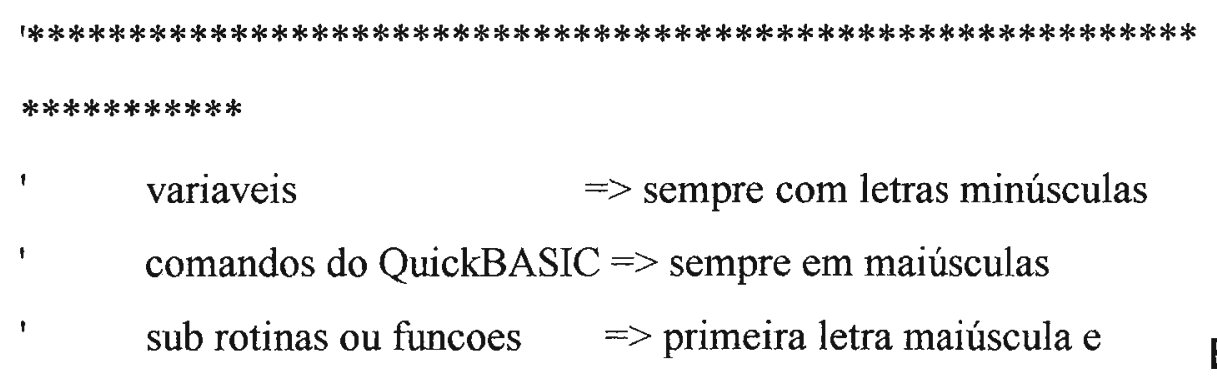

restantes

BIBLIOTECA INSTITUTO DE QUIMICA

minúsculas

$1 * * * * * * * * * * * * * * * * * * * * * * * * * * * * * * * * * * * * * * * * * * * * * * * * * * * * * * * * * *$

$* * * * * * * * * * *$

1. Declaração das sub - rotinas e funções associadas no

módulo principal do programa desenvolvido para titulação

por procura binária:

DECLARE FUNCTION Injeta! (c\$)

DECLARE FUNCTION Leitura! (n AS INTEGER)

DECLARE FUNCTION CursorOperParamKey! (toot!, a\%, B!, c\$)

DECLARE FUNCTION CursorAdvanced! (toot!, a $\%, c \$$ )

DECLARE FUNCTION GetIntegerPositive! (toot!)

DECLARE FUNCTION ComputDesign\$ (toot!)

DECLARE FUNCTION CursorDriveSelect\$ (toot!)

DECLARE FUNCTION ConfirmOperKey $\$$ (toot!, c\$)

DECLARE SUB Referencia (ang!, h AS INTEGER, c!)

DECLARE SUB WaitRoleteUp (n AS INTEGER)

DECLARE SUB PlotaSinal (ponto\%)

DECLARE SUB Numerao (zero.x!, zero.y!, numero!, cor!, delta!)

DECLARE SUB HighNumber (x!, y!, a!, cor!, delta!)

DECLARE SUB PlotaSD ()

DECLARE SUB BinaryName () 
DECLARE SUB Menu ()

DECLARE SUB WaitSegundos (s AS INTEGER)

DECLARE SUB DoInj ()

DECLARE SUB Relatorio ()

DECLARE SUB PrintParam ()

DECLARE SUB InputParam ()

DECLARE SUB OpenDataFile ()

DECLARE SUB ContaRoletes ()

DECLARE SUB TestaValvulas ()

DECLARE SUB Transf (x AS STRING)

DECLARE SUB Valvula (valv AS INTEGER)

DECLARE SUB GetAnyKey (i\$)

DECLARE SUB PressKey (template\$, press\$)

DECLARE SUB WaitTempo (ut AS INTEGER)

2. Declaração das constantes e das variáveis globais e de variáveis locais empregadas no módulo principal do programa:

COMMON SHARED yp0 AS INTEGER 'zero da escala do fiagrama em pixels

COMMON SHARED ypmax AS INTEGER 'max da escala do fiagrama em pixels

COMMON SHARED sig0 AS INTEGER 'zero da escala do fiagrama (digital)

COMMON SHARED sigmax AS INTEGER 'max da escala do fiagrama (digital)

'declaração das variáveis associadas com a interface PCL-711S

COMMON SHARED pa AS INTEGER, pb AS INTEGER 
COMMON SHARED port $\%$, pe1, pe2, da 1 , da2

'declarando as variáveis correspondentes ao diretório e arquivo para salvar os dados da 'titulação por procura binária

COMMON SHARED filename AS STRING, path AS STRING

'declarando as variáveis do sistema:

' - plugT = tempo total de abertura das válvulas solenóides;

' - npul = número de pulsos (pares de alíquotas);

' - replicados $=$ número de réplicas de um mesma tentativa;

- espera $=$ tempo de espera para a leitura dos sinais gerados pelo

detector;

' - le = número de conversöes A/D por leitura;

- pto = número de tentativas de procura.

COMMON SHARED plugT, npul AS INTEGER, replicados AS INTEGER

COMMON SHARED espera AS INTEGER, le AS INTEGER, pto AS INTEGER

'outras variáveis globais

COMMON SHARED clo AS INTEGER, fim AS INTEGER, ini AS

INTEGER COMMON SHARED vaz.ini, vaz.ini.microseg, vol.stringT COMMON SHARED smax AS INTEGER, plugA AS INTEGER, plugB AS INTEGER

COMMON SHARED ptcor, vol

COMMON SHARED escralv AS STRING, save.flag

COMMON SHARED dd AS STRING

COMMON SHARED sig0.media, sig0.sd 
COMMON SHARED signal.leit

COMMON SHARED px, py, old.px, old.py

COMMON SHARED fat.eixo.x, fat.eixo.y

COMMON SHARED conta.ponto, conta.rep

COMMON SHARED base.tempo, tempo.flag, BASET

COMMON SHARED tela

COMMON SHARED opcao6.flag, opcao7.flag, conf.flag

COMMON SHARED zero.x, zero.y, delta, cor

DIM SHARED vv(8) AS INTEGER

DIM SHARED sm(1000)

DIM SHARED Bina(10000)

DIM SHARED Palavra(10000)

DIM SHARED Tela1(16000)

DIM SHARED Tela2(16000)

DIM SHARED ref(20)

DIM SHARED siglido(1000)

'representaçäo das válvulas solenóides

DIM SHARED v1 AS INTEGER, v2 AS INTEGER

DIM SHARED v3 AS INTEGER, v4 AS INTEGER

DIM SHARED v5 AS INTEGER, v6 AS INTEGER

DIM SHARED v7 AS INTEGER, v8 AS INTEGER

'contantes

CONST YES $=1, \mathrm{NO}=0$

CONST HOME $=\& H 47, \mathrm{UP}=\& H 48, \mathrm{PGUP}=\& H 49, \mathrm{DOWlN}=$

\&H50

$\mathrm{CONST} \mathrm{PGDN}=\& \mathrm{H} 51, \mathrm{ENDD}=\& H 4 \mathrm{~F}, \mathrm{RIGHT}=\& H 4 \mathrm{D}, \mathrm{LEFT}=$

\&H4B 
CONST TABB $=\& H 9$, SHIFT $. \mathrm{TABB}=\& H F$, ENTER $=\& H D$

CONST PI $=3.1416$

CONST GRAFXi $=1$

' $x$ esquerdo da moldura grafico

CONST GRAFXf $=639$

'x direito da moldura grafico

CONST GRAFYi $=5$

'y superior da moldura grafico

CONST GRAFYf $=285$

'y inferior da moldura grafico

\section{DIM z AS INTEGER}

DIM valor.ini AS INTEGER

DIM direc.flag AS INTEGER

$\mathrm{DIM}$ GANHO $=4$

Bits de endereçamento para o acionamento das válvulas solenóides:

CONST v1 $=1, \mathrm{v} 2=2, \mathrm{v} 3=4, \mathrm{v} 4=8, \mathrm{v} 5=16, \mathrm{v} 6=32, \mathrm{v} 7=64, \mathrm{v} 8=$ 128

$\mathrm{vv}(1)=\mathrm{v} 1: \mathrm{vv}(2)=\mathrm{v} 2: \mathrm{vv}(3)=\mathrm{v} 3: \mathrm{vv}(4)=\mathrm{v} 4$ $\mathrm{vv}(5)=\mathrm{v} 5: \mathrm{vv}(6)=\mathrm{v} 6: \mathrm{vv}(7)=\mathrm{v} 7: \mathrm{vv}(8)=\mathrm{v} 8$

Definição dos endereçamentos da interface de controle e aquisição de dados, PCL-711S:

'Endereço da interface PCL-711S

port $\%=\& \mathrm{H} 220$

'Endereço para ativar a porta A da PCL-711S

$\mathrm{pb}=$ port $\%+13$

'Endereço para ativar a porta $B$ da PCL-711S

$\mathrm{pa}=$ port $\%+14$

'Endereço da porta de entrada do conversor analógico / digital: bits menos 'significativos 
pe $1=$ port $\%+6$

'Endereço da porta de entrada do conversor analógico / digital: bits mais significativos

pe $2=\operatorname{port} \%+7$

'Endereço da porta de entrada do conversor digital / analógico: bits menos 'significativos

$\mathrm{da} 1=\operatorname{port} \%+4$

'Endereço da porta de entrada do conversor digital / analógico: bits mais 'significativos

da $2=$ port $\%+5$

Coordenadas gráficas:

'pixel correspondente ao zero da escala na ordenada yp0 $=$ GRAFYf -5

'pixel correspondente ao máximo da escala na ordenada

ypmax $=$ GRAFYi

'sinal digital correspondente ao máximo da escala

sigrange $=1000$

'estabelece o número de pixel da ordenada

yrange $=$ ypmax - yp0

'determina o número pixel correspondentes a 1 unidade digital fat.eixo.y $=$ yrange $/$ sigrange

soa $=$ YES 'sinaliza com um bip caso uma tecla inadequada

seja precionada

TIMER ON 'ativa o contador de tempo do microcomputador

BinaryName 'marca e registro do programa

repete $=0$

$\mathrm{BASET}=115$

DO 
DO

CLS 'limpa a tela

Menu 'acessa a subrotina MENU para escolha da

função

'enquanto o MENU estiver aparecendo mostra o horário.

ON TIMER(1) GOSUB HORA

'só avança, saindo da tela de MENU, após pressionadas uma das teclas 1, 2, 3, 4, 5, 6, 7 ou F.

PressKey "1234567F", a\$

TIMER OFF 'Desativa o contador de tempo ao aer

selecionada uma das 'opçöes da sub rotina PressKey

$\mathrm{a} \$=\mathrm{UCASE} \$(\mathrm{a} \$)$

CLS

SELECT CASE a\$

CASE IS = "1" 'Leitura da linha de base (para estimar

Sinal Dig $=>0.0 \mathrm{Abs})$.

CLS

$\mathrm{m}=0$

$\mathrm{le}=2500 \quad$ 'Executa 2500 conversões de sinal analógico

para digital.

$\operatorname{LINE}(0,0)-(210,110), 4, \mathrm{BF}$

$\operatorname{LINE}(20,100)-(100,100)$

CIRCLE $(100,100), 80,-, .0001$, PI

$\mathrm{k}=10 \quad$ 'Por defeito, número de repetiçöes igual a 10.

angi $=\mathrm{PI} / 10$

ang $=0$

FOR $\mathrm{a} \%=1$ TO 10

ref( $(\mathrm{a} \%)=$ Leitura(le) 'Ativa a funçäo de conversão de sinal

analógico em 'digital.

resul $=\operatorname{ref}(\mathrm{a} \%)$

$\mathrm{m}=\mathrm{m}+\mathrm{resul} \quad$ Soma os resultados em sinais digitais.

CALL Referencia(ang, a\%, resul) 
NEXT $\mathbf{a} \%$

$\operatorname{sig} 0=\mathrm{m} / 10 \quad$ 'Faz a média dos 10 resultados.

'Cálculo do desvio padräo para o zero de absorvância.

sig0.media $=$ sig0

sig0. soma $=0$

FOR $\mathrm{a} \%=1$ TO 10

sig0.soma $=$ sig0.soma $+\left((\operatorname{sig} 0-\operatorname{ref}(a \%))^{\wedge} 2\right)$

NEXT a $\%$

sig0.sd $=\mathrm{SQR}(\operatorname{sig} 0$. soma $/(10-1))$

LOCATE 8, 1: PRINT "VALOR DETERMINADO = "; sig0.media

LOCATE 9, 1: PRINT "RSD = "; sig0.sd * 100 / sig0.media

PlotaSD

SLEEP 5

CASE IS = "2" Teste das válvulas solenóides.

CLS

SCREEN 12

'\$INCLUDE: 'C: \\figvalv.bas' Ativa o programa figvalv.bas através 'de metacomando.

TestaValvulas 'Ativa o sub programa TestaValvulas.

CASE IS = "3" 'Determina a base de tempo para o acionamento das 'válvulas solenóides, partindo da referência de tempo 'característica do computador em uso. Caso a opçäo näo 'seja selecionada tempo.flag = 0 e BASET =

115.

tempo.flag $=1$

WaitSegundos 10 'Para o cálculo da nova base de tempo,

o procedimento 'requer, por defeito, 10 segundos, aplicando a sub rotina

'WaitSegundos. 
CASE IS = "4" 'Testa o sincronizador de pulsos da

bomba peristáltica.

CLS

SCREEN 12

'\$INCLUDE: 'C: $\backslash$ dperista.bas' Ativa o programa dperista.bas por 'metacomando.

ContaRoletes 'Sub rotina para contagem de roletes da bomba 'peristáltica que passam por um ponto de referência.

CASE IS = "5" 'Avalia o sinal máximo produzido pelas

soluçöes da 'amostra e do titulante, quando

estas fluem 'continuamente pela célula de fluxo. Permite a avaliação 'do grau de dispersäo das alíquotas nas 2 tentativas

'iniciais da procura binária.

CLS

'\$INCLUDE: 'c:lqb45\mauroltestamo.bas'

sig.max.amostra = Injeta("amostra")

PRINT "Sinal maximo da amostra = ";

PRINT USING "\#\#\#\#.\#\#"; sig.max.amostra

\section{CLS}

'\$INCLUDE: 'c: \qb45\mauroltesttit.bas'

sig.max.titulante = Injeta("titulante")

PRINT "Sinal maximo do titulante = ";

PRINT USING "\#\#\#\#.\#\#"; sig.max.titulante

CASE IS = "6" Seleciona os valores das variáveis

operacionais, define 'se os sinais máximos de

cada tentativa seräo 'armazenados e executa as 2 tentativas iniciais $d a$ 'procura binária. 


$$
\begin{aligned}
& \text { opcao6 } \text { flag }=1 \\
& \text { opcao7.flag }=0 \\
& \text { CLS }
\end{aligned}
$$$$
\text { SCREEN } 12
$$

$\mathrm{DO}$

LOCATE 10,20

perg $\$=$ " Deseja Salvar os Dados "

$\mathrm{r} \$=$ ConfirmOperKey $\$(Y E S$, perg\$)

IF $\mathrm{r} \$=$ "S" THEN

save.flag $=1$

EXIT DO

ELSEIF $r \$=$ "N" THEN

save. flag $=0$

EXIT DO

END IF

LOOP

IF save.flag $=1$ THEN OpenDataFile

DO

PrintParam Imprime no monitor os valores

das variáveis 'estbalecidos por defeito.

conf.flag $=1$

perg $\$=$ " Confirma todos os dados "

$\mathrm{k} \$=$ ConfirmOperKey $\$(\mathrm{YES}$, perg\$)

CLS

IF UCASE\$(k\$) $=$ "S" THEN

EXIT DO

ELSEIF UCASE\$(k\$) = "N" THEN

CLS

InputParam Caso os valores definidos por

defeito näo sejam 'aceitos o

operador pode introduzir novos valores.

END IF 


\section{LOOP}

'Imprime no monitor de vídeo a moldura e a escala para os picos FIA.

fat.eixo. $x=($ GRAFXf - GRAFXi $) /(($ pto +1$) *$ espera $*$ replicados)

LINE (GRAFXi, GRAFYi)-(GRAFXf, GRAFYf), 8, BF

FOR $x=$ GRAFXi TO GRAFXf STEP 20

LINE (x, GRAFYf)-(x, GRAFYi), 0, ,\&H1111

NEXT

FOR $\mathrm{y}=$ GRAFYi TO GRAFYf STEP 40

LINE (GRAFXf, y)-(GRAFXi, y), 0, , \&H1111

NEXT

conta.ponto $=0 \quad$ 'Contador do número de tentativas de procura.

$\begin{array}{ll}\mathrm{ini}=0 & \text { 'Início da busca, por defeito }=0 . \\ \mathrm{fim}=100 & \text { 'Final da busca, por defeito }=100 . \\ \min =\mathrm{ini} & \text { 'Limite mínimo para a procura. } \\ \max =\mathrm{fim} & \text { 'Limite máximo para a procura. } \\ \mathrm{stepmin}=.1 & \text { 'Passo mínimo autorizado de procura. } \\ \mathrm{ptcor}=\min & \text { 'Primeiro ponto a ser testado. } \\ \operatorname{passo}=\max -\min & \text { 'Passo inicial. } \\ \operatorname{direc}=1 & \text { 'Sentido inicial de procura } \\ \text { treshold }=10000 & \text { 'Valor maior que o máximo possível de }\end{array}$

leitura, valor 'máximo de leitura $=$ 4096. Variável que

define o limiar.

DO

$$
\text { conta.ponto }=\text { conta.ponto }+1 \quad \text { Incrementa uma unidade }
$$

na contagem 'das tentativas de

procura.

LOCATE 22,1 
'Por defeito, se for a primeira tentativa de procura, a fraçäo volumétrica será 'aumentada. Caso seja a segunda tentativa em execução, para a terceira 'tentativa de procura, a fraçäo volumétrica será dimuida.

IF conta. ponto $=1$ THEN direc .flag $=1$

IF conta . ponto $=2$ THEN direc . flag $=-1$

PRINT conta.ponto; USING " \#\#\#.\#\#\#"; ptcor

vol $=$ ptcor

DoInj 'Rotina para cáculo dos intervalos de

tempo de 'acionamento das vávulas

solenóides e para executar as

'introduçöes das alíquotas.

res $=\operatorname{smax}$

'Cálculo do valor limiar para execuçäo da procura binária.

IF conta. ponto $=1 \mathrm{THEN}$ valor $. \mathrm{ini}=$ res

IF conta.ponto $=2$ THEN

IF valor.ini $<$ res THEN

treshold $=$ valor.ini $+($ res - valor.ini $) * .1$

tre.flag $=0$

ELSEIF valor.ini > res THEN

treshold $=$ res $+($ valor. ini - res $) * .1$

tre.flag $=1$

ELSE

'Caso os sinais nos dois primeiros passos sejam iguais a rotina informa ao 'operador da impossibidade do prosseguimento da procura binária. 'Requisitando do mesmo a averigüaçäo das válvulas, do comprimento de 'selecionado e das condições das interfaces.

BEEP

CLS

SCREEN 7

PRINT UCASE\$("Nao Pode Ser Realizada") 
PRINT

PRINT

PRINT "Verifique as valvulas,"

PRINT "o comprimento de onda selecionado"

PRINT "e se as interfaces estao ligadas."

DO: LOOP UNTIL INKEY\$ $>$ "'

\section{END}

END IF

END IF

LOCATE 23, 1: PRINT treshold 'Resultado digital a ser

procurado.

cor $=8$

$\operatorname{LINE}(0,350)-(210,480)$, cor, BF

Numerao 5, 370, res, cor, 20

ptold $=$ ptcor 'Guarda ponto de teste

anterior.

ptcor $=$ ptold + passo ${ }^{*}$ direc.flag 'Cálcula novo ponto de teste.

$$
\text { passo }=\text { passo } / 2 \quad \text { Diminui a } 1 / 2 \text { do passo }
$$

de procura.

LOOP UNTI conta. ponto $=2$

GET $(0,0)-(200,285)$, Tela1

CASE IS $=$ "7"

opcao7.flag $=1$

SCREEN 12

repete $=$ repete +1

IF repete $<10$ THEN

$$
\text { repete } \$=" 00 "+\mathrm{STR} \$(\text { repete })
$$

ELSEIF repete $>=10$ AND repete $<100$ THEN

$$
\text { repete } \$=" 0 "+\text { STR } \$(\text { repete })
$$

ELSE

repete $\$=$ STR $\$($ repete $)$ 
END IF

CLS

EXIT DO

CASE IS $=" F "$

END

CASE ELSE

END SELECT

LOOP

$\mathrm{DO}$

SCREEN 12

tela $=1$

LINE (GRAFXi, GRAFYi)-(GRAFXf, GRAFYf), 8, BF

FOR $x=$ GRAFXi TO GRAFXf STEP 20

LINE (x, GRAFYf)-(x, GRAFYi), 0, , \&H1111

NEXT

FOR $y=$ GRAFYi TO GRAFYf STEP 40

LINE (GRAFXf, y)-(GRAFXi, y), 0, \&H1111

NEXT

IF opcao6.flag $=1$ AND opcao7.flag $=1$ THEN

PUT $(0,0)$, Tela1, PSET Salva a impressäo dos picos FIA

e da moldura.

ELSE

END IF

DO

conta. ponto $=$ conta. ponto $+1 \quad$ 'incrementa contador

LOCATE 20, 1

PRINT conta.ponto; USING " \#\#\#.\#\#\#"; ptcor; passo * direc.flag;

vol $=$ ptcor

DoInj

res $=\operatorname{smax}$

LOCATE 28, 37: PRINT "LIMIAR => "; treshold

cor $=8$ 
$\operatorname{LINE}(0,350)-(210,480)$, cor, BF

Numerao 5, 370, res, cor, 20

IF conta.ponto $>=3 \mathrm{THEN}$

SELECT CASE res

'Determina o sentido de

procura.

CASE IS $=$ treshold

passo $=0$

BEEP

$\mathrm{g} \$=$ " Ponto Final"

$\mathrm{x} \%=40-\mathrm{LEN}(\mathrm{g} \$) / 2$

LOCATE 3, $\mathrm{x} \%$

PRINT $g \$$

CASE IS $>$ treshold

IF tre.flag $=0$ THEN

direc.flag $=-1$

ELSE

direc.flag $=1$

END IF

CASE IS $<$ treshold

IF tre.flag $=0$ THEN

direc.flag $=1$

ELSE

direc.flag $=-1$

END IF

END SELECT

END IF

ptold $=$ ptcor

'Guarda ponto de teste anterior.

ptcor $=$ ptold + passo ${ }^{*}$ direc.flag 'Cálcula novo ponto de teste .

passo $=$ passo $/ 2 \quad$ Diminui a $1 / 2$ o passo de

procura.

LOOP UNTL passo $<=$ stepmin $/ 2$

CLOSE \#1

'Fecha arquivo de dados. 
arquivo $\$=$ filename $+" . "+$ repete $\$$

Valvula 0

'Desativa todas as valvulas.

BEEP

GetAnyKey a\$

$\mathrm{xp}=0$

LOOP WHILE UCASE $\$(\mathrm{a} \$)=$ "R" 'Pressionando a tecla $\langle R>$

libera a rotina.

LOOP

END

HORA:

LOCATE 7, 43: PRINT " "; TIME\$; " "

RETURN

'Os sub programas:

SUB ArmazenaTela1

GET $(0,0)-(640,289)$, Tela1

CLS

LINE (GRAFXi, GRAFYi)-(GRAFXf, GRAFYf), 15, B

tela $=2$

END SUB

SUB BinaryName

SCREEN 8

LOCATE 2, 2

COLOR 15,9

LINE $(0,0)-(200,40), 9, \mathrm{BF}$

PRINT "BINARY SEARCH TITRATION"

LOCATE 3, 2

PRINT "v. 2, 1994"

LOCATE 4, 2 
$\operatorname{GET}(0,0)-(200,40)$, Bina

COLOR 15,15

CLS

COLOR 15,9

LOCATE 2, 2

PRINT "Enter"

GET $(0,0)-(50,20)$, Palavra

CLS

END SUB

FUNCTION ComputDesign\$ (toot)

'Aceita sómente teclas de direcionamentos UP, DOWN além de

$<$ ENTER>.

Se toot $=1$ (YES), soa o beep se a tecla pressionada for inadequada.

\section{SCREEN 9}

WINDOW $(0,0)-(100,100)$

$\operatorname{LINE}(10,10)-(40,90), 15, \mathrm{~B}$

$\operatorname{LINE}(15,75)-(35,85), 15, \mathrm{~B}$

LINE $(15,50)-(30,55), 15$, B

'Círculo do drive $c$.

CIRCLE $(35,40), 1$

'Círculo do drive $b$.

CIRCLE $(33,51), .5,,,, .5$

'Círculo do drive a.

CIRCLE $(18,83), .5,,,, .5$

$\mathbf{w}=1$

LOCATE 5, 20: PRINT " A "

LOCATE 11, 20: PRINT " B "

LOCATE 16, 20: PRINT " C"

DO

keycode $=0$ 
DO

$$
\mathrm{k} \$=\mathrm{INKEY} \$
$$

LOOP UNTIL $\mathrm{k} \$>^{\prime \prime \prime}$

IF LEN $(\mathrm{k} \$)=2$ THEN

keycode $=\operatorname{ASC}(\operatorname{RIGHT} \$(\mathrm{k} \$, 1))$

ELSE

keycode $=\operatorname{ASC}(\mathrm{k} \$)$

END IF

SELECT CASE keycode

CASE UP

$\mathrm{w}=\mathrm{w}-1$

IF $\mathrm{w}<1$ THEN $\mathrm{w}=3$

'Círculo do drive $c$.

CIRCLE $(35,40), 1$

IF $\mathrm{w} \diamond 3$ THEN DRAW "p0,15"

IF $\mathbf{w}=3$ THEN DRAW "p14,15"

'Círculo do drive $b$.

CIRCLE $(33,51), .5,,,, .5$

IF $\mathrm{w}<2$ THEN DRAW "p0,15"

IF $\mathrm{w}=2$ THEN DRAW "p14,15"

'Círculo do drive a.

CIRCLE $(18,83), .5,,,, .5$

IF $\mathrm{w}>1$ THEN DRAW "p0,15"

IF $w=1$ THEN DRAW "p14,15"

CASE DOWN

$w=w+1$

IF $w>3$ THEN $w=1$

'Círculo do drive $c$.

CIRCLE $(35,40), 1$

IF $w>3$ THEN DRAW "p0,15"

IF $w=3$ THEN DRAW "p14,15"

'Círculo do drive $b$. 
CIRCLE $(33,51), .5,,,, .5$

IF $\mathrm{w} \diamond 2$ THEN DRAW "p0,15"

IF $\mathrm{w}=2$ THEN DRAW "p14,15"

'Círculo do drive a.

CIRCLE $(18,83), .5,,,, .5$

IF $\mathrm{w} \diamond 1$ THEN DRAW "p0,15"

IF $w=1$ THEN DRAW "p14,15"

CASE ENTER

EXIT DO

CASE ELSE

IF toot $=$ YES THEN

SOUND 2580, 2

SOUND 2510, 3

SOUND 2460, 4

END IF

END SELECT

LOOP

IF $\mathrm{w}=1$ THEN ComputDesign $\$=$ "A"

IF $w=2$ THEN ComputDesign $\$=$ "B"

IF $\mathrm{w}=3$ THEN ComputDesign $\$=$ " $\mathrm{C} "$

END FUNCTION

FUNCTION ConfirmOperKey\$ (toot, c\$)

'Aceita somente direcionamentos do prompt e $<$ ENTER $>$.

'Se toot $=1$ (YES), soa o beep quando a tecla pressionada for

inadequada.

SCREEN 12

LINE $(258,423)-(286,453), 7$, BF

LINE $(290,423)-(318,453), 7, \mathrm{BF}$

LOCATE 28, 38: PRINT CHR\$(17); CHR\$(205)

LINE $(322,423)-(350,453), 7, \mathrm{BF}$

LOCATE 28, 42: PRINT CHR\$(205); CHR\$(16) 
$\operatorname{LINE}(354,423)-(382,453), 7, \mathrm{BF}$

LINE $(420,423)-(470,480), 7, \mathrm{BF}$

$\operatorname{LINE}(390,510)-(420,450), 7, \mathrm{BF}$

PUT (391, 453), Palavra, OR

LINE (467, 350)-(573, 400), 4, BF

$\operatorname{LINE}(67,350)-(173,400), 5, \mathrm{BF}$

LOCATE 24, 62: PRINT" SIM "

LOCATE 24, 12: PRINT " NAO "

LINE $(0,282)-(640,310), 15, \mathrm{BF}$

$\mathrm{x} \%=40-\mathrm{LEN}(\mathrm{c} \$) / 2$

LOCATE 19, $x \%$ : PRINT UCASE\$(c\$)

DO

keycode $=0$

DO

$\mathrm{k} \$=\mathrm{INKEY} \$$

LOOP UNTIL $\mathrm{k} \$>$ "'"

IF LEN(k\$) $=2$ THEN

keycode $=$ ASC $(\operatorname{RIGHT} \$(\mathrm{k} \$, 1))$

ELSE

keycode $=\mathrm{ASC}(\mathrm{k} \$)$

END IF

SELECT CASE keycode

CASE RIGHT

$\mathrm{k}=50$

FOR $\mathrm{x}=1$ TO 79

LOCATE 22, $x$ : PRINT " "

LOCATE 26, x: PRINT " "

NEXT

FOR $\mathrm{x}=9$ TO 22

LOCATE 26, $x+k$ : PRINT CHR $\$(196)$

LOCATE 22, $\mathrm{x}+\mathrm{k}$ : PRINT CHR\$(196)

NEXT 
ConfirmOperKey $\$=$ "S"

CASE LEFT

$\mathrm{k}=0$

FOR $x=1$ TO 79

LOCATE 22, $\mathrm{x}$ : PRINT " "

LOCATE 26, $\mathrm{x}$ : PRINT " "

NEXT

FOR $x=9$ TO 22

LOCATE $26, x+k$ : PRINT CHR\$(196)

LOCATE 22, $x+k$ : PRINT CHR $\$(196)$

NEXT

ConfirmOperKey $\$=" \mathrm{~N} "$

CASE ENTER

EXIT FUNCTION

CASE ELSE

IF toot $=$ YES THEN

SOLND 1580, 2

SOUND 1320, 4

SOUND 1650, 2

END IF

END SELECT

LOOP

END FUNCTION

SUB ContaRoletes

LOCATE 2, 2: PRINT "Teste de detecçäo de roletes (qualquer tecla

para sair)"

$\mathrm{CONT}=0$

DO

$\mathrm{t}=\mathrm{TIMER}$

DO

olda $=\mathbf{a}$ 
$\mathrm{a}=\mathrm{INP}(\mathrm{pe} 1)$

LOOP UNTL olda $-\mathrm{a}=2$

PRINT TIMER - $\mathrm{t}$

LOOP UNTIL INKEYS $>$ "'"

END SUB

FUNCTION CursorAdvanced (toot, $\mathrm{a} \%, \mathrm{c} \$$ )

'Aceita somente a tecla UP, DOWN e ENTER.

'Se toot $=1$ (YES), soa o beep quando a tecla pressionada for

inadequada.

DO

keycode $=0$

'Aguarda uma tecla ser pressionada.

DO

$$
\mathrm{k} \$=\mathrm{INKEY} \$
$$

LOOP UNTL $\mathrm{k} \$<" "$

'Faz o codigo da tecla ser igual ao codigo ASCII relativo a tecla.

IF LEN(k\$) $=2$ THEN

keycode $=$ ASC $(\operatorname{RIGHT} \$(\mathrm{k} \$, 1))$

ELSE

keycode $=\operatorname{ASC}(\mathrm{k} \$)$

END IF

'Sinaliza quando a tecla for inapropriada.

'Constantes para os códigos devem ser definidas no programa.

SELECT CASE keycode

CASE UP

$\mathrm{a} \%=\mathrm{a} \%+1$

IF $\mathrm{c} \$=$ "Diametro" AND a $\%>2$ THEN a $\%=0$

IF (c\$ = "plugT" OR c $\$=$ "npul") AND a $\%>3$ THEN a $\%=0$

CASE DOWN

$\mathrm{a} \%=\mathrm{a} \%-1$

IF $\mathrm{c} \$=$ "Diametro" AND a $\%<0$ THEN a $\%=2$ 
IF $(\mathrm{c} \$=$ "plugT" OR $\mathrm{c} \$=$ "npul") AND a $\%<0$ THEN a $\%=3$

CASE ENTER

EXIT DO

CASE ELSE

IF toot $=$ YES THEN BEEP

END SELECT

IF $\mathbf{c} \$=$ "Diametro" THEN

IF $\mathbf{a} \%=0$ THEN

$\mathrm{q}=.5$

ELSEIF $a \%=1$ THEN

$$
\mathrm{q}=.8
$$

ELSEIF $\mathrm{a} \%=2$ THEN

$$
\mathrm{q}=1
$$

END IF

ELSEIF c $\$=$ "plugT" THEN

IF $\mathrm{a} \%=0$ THE]N

$$
\mathrm{q}=1.28
$$

ELSEIF $\mathrm{a} \%=1$ THEN

$$
\mathrm{q}=2.56
$$

ELSEIF $\mathrm{a} \%=2$ THEN

$$
\mathrm{q}=5.12
$$

ELSEIF $\mathrm{a} \%=3$ THEN

$$
\mathrm{q}=10.24
$$

END IF

ELSEIF c $\$=$ "npul" THEN

IF $\mathbf{a} \%=0$ THEN

$$
\mathrm{q}=1
$$

ELSEIF $a \%=1$ THEN

$$
\mathrm{q}=2
$$

ELSEIF $\mathrm{a} \%=2$ THEN

$$
\mathrm{q}=5
$$

ELSEIF $\mathrm{a} \%=3$ THEN 


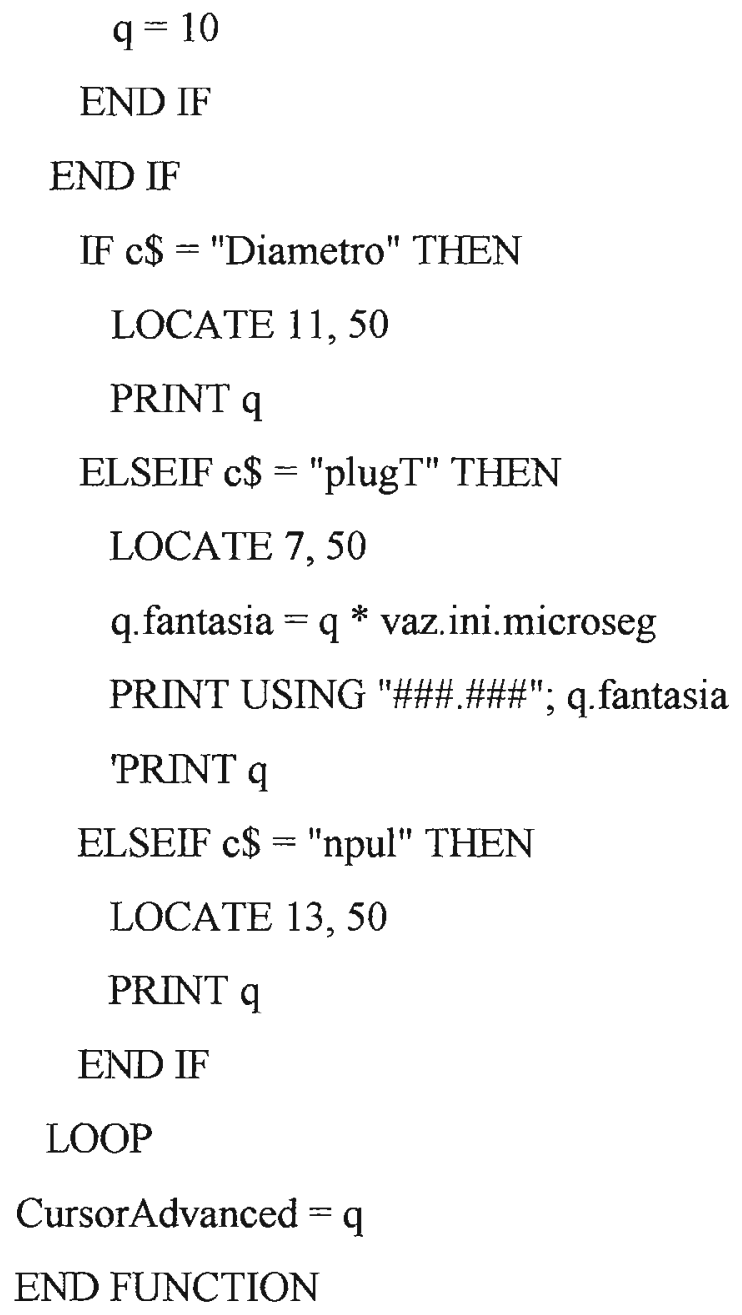


LOCATE 10, 20: PRINT " B "

LOCATE 15, 20: PRINT " C "

DO

keycode $=0$

DO

$\mathrm{k} \$=\mathrm{INKEY} \$$

LOOP UNTI $\mathrm{k} \$<$ "'

IF LEN $(\mathrm{k} \$)=2$ THEN

keycode $=$ ASC $(\operatorname{RIGHT} \$(\mathbf{k} \$, 1))$

ELSE

keycode $=\operatorname{ASC}(\mathrm{k} \$)$

END IF

SELECT CASE keycode

CASE UP

$\mathrm{B}=\mathrm{B}-5$

IF $\mathrm{B}<4$ THEN $\mathrm{B}=15$

FOR $x=15$ TO 27

FOR $\mathrm{a}=5$ TO 15 STEP 5

LOCATE $a, x$

PRINT " "

NEXT a

NEXT $x$

FOR $x=15$ TO 27

LOCATE $\mathrm{B}, \mathrm{x}$

PRINT CHR\$(219)

NEXT

LOCATE 5, 20

PRINT " A "

LOCATE 10, 20

PRINT " B "

LOCATE 15,20

PRINT " C " 


\section{CASE DOWN}

$\mathrm{B}=\mathrm{B}+5$

IF $\mathrm{B}>16$ THEN B $=5$

FOR $x=15$ TO 27

FOR $\mathrm{a}=5$ TO 15 STEP 5

LOCATE $\mathbf{a}, \mathrm{x}$

PRINT " "

NEXT a

NEXT $\mathrm{x}$

FOR $x=15$ TO 27

LOCATE $\mathrm{B}, \mathrm{x}$

PRINT CHR\$(219)

NEXT

LOCATE 5, 20

PRINT " A "

LOCATE 10, 20

PRINT " B "

LOCATE 15,20

PRINT " C "

CASE EN'TER

EXIT DO

CASE ELSE

IF toot $=$ YES THEN

SOUND 2580, 2

SOUND 2510, 3

SOUND 2460, 4

END IF

END SELECT

LOOP

IF $\mathrm{B}=5$ THEN CursorDriveSelect $\$=$ "A"

IF B $=10$ THEN CursorDriveSelect $\$=$ "B"

IF $\mathrm{B}=15$ THEN CursorDriveSelect $\$=$ " $\mathrm{C} "$ 


\section{END FUNCTION}

FUNCTION CursorOperParamKey (toot, a\%, B, c\$)

'Aceita somente direcionamentos do cursos, UP e DOWN, além de $<$ ENTER> .

'Se toot $=1$ (YES), soa o beep quando a tecla pressionada for inadequada.

$\mathrm{z}=\mathrm{a} \%$

DO

keycode $=0$

'Espera uma tecla ser pressionada.

DO

$\mathrm{k} \$=\mathrm{INKEY} \$$

LOOP UNTIL $\mathrm{k} \$ \diamond " "$

'Faz o código da tecla ser igual ao codigo ASCII relativo a tecla.

IF LEN $(\mathrm{k} \$)=2$ THEN

keycode $=$ ASC $(\operatorname{RIGHT} \$(\mathrm{k} \$, 1))$

ELSE

keycode $=\operatorname{ASC}(\mathrm{k} \$)$

END IF

'Sona o BEEP quando a tecla for inapropriada.

'As constantes para o codigos devem ser definidos no programa acionado.

SELECT CASE keycode

CASE UP

$\mathrm{a} \%=\mathrm{a} \%+1$

CASE DOWN

$\mathrm{a} \%=\mathrm{a} \%-1$

CASE ENTER

EXIT DO

CASE ELSE 
IF toot $=$ YES THEN BEEP

END SELECT

IF $\mathrm{c} \$=$ "Bomba Peristaltica" THEN

IF $a \%<0$ THEN

LOCATE 23, 15: PRINT "A "; c\$; " Nao Pode Entrar em Funcao."

ELSE

LOCATE 23, 15: PRINT TAB(79); "'"

END IF

ELSEIF c $\$=$ "plugT" THEN

IF $\mathrm{a} \%<=0$ OR $\mathrm{a} \%>=16000 \mathrm{THEN}$

LOCATE 23, 15: PRINT "O "; c\$; " Nao Pode Ser Preparado."

ELSE

LOCATE 23, 15: PRINT TAB(79); "'

END IF

ELSEIF c $\$=$ "espera" THEN

IF $\mathbf{a} \%<=0$ THEN

LOCATE 23, 15: PRINT "A string tem que passar pelo

percurso analitico."

ELSE

LOCATE 23, 15: PRINT TAB(79); "'

END IF

ELSEIF $\mathrm{c} \$=$ "pto" THEN

IF $\mathrm{a} \%<0$ OR $\mathrm{a} \%>13$ THEN

LOCATE 23, 15: PRINT "Número de tentativas nao

aconselhável."

ELSE

LOCATE 23, 15: PRINT TAB(79); "'"

END IF

ELSEIF c $\$=$ "npul" THEN

IF $\mathbf{a} \%<0$ OR $\mathbf{a} \%>20$ THEN 
LOCATE 23, 15: PRINT "Número de pulsos nao

aconselhável."

\section{ELSE}

LOCATE 23, 15: PRINT TAB(79); "'"

END IF

ELSEIF $\mathrm{c} \$=$ "le" THEN

IF $\mathrm{a} \%<2$ THEN

LOCATE 23, 15: PRINT "Número de leituras acarreta imprecisao."

ELSE

LOCATE 23, 15: PRINT TAB(79); "'"

END IF

ELSEIF c $\$=$ "replicados" THEN

IF $a \%<=0$ OR $a \%>11$ THEN

LOCATE 23, 15: PRINT "Nao Deve Ser Realizado."

ELSE

LOCATE 23, 15: PRINT TAB(79); "'

END IF

END IF

$\mathrm{q}=\mathrm{a} \% * \mathrm{~B}$

IF cS = "plugT" THEN

LOCATE 7, 50: PRINT q

ELSEIF $\mathrm{c} \$=$ "Bomba Peristaltica" THEN

$$
\mathrm{zq} \%=\mathrm{q} * 100
$$

$\mathrm{q}=\mathrm{zq} \% / 100$

LOCATE 5, 50: PRINT USING "\#\#.\#\#"; q

ELSEIF c $\$=$ "espera" THEN

LOCATE 9, 50: PRINT q

ELSEIF c $\$=$ "pto" THEN

LOCATE 11, 50: PRINT q

ELSEIF $\mathbf{c} \$=$ "npul" THEN

LOCATE 13, 50: PRINT q 
ELSEIF c $\$=$ "le" THEN

LOCATE 15, 50: PRINT q

ELSEIF c\$ = "replicados" THEN

LOCATE 17, 50: PRINT q

END IF

LOOP

CursorOperParamKey $=\mathrm{q}$

END FUNCTION

SUB DoInj

SCREEN 12

DIM n AS INTEGER

DIM s AS INTEGER

DIM tc AS INTEGER

plugA $=(100-$ vol $) *($ plugT $/ 100) /$ npul

plugB $=($ plugT - npul * plugA $) /$ npul

IF opcao7,flag $=1$ THEN

Relatorio

LOCATE 22, 1

PRINT plugT; " "; plugA; " "; plugB; " ";

ELSE

END IF

IF save.flag $=1$ THEN PRINT \#1, vol; 'Transfere dados para o arquivo.

FOR conta.rep $=1$ TO replicados

IF opcao7.flag = 1 THEN

PRINT "Rep:"; conta.rep; "/"; replicados

END IF

WaitRoleteUp 1 'espera que o rolete suba para comecar a 'introducäo do trem de plugs

' injeta trem de npul plugs de reagente e amostra 
'o tempo de cada plug , controlado por $t$ t\% e td\%

$$
\text { , }
$$

FOR $\mathrm{n}=1$ TO npul

Valvula $v 1+\mathrm{v} 3$

'Aciona válvulas VI e V3.

WaitTempo plugA

'Espera tt\% unidades de tempo.

Valvula v2 + v3

'Aciona válvulas V2 e V3.

WaitTempo plugB

'Espera td\% unidades de tempo.

\section{NEXT $n$}

Valvula 0

'Desativa todas as válvulas.

$\operatorname{smax}=0$

FOR tc $=1$ TO espera

signal.leit $=$ Leitura $($ le $)$

sig = signal.leit

signal.leit $=$ signal.leit - sig0. media

'Sinal digital

adquirido.

IF signal.leit $>$ smax THEN smax $=$ signal.leit

PlotaSinal (tc)

IF tc = espera THEN sig0. media $=$ sig

NEXT tc

trat $=$ trat + smax

$\operatorname{sm}($ conta.rep $)=\operatorname{smax}$

IF save.flag = 1 THEN PRINT \#1, sm(conta.rep);

NEXT conta.rep

rat $=$ trat $/$ replicados

IF save.flag = 1 THEN PRINT \#1, "'

END SUB

FUNCTION GetIntegerPositive (toot)

'marca e salva a posicao atual do cursor.

xcursor $=\operatorname{POS}(0)$

ycursor $=\mathrm{CSRLIN}$ 
'inicia uma palavra vazia para colecionar os caracteres de entrada.

num $\$=" '$

DO

$\mathrm{DO}$

$\mathrm{k} \$=\mathrm{INKEY} \$$

LOOP UNTIL $\mathrm{k} \$>^{\prime \prime \prime}$

'O bloco IF segue os seguintes preceitos:

' (1) Aceita qualquer digito.

'(2) De outro modo, soa o beep caso toot seja $=1$.

IF ASC(k\$) = ENTER THEN

PRINT

EXIT DO

ELSEIF $($ ASC $(\mathrm{k} \$)>47$ AND ASC $(\mathrm{k} \$)<58)$ THEN

num $\$=$ num $\$+\mathrm{k} \$$

ELSE

IF toot $=$ YES THEN BEEP

END IF

'Retorna o cursor a posicao original.

'Printa o caracter que foi introduzido.

LOCATE ycursor, xcursor

PRINT num\$,

LOOP

'Converte a palavra em um número inteiro.

GetIntegerPositive $=$ VAL(num\$)

END FUNCTION

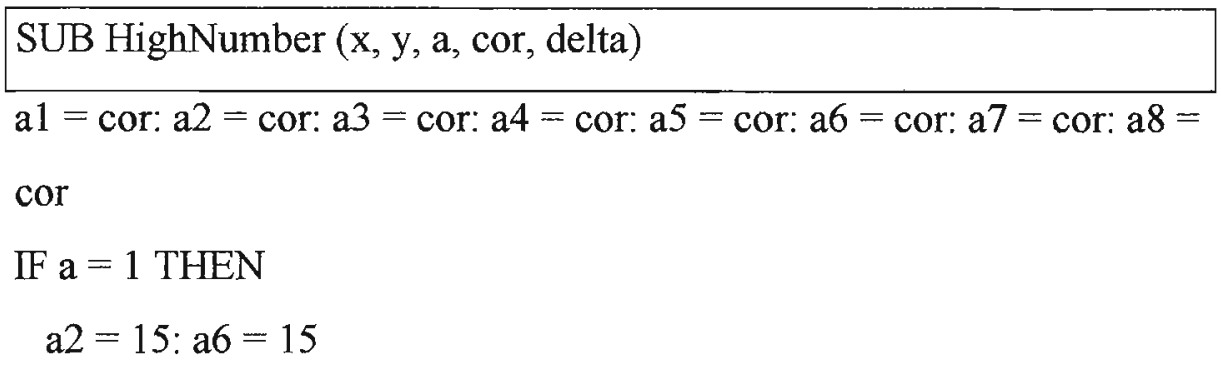

ELSEIF $\mathrm{a}=2$ THEN 


$$
\mathrm{a} 1=15: \mathrm{a} 2=15: \mathrm{a} 3=15: \mathrm{a} 8=15: \mathrm{a} 7=15
$$

ELSEIF $\mathrm{a}=3$ THEN

$$
\mathrm{a} 1=15: \mathrm{a} 2=15: \mathrm{a} 3=15: \mathrm{a} 6=15: \mathrm{a} 7=15
$$

ELSEIF $\mathrm{a}=4$ THEN

$$
\mathrm{a} 2=15: \mathrm{a} 4=15: \mathrm{a} 3=15: \mathrm{a} 6=15
$$

ELSEIF $\mathrm{a}=5$ THEN

$$
a 1=15: a 4=15: a 3=15: a 6=15: a 7=15
$$

ELSEIF $a=6$ THEN

$$
\mathrm{a} 4=15: \mathrm{a} 3=15: \mathrm{a} 6=15: \mathrm{a} 7=15: \mathrm{a} 8=15
$$

ELSEIF $\mathbf{a}=7$ THEN

$$
\mathrm{a} 1=15: \mathrm{a} 2=15: \mathrm{a} 6=15
$$

ELSEIF a $=8$ THEN

$$
\mathrm{a} 1=15: \mathrm{a} 2=15: \mathrm{a} 3=15: \mathrm{a} 4=15: \mathrm{a} 6=15: \mathrm{a} 7=15: \mathrm{a} 8=15
$$

ELSEIF $a=9$ THEN

$$
\mathrm{a} 1=15: \mathrm{a} 2=15: \mathrm{a} 3=15: \mathrm{a} 4=15: \mathrm{a} 6=15
$$

ELSEIF $a=0$ THEN

$$
\mathrm{a} 1=15: \mathrm{a} 2=15: \mathrm{a} 4=15: \mathrm{a} 6=15: \mathrm{a} 7=15: \mathrm{a} 8=15
$$

END IF

LINE (zero. $x+x+$ delta, zero.y)-STEP(delta, 0), a1

LINE STEP(0,0)-STEP(-delta / 2, delta), a2

LINE STEP(0, 0)-STEP(-delta, 0), a3

LINE STEP(0,0)-STEP(delta / 2, -delta), a4

LINE (zero. $x+x+$ delta, zero.y + delta)-STEP(delta, 0), a3

LINE STEP(0, 0)-STEP(-delta / 2, delta), a6

LINE STEP(0, 0)-STEP(-delta, 0), a7

LINE STEP(0, 0)-STEP(delta / 2, -delta), a8

END SUB

FUNCTION Injeta (c\$)

DIM proc(50) AS SINGLE

DIM aciona AS INTEGER

IF LCASE\$(c\$) = "amostra" THEN

$$
\text { aciona }=\mathrm{v} 2+\mathrm{v} 3
$$


ELSEIF LCASE $\$(c \$)=$ "titulante" THEN

aciona $=\mathrm{v} 1+\mathrm{v} 3$

END IF

Valvula aciona

SLEEP 5

sig.proc. $\max =-10000$

sig. proc. $\min =-10000$

conta $=0$

soma. proc $=0$

DO

sig. $1=$ Leitura $(500)-$ sig0.media

IF sig. $1>$ sig.proc.max THEN

sig. proc. $\max =\operatorname{sig} .1+(\operatorname{sig} .1 * .01)$

sig. proc. $\min =\operatorname{sig} .1-(\operatorname{sig} .1 * .01)$

soma. proc $=0$

ELSEIF sig. $1<$ sig.proc.min THEN

conta $=0$

soma.proc $=0$

ELSEIF sig. $1>=$ sig.proc.min AND sig. $1<=$ sig.proc.max THEN

conta $=$ conta +1

proc $($ conta $)=$ sig.proc

IF conta $=5$ THEN

soma. $\operatorname{proc}=$ soma. $\operatorname{proc}+$ proc $($ conta $)$

Valvula 0

EXIT DO

END IF

END IF

LOOP

DO

volta $=$ Leitura $(500)-$ sig0.media

volta.max $=\operatorname{sig} 0$. media $+\operatorname{sig} 0$. media $* .01$

volta $. \min =$ sig0.media - sig0. media $* .01$ 
IF volta. $\min >=\operatorname{sig} 0$. media $A N D$ volta. $\max <=\operatorname{sig} 0$. media THEN

EXIT DO

END IF

LOOP

IF LCASE\$(c\$) = "amostra" THEN

sig0.amostra $=$ soma $\cdot$ proc $/ 5$

ELSEIF LCASE\$(c\$) = "titulante" THEN

sig0.titulante $=$ soma. proc $/ 5$

END IF

Injeta $=$ soma. proc $/ 5$

END FUNCTION

\section{SUB InputParam}

CLS

LINE $(258,423)-(286,453), 7, \mathrm{BF}$

LOCATE 28, 34: PRINT CHR\$(25)

LINE $(290,423)-(318,453), 7, \mathrm{BF}$

LINE $(322,423)-(350,453), 7, \mathrm{BF}$

LINE $(354,423)-(382,453), 7, \mathrm{BF}$

LOCATE 28, 46: PRINT CHR\$(24)

'moldura

$\operatorname{LINE}(30,40)-(490,50), 12, \mathrm{BF}$

$\operatorname{LINE}(480,230)-(490,50), 12, \mathrm{BF}$

FOR $x=2$ TO 59

LOCATE $4, x$

PRINT CHR\$(196)

LOCATE $18, \mathrm{x}$

PRINT CHR\$(196)

NEXT

FOR $x=5$ TO 17

LOCATE $\times, 1$

PRINT CHR\$(179) 
LOCATE $\mathrm{x}, 47$

PRINT CHR\$(179)

LOCATE $x, 60$

PRINT CHR\$(179)

NEXT

LOCATE 4, 1: PRINT CHR\$(218)

LOCATE 18, 1: PRINT CHR\$(192)

LOCATE 4, 60: PRINT CHR\$(191)

LOCATE 18, 60: PRINT CHR\$(217)

LOCATE 4, 47: PRINT CHR\$(194)

LOCATE 18, 47: PRINT CHR\$(193)

LOCATE 5, 5: PRINT "VAZAO"

LOCATE 5, 50: PRINT vaz.ini

LOCATE 7, 5: PRINT "VOLUME DA STRING"

LOCATE 7, 50: PRINT USING "\#\#\#.\#\#"; vol.stringT

LOCATE 9, 5: PRINT "TEMPO DE ESPERA PARA LEITURA DO

SINAL"

LOCATE 9, 50: PRINT espera

LOCATE 11, 5: PRINT "NUMERO DE PONTOS"

LOCATE 11, 50: PRINT pto

LOCATE 13, 5: PRINT "NUMERO DE PULSOS"

LOCATE 13, 50: PRINT npul

LOCATE 15, 5: PRINT "NUMERO DE LEITURAS"

LOCATE 15, 50: PRINT le

LOCATE 17, 5: PRINT "NUMERO DE REPLICADOS"

LOCATE 17, 50: PRINT replicados

FOR $x=5$ TO 17 STEP 2

LOCATE $x, 49:$ PRINT " "

NEXT

LOCATE 5, 49: PRINT CHR\$(178)

vaz.ini $=$ CursorOperParamKey(YES, 277, .01, "Bomba Peristaltica") 
vaz.ini.microseg $=$ vaz.ini $* 1000 / 60$

FOR $x=5$ TO 17 STEP 2

LOCATE $x, 49$ : PRINT " "

NEXT

LOCATE 7, 49: PRINT CHR\$(178)

plugT $=$ CursorAdvanced(YES, 2, "plugT")

plug $\mathrm{T}=$ plug $\mathrm{T} * 1000$

FOR $x=5$ TO 17 STEP 2

LOCATE $x, 49:$ PRINT " "

NEXT

LOCATE 9, 49: PRINT CHR\$(178)

espera $=$ CursorOperParamKey(YES, 10, 10, "espera")

FOR $\mathrm{x}=5$ TO 17 STEP 2

LOCATE x, 49: PRINT " "

NEXT

LOCATE 11, 49: PRINT CHR\$(178)

pto $=$ CursorOperParamKey(YES, 11, 1, "pto")

FOR $\mathrm{x}=5$ TO 17 STEP 2

LOCATE $x, 49:$ PRINT " "

NEXT

LOCATE 13, 49: PRINT CHR\$(178)

npul = CursorAdvanced(YES, 2, "npul")

FOR $\mathrm{x}=5$ TO 17 STEP 2

LOCATE $x, 49:$ PRINT " "

NEXT

LOCATE 15, 49: PRINT CHR\$(178)

le = CursorOperParamKey(YES, 5, 100, "le")

FOR $x=5$ TO 17 STEP 2

LOCATE $x, 49:$ PRINT " "

NEXT

LOCATE 17, 49: PRINT CHR\$(178)

replicados $=$ CursorOperParamKey(YES, 1, 1, "replicados") 
'Valores por defeito.

IF vaz.ini $=0$ THEN vaz.ini $=2.77$

IF plugT $=0$ THEN plugT $=5.12$

IF espera $=0$ THEN espera $=100$

IF pto $=0$ THEN pto $=11$

IF npul $=0$ THEN npul $=5$

IF le $=0$ THEN le $=500$

IF replicados $=0$ THEN replicados $=1$

END SUB

FUNCTION Leitura (n AS INTEGER)

'sub rotina de leitura do sinal no sistema $T \& R$

' adquire o sinal analógico após conversäo.

' Faz n leituras e guarda a média em rat.

DIM z AS INTEGER

wat $=0$

OUT port $\%+10,0$

OUT port $\%+9$, GANHO

FOR $\mathrm{z}=1$ TO $\mathrm{n}$

OUT port $\%+12,1$

$\mathrm{dat}=\mathrm{INP}(\mathrm{da} 1)$

$\mathrm{sat}=(\mathrm{INP}(\mathrm{da} 2)$ AND \&HF $)$

cat $=$ sat $* 256+$ dat

wat $=$ wat + cat

NEXT z

Leitura $=$ wat $/ \mathrm{n}$

END FUNCTION

\section{SUB Menu}

SCREEN 12

CLS

$\operatorname{LINE}(0,0)-(640,480), 9, \mathrm{BF}$ 


\section{'moldura}

FOR $\mathrm{x}=14$ TO 54

LOCATE 9, $x$ : PRINT CHR\$(205)

LOCATE 27, $x$ : PRINT CHR\$(205)

NEXT

FOR $x=10$ TO 26

LOCATE $x, 13$ : PRINT CHR $\$(186)$

LOCATE $x, 55$ : PRINT CHR\$(186)

NEXT

LOCATE 9, 13: PRINT CHR\$(201)

LOCATE 27, 13: PRINT CHR\$(200)

LOCATE 9, 55: PRINT CHR\$(187)

LOCATE 27, 55: PRINT CHR\$(188)

$\mathrm{dd}=\operatorname{MTD} \$(\mathrm{DATE} \$, 4,2)+$ "." + LEFT\$(DATE\$, 2) + "." +

RIGHT\$(DATE\$, 2)

LOCATE 7, 15: PRINT " "; dd; " "

LOCATE 7, 43: PRINT " "; TIME\$; " "

COLOR 7

FOR $\mathrm{c}=15$ TO 24

LOCATE 6, c

PRINT CHR\$(196)

NEXT

FOR $\mathrm{c}=43$ TO 52

LOCATE 6, c

PRINT CHR\$(196)

NEXT

LOCATE 6, 18

PRINT "DATA"

LOCATE 6, 46

PRINT "HORA"

COLOR 15 
LOCATE 11,15

PRINT " Referencia "

LOCATE 11,50

PRINT " 1 "

LOCATE 13,15

PRINT " Testa as Válvulas "

LOCATE 13, 50

PRINT " 2 "

LOCATE 15,15

PRINT " Contagem de Segundos "

LOCATE 15, 50

PRINT " 3 "

LOCATE 17,15

PRINT " Testa Roletes "

LOCATE 17,50

PRINT " 4 "

LOCATE 19, 15

PRINT " Referencias Reagentes "

LOCATE 19, 50

PRINT " 5 "

LOCATE 21,15

PRINT " Inicializa a Titulaçäo "

LOCATE 21, 50

PRINT " 6 "

LOCATE 23, 15

PRINT " Titulaçäo "

LOCATE 23, 50

PRINT " 7 "

LOCATE 25, 15

PRINT " Encerra a Execuçäo "

LOCATE 25, 50

PRINT " F " 


\section{COLOR 15}

PUT $(165,15)$, Bina, OR

PAINT $(300,300), 1,15$

END SUB

SUB Numerao (zero.x, zero.y, numero, cor, delta)

SCREEN 12

$\mathrm{a} 1=$ cor: $\mathrm{a} 2=$ cor: $\mathrm{a} 3=$ cor: $\mathrm{a} 4=$ cor

$a 5=$ cor: $a 6=$ cor: $a 7=$ cor: $a 8=$ cor

FOR $\mathrm{x}=0$ TO $3 *($ delta +10$)$ STEP delta +10

LINE (zero. $x+x+$ delta, zero.y)-STEP(delta, 0), a1

LINE STEP $(0,0)-\operatorname{STEP}(-$ delta $/ 2$, delta), a2

LINE STEP(0, 0)-STEP(-delta, 0), a3

LINE STEP(0,0)-STEP(delta / 2, -delta), a4

LINE (zero. $x+x+$ delta, zero. $y+$ delta)-STEP(delta, 0$), a 3$

LINE STEP(0,0)-STEP(-delta / 2, delta), a6

LINE STEP(0, 0)-STEP(-delta, 0), a7

LINE STEP $(0,0)$-STEP(delta / 2, -delta), a8

\section{NEXT}

$1=$ numero

$\mathrm{a}=1 \mathrm{MOD} 10$

$\mathrm{x}=150+$ zero. $\mathrm{x}$

HighNumber $x$, zero.y, a, cor, delta

$1=$ numero $\backslash 10$

$a=1$ MOD 10

$\mathrm{x}=100+$ zero. $x$

HighNumber $x$, zero.y, a, cor, delta

$1=$ numero $\backslash 100$

$a=1 \mathrm{MOD} 10$

$x=50+$ zero. $x$

HighNumber $\mathrm{x}$, zero.y, a, cor, delta

$1=$ numero $\backslash 1000$ 
$a=1$ MOD 10

$\mathrm{x}=0+$ zero. $\mathrm{x}$

HighNumber $\mathrm{x}$, zero.y, a, cor, delta

END SUB

SUB OpenDataFile

'Cria nome de arquivo baseado na data e hora em que foi inicializada

$a$

'operacao. O nome tem a seguinte estrutura: MMDDhhmm.dat

'os dois primeiros caracteres correspondem ao mês, os dois seguintes

' ao dia, os dois seguintes 'a hora e os restantes dois aos minutos.

'A estensäo é (por defeito) ".DAT"

$\mathrm{d} \$=$ DATE $\$$

$\mathbf{t} \$=$ TIME\$

$\mathrm{dd}=\operatorname{LEFT} \$(\mathrm{~d} \$, 2)$

$\mathrm{dd}=\mathrm{dd}+\operatorname{MID} \$(\mathrm{~d} \$, 4,2)$

BIELBOTECA

INSTTUTO DE QUIMICA

$\mathrm{tt} \$=\operatorname{LEFT} \$(\mathrm{t} \$, 2)$

$\mathrm{tt} \$=\mathrm{tt} \$+\operatorname{MID} \$(t \$, 4,2)$

filename $=\mathrm{dd}+\mathrm{tt} \$+$ ".dat"

perg $\$=$ "Deseja Salvar o Arquivo no Driver $<\mathrm{A}>,<\mathrm{B}>$ ou $<\mathrm{C}>$ "

PRINT UCASE\$(perg\$)

$\mathrm{r} \$=$ ComputDesign $\$(Y E S)$

SCREEN 12

CLS

IF $\mathrm{r} \$=$ "C" THEN

path $=" \mathrm{C}: \backslash$ "

ELSEIF $r \$=$ "A" THEN

PRINT UCASE\$("Insira o disquete no drive A e tecle <ENTER>

para continuar")

$\operatorname{LINE}(0,280)-(640,310), 15, \mathrm{BF}$

LINE $(310,423)-(360,480), 7, \mathrm{BF}$

LINE $(280,510)-(310,450), 7, \mathrm{BF}$ 
PUT (281, 453), Palavra, OR

DO: LOOP UNTL INKEY\$ $>$ "'"

path $=" \mathrm{~A}:{ }^{\prime \prime}$

ELSEIF $r \$=$ "B" THEN

PRINT UCASE $\$$ ("Insira o disquete no drive $\mathrm{B}$ e tecle $<$ ENTER $>$

para continuar")

LINE $(0,280)-(640,310), 15, \mathrm{BF}$

LINE $(310,423)-(360,480), 7, \mathrm{BF}$

$\operatorname{LINE}(280,510)-(310,450), 7, \mathrm{BF}$

PUT (281, 453), Palavra, OR

DO: LOOP UNTIL INKEY\$ $>$ "'"

path $=$ "B: ${ }^{\prime \prime}$

ELSE

END IF

CLOSE \#1

OPEN path + filename FOR OUTPUT AS \#1

CLS

$\mathrm{g} \$=$ "Os dados desta análise seräo armazenados em "

$\mathrm{x}=40-\mathrm{LEN}(\mathrm{g} \$) / 2$

LOCATE 10, $\mathrm{x}$

PRINT UCASE\$(g\$)

$\mathrm{x}=40-\mathrm{LEN}($ path $) / 2$

LOCATE 12, $\mathrm{x}$

PRINT path

$\mathrm{g} \$=$ "Sendo o arquivo nomeado de "

$x=40-\operatorname{LEN}(g \$) / 2$

LOCATE 15, $\mathrm{x}$

PRINT UCASE\$(g\$) 
$\mathrm{x}=40-\mathrm{LEN}($ filename $) / 2$

LOCATE $17, \mathrm{x}$

PRINT filename

LINE $(0,280)-(640,310), 15, \mathrm{BF}$

$\operatorname{LINE}(310,423)-(360,480), 7, \mathrm{BF}$

$\operatorname{LINE}(280,510)-(310,450), 7, \mathrm{BF}$

PUT $(281,453)$, Palavra, OR

DO

LOOP UNTIL INKEY\$ > "'"

END SUB

\section{SUB PlotaSD}

IF sig0.sd $=0$ THEN

sig0.sd $=$ sig0.media $* .01$

END IF

sig0.sup $=$ sig0. media + sig0. sd

sig0.inf $=$ sig0. media - sig0. sd

psup $=470-200 * \operatorname{sig} 0 . \sup / 5000$

pinf $=470-200 * \operatorname{sig} 0 . \inf / 5000$

LINE (15, pinf)-STEP(-10, 25), , , \&HFF

LINE $(615$, pinf)-STEP(-10, 25), , \&HFF

LINE (15, pinf)-(615, pinf $),$, , \&HFF

$\operatorname{LINE}(5, \operatorname{pinf}+25)-(605, \operatorname{pinf}+25),,, \& H F F$

LINE (15, psup)-STEP(-10, 25), , , \&H1111

LINE (615, psup)-STEP(-10, 25), , , \&H1111

LINE (15, psup)-(615, psup), , , \&H1111

LINE (5, psup + 25)-(605, psup + 25), , , \&H1111

END SUB 
SUB PlotaSinal (ponto \%)

'imprime o ponto (leitura do espectrofotometro) no monitor no modo gráfico

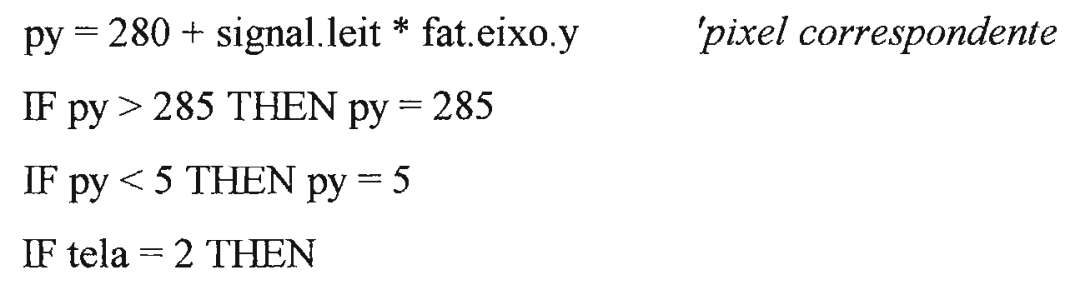

$$
\mathrm{px}=\mathrm{px}-\mathrm{GRAFXf}
$$

END IF

IF conta ponto $=1 \mathrm{AND}$ conta $\mathrm{rep}=1 \mathrm{AND}$ ponto $\%=1 \mathrm{THEN}$

$\mathrm{px}=\mathrm{GRAFXi}$

$\operatorname{PSET}(\mathrm{px}, \mathrm{py})$

\section{ELSE}

$\mathrm{px}=$ old.px + fat.eixo. $\mathrm{x}$

LINE (old.px, old.py)-(px, py)

\section{END IF}

old.py $=$ py

old.px $=p x$

END SUB

SUB PressKey (template\$, press\$)

'Após entrar nesta rotina, só será liberada se for pressionada alguma das teclas

' definidas no (template\$).

'(press\$) - variavel que retorna ao modulo de chamada indicando

' a tecla que foi premida

DO

GetAnyKey press\$

IF INSTR(template\$, press\$) =0 THEN BEEP ELSE EXIT DO

LOOP WHILE 1 
END SUB

SUB PrintParam

CLS

'valores por defeito

IF vaz.ini $=0$ THEN vaz.ini $=2.77$

IF plugT $=0$ THEN plug $\mathrm{T}=5.12$

IF espera $=0$ THEN espera $=100$

FF pto $=0$ THEN pto $=11$

IF npul $=0$ THEN npul $=5$

IF le $=0$ THEN le $=500$

IF replicados $=0$ THEN replicados $=1$

'moldura

FOR $\mathrm{x}=2$ TO 59

LOCATE $4, x$

PRINT CHR\$(196)

LOCATE $18, x$

PRINT CHR \$(196)

NEXT

FOR $\mathrm{x}=5$ TO 17

LOCATE $x, 1$

PRINT CHR $\$(179)$

LOCATE $\mathrm{x}, 47$

PRINT CHR\$(179)

LOCATE $\mathrm{x}, 60$

PRINT CHR\$(179)

NEXT

LOCATE 4, 1: PRINT CHR\$(218)

LOCATE 18, 1: PRINT CHR\$(192)

LOCATE 4, 60: PRINT CHR\$(191)

LOCATE 18, 60: PRINT CHR\$(217)

LOCATE 4, 47: PRINT CHR\$(194) 
LOCATE 18, 47: PRINT CHR\$(193)

LOCATE 5, 5: PRINT "VAZAO"

LOCATE 5, 50: PRINT vaz.ini

LOCATE 7, 5: PRINT "VOLUME DA STRING"

IF conf.flag $=1$ THEN

vol.string $\mathrm{T}=$ plugT $*$ vaz.ini $/ 60$

ELSE

vol.string $\mathrm{T}=$ plugT $*$ vaz.ini $* 1000 / 60$

END IF

LOCATE 7, 50: PRINT USING "\#\#\#.\#\#"; vol.stringT

LOCATE 9, 5: PRINT "TEMPO DE ESPERA PARA LEITURA DO

SINAL"

LOCATE 9, 50: PRINT espera

LOCATE 11, 5: PRINT "NUMERO DE PONTOS"

LOCATE 11, 50: PRINT pto

LOCATE 13, 5: PRINT "NUMERO DE PULSOS"

LOCATE 13, 50: PRINT npul

LOCATE 15, 5: PRINT "NUMERO DE LEITURAS"

LOCATE 15, 50: PRINT le

LOCATE 17, 5: PRINT "NUMERO DE REPLICADOS"

LOCATE 17, 50: PRINT replicados

END SUB

SUB Referencia (ang, h AS INTEGER, c)

CIRCLE $(100,100), 80,15,-.0001$, ang - PI

IF $\mathrm{h}=1$ THEN PAINT $(21,99), 15$

IF $\mathrm{h}=2$ THEN PAINT $(51,70), 15$

IF $\mathrm{h}=3$ THEN PAINT $(51,40), 15$

IF $\mathrm{h}=4$ THEN PAINT $(71,40), 15$

IF $\mathrm{h}=5$ THEN PAINT $(99,21), 15$ 
IF $\mathrm{h}=6$ THEN PAINT $(101,21), 15$

IF $\mathrm{h}=7$ THEN PAINT $(121,40), 15$

IF $h=8$ THEN PAINT $(139,50), 15$

IF $\mathrm{h}=9$ THEN PAINT $(139,80), 15$

IF $\mathrm{h}=10$ THEN PAINT $(121,99), 15$

LINE $(0,270)-(630,470)$, , B

$f x=60$

fy $=200 / 5000$

$c y=470-c * f y$

$\mathrm{hx}=\mathrm{h} * \mathrm{fx}-10$

$\mathrm{x} \$=$ "P" + STR $\$(\mathrm{~h})+$ ",15"

CIRCLE (hx, cy), 25, , ,, .5

DRAW X\$

LINE $(h x-26$, cy)-(hx $+26,470)$, , B

LINE (hx $-26, c y)-(h x+26, c y), h$

END SUB

SUB Relatorio

FOR $\mathrm{x}=1$ TO 79

LOCATE 19, $x$

PRINT CHR\$(205)

NEXT

LOCATE 20, 42

PRINT " R E L A T O R I O "

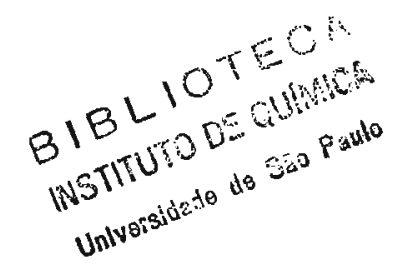

LOCATE 22, 37

PRINT LEFT\$(DATE\$, 2) + "/" + MID\$(DATE\$, 4, 2) + " $"$ + RIGHT\$(DATE\$, 2)

LOCATE 22, 54

PRINT filename

LOCATE 23, 37

PRINT "VOLUME DA STRING = "; ; plugT; ; " æl"

LOCATE 24, 37 
PRINT "NUMERO DE PULSOS $="$; ; npul

LOCATE 25, 37

PRINT "TEMPO DE ESPERA = "; ; espera; ; " s"

LOCATE 26, 37

PRINT "NUMERO DE PONTOS $=" ; ;$ pto +1

END SUB

\begin{tabular}{|c|c|c|}
\hline \multicolumn{3}{|l|}{ SUB SOSPCL } \\
\hline PRINT " & \multicolumn{2}{|c|}{ MAPA DE ENDEREÇAMENTO" } \\
\hline PRINT " 'LOCACAO & READ & WRITE"' \\
\hline PRINT " BASE+0 & COUNTER 0 & COUNTER $0^{\prime \prime \prime}$ \\
\hline PRINT " 'BASE+1 & COUNTER 1 & COUNTER $1^{\prime \prime \prime}$ \\
\hline PRINT " 'BASE+2 & COUNTER 2 & COUNTER 2"' \\
\hline PRINT " 'BASE+3 & N/A & NTER \\
\hline \multicolumn{3}{|l|}{ CONTROL"' } \\
\hline PRINT " 'BASE+4 & A/D LOW BYTE & D/A LOW \\
\hline \multicolumn{3}{|l|}{ BYTE"' } \\
\hline PRINT " 'BASE+5 & A/D HIGH BYTE & D/A HIGH \\
\hline \multicolumn{3}{|l|}{ BYTE"' } \\
\hline PRINT " 'BASE+6 & D/I LOW BYTE & N/A"' \\
\hline PRINT " 'BASE+7 & D/I HIGH BYTE & N/A"' \\
\hline PRINT" 'BASE+8 & N/A & R INTERRUPT \\
\hline \multicolumn{3}{|l|}{ STATUS"' } \\
\hline PRINT " 'BASE+9 & N/A & IN CONTROL"' \\
\hline PRINT " 'BASE+10 & $\mathrm{N} / \mathrm{A}$ & ГIPLEXER SCAN \\
\hline \multicolumn{3}{|l|}{ CONTROL'" } \\
\hline PRINT " 'BASE+11 & N/A & $\Xi$ AND \\
\hline \multicolumn{3}{|c|}{ INTERRUPT CONTROL'" } \\
\hline PRINT " 'BASE+12 & N/A & TWARE A/D \\
\hline \multicolumn{3}{|l|}{ TRIGGER'" } \\
\hline PRINT " 'BASE+13 & $\mathrm{N} / \mathrm{A}$ & O LOW BYTE"' \\
\hline PRINT " 'BASE+14 & N/A & O HIGH BYTE'" \\
\hline
\end{tabular}


END SUB

SUB TestaValvulas

'Rotina para testar as válvulas

$\mathrm{g} \$=$ "Pressione teclas correspondentes as valvulas (1-8)"

LOCATE 2, 40 - (LEN(g\$) / 2)

PRINT g\$

$\mathrm{g} \$=$ "(F para sair)"

LOCATE 3, 40 - (LEN(g\$) / 2)

PRINT g\$

FOR $\mathrm{x}=1$ TO 80

LOCATE 5, $x$

PRINT CHR\$(205)

NEXT $x$

LOCATE 7, 2: PRINT " Valv Estado"

FOR $x=2$ TO 15

LOCATE $8, x$

PRINT CHR\$(196)

NEXT

DO

PressKey "012345678F", escvalv

IF escvalv = "F" THEN EXIT DO

Transf escualv

LOOP WHILE 1

Valvula 0

'Desativa as válvulas

END SUB

SUB Transf (x AS STRING) STATIC

' Rotina que cria um numero binario que reflete o estado de até 8

valvulas. 
'De inicio, vs() encontra-se zerado e o estado de cada elemento deste vector

'é modificado de (0 a 1 ou de l a 0) cada vez que a rotina é chamada para

'esse elemento.

' $x$ é o número da válvula cujo estado vai ser alterado (de ligado a

des-

'ligado, ou de desligado a ligado).

DIM vs(8) AS INTEGER 'estado das valvulas

DIM xv AS INTEGER 'tecla premida (numerico)

DIM vbin AS INTEGER 'numero binario total, das valvulas

DIM a AS INTEGER 'ciclo FOR - Next

$\mathrm{xV}=\operatorname{VAL}(\mathrm{x})$

$\mathrm{vs}(\mathrm{xv})=1-\mathrm{vs}(\mathrm{xv})$

$\operatorname{vbin}=0$

FOR $\mathrm{a}=1$ TO 8

$\mathrm{vbin}=\mathrm{vbin}+\mathrm{vv}(\mathrm{a}) * \mathrm{vs}(\mathrm{a})$

LOCATE $9+\mathrm{a}, 4$

COLOR 15

PRINT a;

COLOR 14

$\mathrm{r}=46+174 * v s(\mathrm{a})$

IF $r=46$ THEN COLOR 15

PRINT " "; SPACE\$(vs(a) * 2); CHR\$(r); " "

NEXT a

Valvula vbin

END SUB

SUB ValvStatus (v AS INTEGER)

'Imprime no canto inferior do monitor o estado de 8 válvulas

'ON E OFF

' Usa rotina de transformacao de decimal em binario 


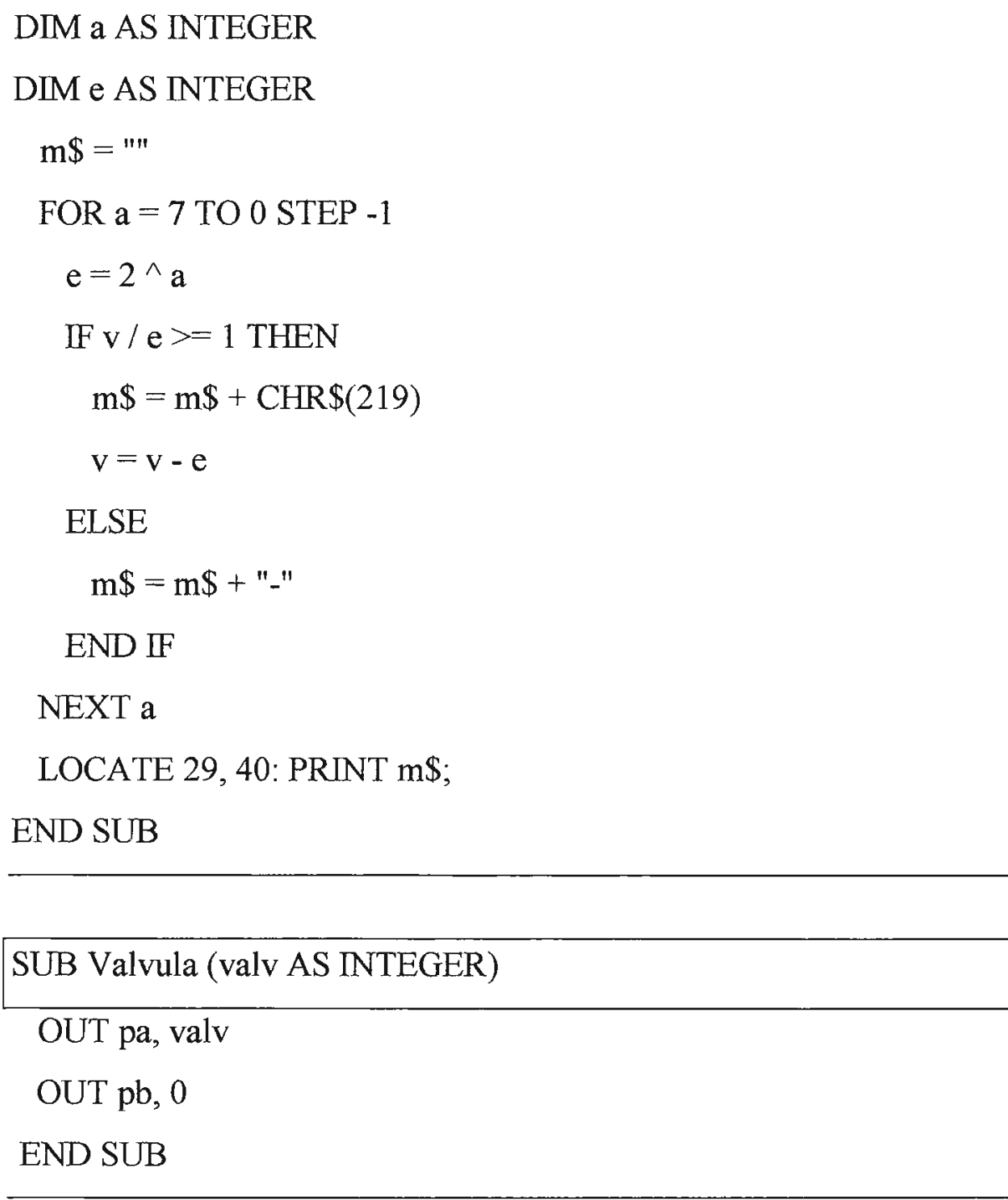

\section{SUB WaitRoleteUp (n AS INTEGER)}

' Esta rotina detecta a passagem do rolete da posiçäo baixa para

'alta. Se quando é chamada o rolete está baixo só sai quando

'sobe. Se ele está alto, só depois de descer e tornar a subir é que

'sai da sub rotina.

'O argumento $n$ deve ser maio ou igual a 1.

'Só sai da rotina após contar (n) subidas do rolete.

DIM $x$ AS INTEGER

FOR $x=1$ TO $n$

DO

$$
\begin{aligned}
& \text { olda }=a \\
& a=\operatorname{NP}(\text { pe1 })
\end{aligned}
$$


LOOP UNTIL olda $-\mathbf{a}=2$

NEXT $x$

END SUB

SUB WaitSegundos (s AS INTEGER)

DIM k AS INTEGER

SCREEN 8

COLOR 15,1

DIM j AS SINGLE

$\operatorname{LINE}(0,0)-(640,200), 12, \mathrm{BF}$

LINE $(20,0)-(620,7), 1, \mathrm{BF}$

$\mathrm{g} \$=$ "definindo a base de tempo"

LOCATE 1, (40 - LEN(g\$) / 2)

PRINT UCASE\$(g\$)

$\operatorname{LINE}(1,80)-(639,120), 8, \mathrm{BF}$

PAINT $(10,91), 6,8$

CIRCLE $(300,100), 80,15$

PAINT $(300,100), 7,15$

LINE (440, 143)-(490, 200), 7, BF

LINE $(410,200)-(440,170), 7, \mathrm{BF}$

PUT (411, 173), Palavra, OR

DO

$\operatorname{LINE}(300,100)-(300,130), 7$, , \&HFFFF

LINE $(300,100)-(230,100), 0$, , \&HFFFF

SLEEP 1

LINE $(300,100)-(230,100), 7$, , \&HFFFF

LINE $(300,100)-(300,70), 0$, , \&HFFFF

SLEEP 1

LINE $(300,100)-(300,70), 7$, , \&HFFFF

$\operatorname{LINE}(300,100)-(370,100), 0$, , \&HFFFF

SLEEP 1

$\operatorname{LINE}(300,100)-(370,100), 7$, , \&HFFFF 
LINE $(300,100)-(300,130), 0,, \&$ HFFFF

SLEEP 1

LOOP UNTL INKEY\$ $\diamond " ' "$

$\mathrm{t}=\mathrm{TIMER}$

$\mathrm{k}=0$

DO

$\mathrm{k}=\mathrm{k}+1$

LOOP WHILE TIMER $-\mathrm{t}<=\mathrm{s}$

COLOR 15,1

$\mathrm{g} \$=$ " BASE PARA" + STR $\$(\mathrm{~s})+$ " SEGUNDOS = " + STR $\$(\mathrm{k})+$ " "

LOCATE 20, 40 - LEN(g\$)/ 2

PRINT g\$

DO: LOOP UNTLL INKEY\$ $>$ "'"

base tempo $=\mathrm{k} / 100$

END SUB

SUB WaitTempo (ut AS INTEGER)

DIM ta AS INTEGER

DIM x AS INTEGER

FOR ta $=1$ TO ut

FOR $\mathrm{x}=1$ TO BASET

NEXT $x$

NEXT ta

END SUB 